\title{
INVESTIGATION OF DESIGN, MANUFACTURE, ANALYSIS AND TEST OF A COMPOSITE CONNECTING ROD UNDER COMPRESSION
}

\author{
A Thesis \\ presented to \\ the Faculty of California Polytechnic State University, \\ San Luis Obispo
}

\author{
In Partial Fulfillment \\ of the Requirements for the Degree \\ Master of Science in Mechanical Engineering
}

by

Thomas Juhl Rohrbach

March 2019 
(C) 2019

Thomas Juhl Rohrbach

ALL RIGHTS RESERVED 


\section{COMMITTEE MEMBERSHIP}

TITLE:

Investigation of Design, Manufacture, Analysis and Test of a Composite Connecting Rod Under Compression

AUTHOR:

Thomas Juhl Rohrbach

DATE SUBMITTED: $\quad$ March 2019

COMMITTEE CHAIR: Eltahry Elghandour, Ph.D.

Associate Professor of Mechanical Engineering

COMMITTEE MEMBER: Mohammed Noori, Ph.D.

Professor of Mechanical Engineering

COMmitTee MemBer: Dianne DeTurris, Ph.D.

Professor of Aerospace Engineering 


\begin{abstract}
Investigation of Design, Manufacture, Analysis and Test of a Composite Connecting Rod Under Compression
\end{abstract}

Thomas Juhl Rohrbach

Composite materials hold great potential for the replacement of traditional materials in machines utilized on a daily basis. One such example is within an engine block assembly where massive components inherently reduce the efficiency of the system they constitute. By replacing metal elements such as connecting rods, cylinder caps, or a crank shaft with composite alternatives, a significant increase in performance may be achieved with respect to mechanical strength, thermal stability, and durability, while also reducing mass. Exploration of this technology applied to a connecting rod geometry was investigated through a combination of process development, manufacturing, numerical analysis and testing. Process development explored composite material options based on experimental characterization, fabrication, and machining methods. Finite element analysis provided insight into model and data accuracy, as well as a basis for study on a unidirectional composite I-beam geometry. Destructive testing of the composite connecting rods provided data for a strength to weight ratio comparison with the original steel component. The composite connecting rods exhibited weight savings of $15 \%-17 \%$ that of the steel component. The rod made of woven composite material exhibited an elastic modulus of 68.1 Msi in its linear behavior be-

fore failure, thereby exhibiting a higher stiffness than the steel rod tested. Although the failure strengths were $25 \%$ below the required design load, the calculated strength to weight ratios showed favor for the composite alternatives.

Keywords: Composites, Connecting Rod, Compression, Process Development 


\section{ACKNOWLEDGMENTS}

Dr. Eltahry Elghandour, your guidance and patience have been a strong driving force for my time at Cal Poly. Thank you for providing the best possible environment to explore composites.

Dr. Mohammed Noori, thank you for being on my committee and showing genuine interest in my research.

Dr. Dianne DeTurris, thank you for sitting on my committee. Your classes remain some of my fondest memories at Cal Poly.

Cody Mac Thompson and Trian Georgeou, you both saved me in a desperate time. Providing insight and machine access, as well as shop techs eager to help with my parts made my work possible. Jared Graef, you were a great hand in making machining happen. Thank you all.

I would like to acknowledge Prototype Vehicles Laboratory and Dr. Graham Doig for providing me with a laboratory space, world-class project, and amazing team to experiment with composites and face real design problems before tackling my thesis.

Austin Gasbarra, thank you for proofreading my work.

To my parents, your ability to put up with my determination will always amaze me. Tusind tak... L'chaim! 


\section{TABLE OF CONTENTS}

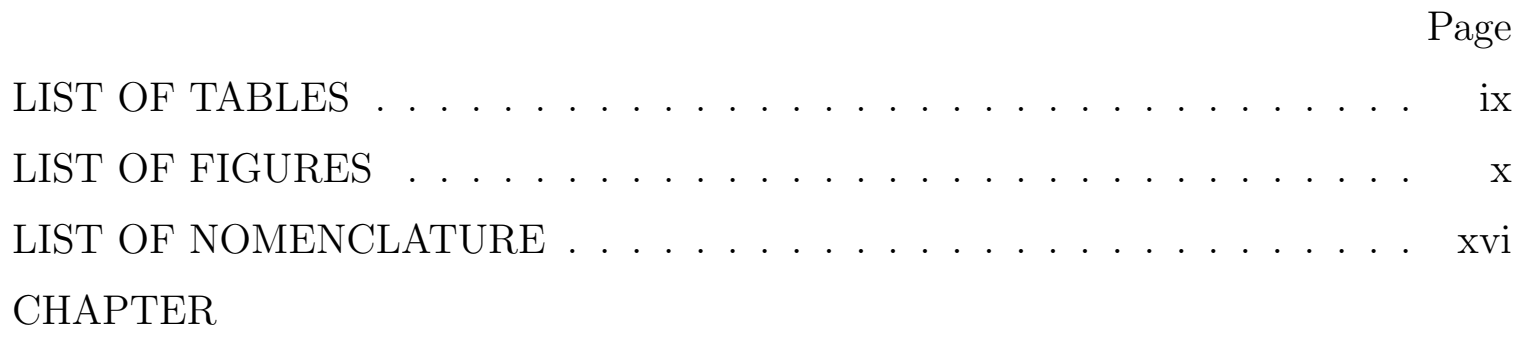

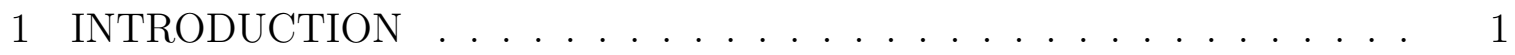

1.1 Overview . . . . . . . . . . . . . . . . . . . 1

1.2 Literature Review . . . . . . . . . . . . . . . . . . . . . 1

1.3 Inspiration . . . . . . . . . . . . . . . . . . . . . . . 9

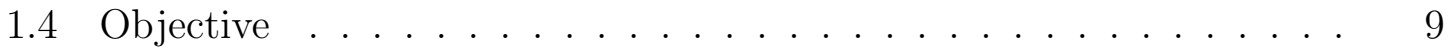

1.5 Scope of Thesis . . . . . . . . . . . . . . . . . . 10

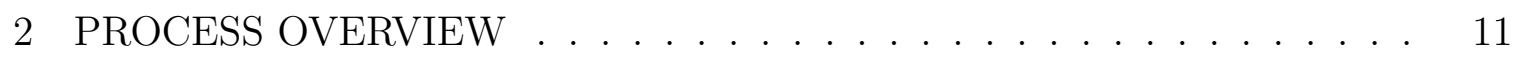

3 MATERIAL SELECTION AND PROCESS DEVELOPMENT . . . . . . . 14

3.1 Overview . . . . . . . . . . . . . . . . . . . . 14

3.2 Materials of Interest f . . . . . . . . . . . . . . . . 14

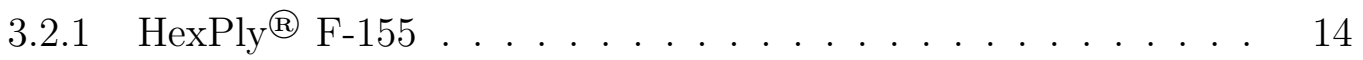

3.2.1.1 Cure Cycle . . . . . . . . . . . . . . 15

3.2.2 AMC $^{\circledR}$ Chopped Fiber Pre-preg . . . . . . . . . . . . . . 18

3.2.2.1 Cure Cycle . . . . . . . . . . . . 18

3.2.3 TenCate Ambertool ${ }^{\circledR}$ HX42 Tooling Prepreg . . . . . . . . . . 21

3.2.3.1 Cure Cycle . . . . . . . . . . . . . . 22

3.3 Manufacture Methodology Iterations . . . . . . . . . . . 25

3.3.1 Early Concepts . . . . . . . . . . . . . . 25

3.3.2 Final Mold Design and Composite Manufacture Method . . . 34

3.4 Material Mechanical Characteristics . . . . . . . . . . . . . . . . . 44

3.4.1 Sample Manufacture and Preparation . . . . . . . . . . . 45

3.4.1.1 LD-50 Tensile Tester . . . . . . . . . . . . 53

3.4.1.2 Instron 1331 Hydraulic Tester . . . . . . . . . 54

3.4.2 Elastic Moduli and Ultimate Strengths . . . . . . . . . . . 58 
3.4 .3 Poisson's Ratio . . . . . . . . . . . . . . . . . . . . 61

3.4.4 Failure Mode Analysis . . . . . . . . . . . . . . . . 63

3.4 .5 Error Analysis . . . . . . . . . . . . . . . . . . . . . 68

3.4.6 Material Testing Results and Discussion _. . . . . . . . . 69

3.5 Material Machinability . . . . . . . . . . . . . . . . . . . 70

3.5 .1 Tool Selection . . . . . . . . . . . . . . . . . . . . . . 70

3.5.2 Machining and Machinability Results . . . . . . . . . . 73

3.6 Material Selection Criteria and Decision _... . . . . . . 76

4 CONNECTING ROD NUMERICAL SIMULATION AND ANALYSIS . . 78

4.1 Overview . . . . . . . . . . . . . . . . . . . . . . . 78

4.2 CAD Model . . . . . . . . . . . . . . . . . . . 78

4.3 Finite Element Analysis . . . . . . . . . . . . . . . . . . . 79

4.3.1 Steel Connecting Rod Numerical Analysis _ . . . . . . . . . . 79

4.3.2 Steel Connecting Rod Testing for Verification . . . . . . . . 83

5 CONNECTING ROD MANUFACTURE AND TEST . . . . . . . . . . 86

5.1 Overview . . . . . . . . . . . . . . . . . 86

5.1 .1 Geometric Accommodations . . . . . . . . . . . . . . . 86

$5.1 .2 \quad$ Speeds and Feeds . . . . . . . . . . . . . . 88

5.1 .3 Toolpath . . . . . . . . . . . . . . . . . . 89

5.1.3.1 Cutting Operation $1 \ldots \ldots \ldots$

5.1.3.2 Cutting Operation $2 \ldots \ldots \ldots$

5.2 CNC Machining . . . . . . . . . . . . . . . . . . . . . 91

5.3 Experimental Testing and Results . . . . . . . . . . . . . . 96

6 RESULTS AND DISCUSSION . . . . . . . . . . . . . . . . . . . 103

7 UNIDIRECTIONAL COMPOSITE I-BEAM STUDY . . . . . . . . . . 107

7.1 Overview . . . . . . . . . . . . . . . . . . . . . 107

7.2 Composite FEA Test Case . . . . . . . . . . . . . . . . 107

7.3 Unidirectional Composite I-beam . . . . . . . . . . . . . . . . . 111

8 CONCLUSION . . . . . . . . . . . . . . . . . . . . . . . . . . . 119 APPENDICES

A Aluminum Mold Dimensions . . . . . . . . . . . . . . . . . 125

B Brick Dimension Measurements . . . . . . . . . . . . . . . . 131 
C Actual Test Specimen Dimensional Measurements . . . . . . . . . . . 132 


\section{LIST OF TABLES}

Table

Page

3.1 Hardware used in mold . . . . . . . . . . . . . . 36

3.2 Average measurements of first three brick attempts . . . . . . . . . 44

3.3 Asserted dimensions for test specimen . . . . . . . . . . . 45

3.4 Nominal dimensions for cut specimen . . . . . . . . . . . . . . 47

3.5 Strain measurement errors . . . . . . . . . . . . 58

3.6 Elastic modulus and ultimate strength averages . . . . . . . . . 60

3.7 Experimentally obtained poisson's ratios . . . . . . . . . 63

3.8 Cutter specifications and dimensions in inches . . . . . . . . . . . 72

4.1 Material properties of steel applied in Abaqus . . . . . . . . . . 80

4.2 Steel connecting rod strain comparison . . . . . . . . . . 85

5.1 Weight of experimental connecting rods in pounds . . . . . . . . . 97

6.1 Design load strength to weight ratios of rods . . . . . . . . 103

6.2 Failure load strength to weight ratios of rods . . . . . . . . . . . . 104

7.1 Solutions to trial problem from Matlab . . . . . . . . . . . . . 108

7.2 Material properties applied to UD composite . . . . . . . . . 115

7.3 Weight per unit length material comparison . . . . . . . . . 118

B.1 Measurements at varied locations on all bricks . . . . . . . . . . 131

C.1 Woven 1 direction tension sample dimensions . . . . . . . . . . . 132

C.2 Woven 2 direction tension sample dimensions . . . . . . . . . . 132

C.3 Woven 1 direction compression sample dimensions . . . . . . . . 133

C.4 Woven 2 direction compression sample dimensions . . . . . . . . 133

C.5 Chopped fiber tension sample dimensions . . . . . . . . . . . . 133

C.6 Chopped fiber compression sample dimensions . . . . . . . . . . . . 134 


\section{LIST OF FIGURES}

Figure

Page

1.1 Cranktrain assembly schematic (Norton, 1999) . . . . . . . . . 2

1.2 Failure locations provided in Dynamic Analysis of Loads and Stresses in Connecting Rods (Shenoy and Fatemi, 2006) . . . . . . . . . . 3

1.3 Plain weave (Rockwest, 2019) . . . . . . . . . . . . . 5

1.4 Short fiber material (Adams, 2013) . . . . . . . . . . . . 5

1.5 Vulcan V6 engine ("Ford Vulcan engine," 2019) . . . . . . . . . . 8

2.1 Geometry of interest . . . . . . . . . . . . . . 11

3.1 HexPly ${ }^{\circledR}$ F-155 uncured sample . . . . . . . . . . . . . . . 15

$3.2 \quad$ HexPly $^{\circledR}$ F-155 Cure Cycle (Hexcel, 2016) . . . . . . . . . . . 15

3.3 Mechanical Engineering composite oven . . . . . . . . . . . 16

3.4 Bagging schedule for oven cured material . . . . . . . . . . . 17

3.5 Prepping for cure . . . . . . . . . . . . . . . . . . 17

3.6 Sample post cure . . . . . . . . . . . . . . . . . . . 17

$3.7 \quad \mathrm{AMC}^{\circledR} 8593$ uncured material . . . . . . . . . . . . . . . . 18

$3.8 \quad$ AMC $^{\circledR} 8593$ cure cycle (Schulman, n.d.-a) . . . . . . . . . . . 19

3.9 Hot press material layup schedule . . . . . . . . . . . . . 20

3.10 Cal Poly Aerospace Engineering composite press . . . . . . . . . . . 20

3.11 Prepped chopped fiber sample . . . . . . . . . . . 20

3.12 Oven cured sample . . . . . . . . . . . . . . . . . . 21

3.13 Hot press cured sample . . . . . . . . . . . . . . . 21

3.14 Triaxial weave diagram and convention ("3D composites," 2019) . . 22

3.15 Uncured HX42 material . . . . . . . . . . . . . . . . . 22

3.16 HX42 Cure Cycle (Tencate, n.d.) . . . . . . . . . . 23

3.17 Woven flat plate . . . . . . . . . . . . . 24

3.18 Prepped for press cure . . . . . . . . . . . . . 24

3.19 Cured HX42 sample . . . . . . . . . . . . . . . 24

3.20 HDF mold setup and chopped fiber layup . . . . . . . . . . . 26 
3.21 HDF cure failure $\ldots \ldots \ldots \ldots \ldots \ldots \ldots \ldots \ldots$

3.22 First HDF cured result . . . . . . . . . . . . . . . . . . 27

3.23 Aerospace Engineering tile saw . . . . . . . . . . . . 27

3.24 Chopped fiber sample cut . . . . . . . . . . . . . . 28

3.25 Side view of sample cut . . . . . . . . . . . . . 28

3.26 Second HDF perimeter mold attempt . . . . . . . . . . . . . . 29

3.27 HDF perimeter second attempt result . . . . . . . . . . 30

3.28 MDF perimeter result . . . . . . . . . . . . . . . . . 31

3.29 MDF sample cut . . . . . . . . . . . . . . . . . . . 32

3.30 Sample cut side view . . . . . . . . . . . . . . . . . . 32

3.31 Aluminum mold mockup materials . . . . . . . . . . . . . 33

3.32 Woven sample cut . . . . . . . . . . . . . . . . . 34

3.33 Woven block side view . . . . . . . . . . . . . . . . . 34

3.34 Exploded view of aluminum mold concept . . . . . . . . . . 35

3.35 Assembled aluminum mold concept CAD . . . . . . . . . . . . 36

3.36 Aerospace Engineering Haas mill _ . . . . . . . . . . . . 38

3.37 Walls before polish . . . . . . . . . . . . . . . . 38

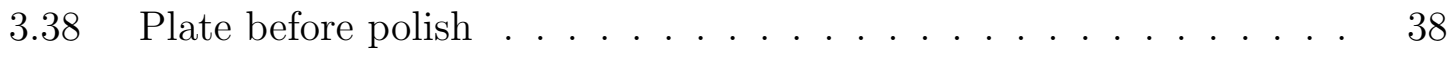

3.39 Bars after polish . . . . . . . . . . . . . . . . . 39

3.40 Plate after polish . . . . . . . . . . . . . . . . . . 39

3.41 Mold ready for cure . . . . . . . . . . . . . . . . 40

3.42 Mold top view after cure . . . . . . . . . . . . . . . . 41

3.43 Uncleaned chopped fiber brick . . . . . . . . . . . . . . . . . 41

3.44 Chopped fiber block after cleaning . . . . . . . . . . . . . . . 41

3.45 Triaxial weave 2 direction brick prepared for curing . . . . . . . . 42

3.46 Triaxial weave 1 direction brick prior to edge sanding . . . . . . . 43

3.47 Example of a stress strain relationship (Instructables, 2017) . . . . 44

3.48 Unusable chopped fiber flat plates . . . . . . . . . . . . . . 46

3.49 Usable chopped fiber flat plate . . . . . . . . . . . . 46

$3.50 \quad$ HX42 specimen plate layups . . . . . . . . . . . . . . 46

3.51 Mechanical Engineering hot press . . . . . . . . . . . . 48

3.52 Glass tab cured with structural film adhesive . . . . . . . . . . 48 
3.53 Micro-Measurements strain gauge . . . . . . . . . . . . . . . . . 49

3.54 M-Bond kit adhesive materials . . . . . . . . . . . . 50

3.55 Removal of gauge from slide (Vishay, n.d.) . . . . . . . . . 50

3.56 Isolation tape between bonding terminal and gauge . . . . . . . 52

3.57 Example of completed gauge installation . . . . . . . . . 52

3.58 Fully prepared woven material specimen . . . . . . . . . . . 52

3.59 Ametek ${ }^{\circledR}$ LD-50 . . . . . . . . . . . . . . . . . . . . . 53

3.60 Vice grips on LD-50 machine . . . . . . . . . . . . . 54

3.61 Instron 1331 Hydraulic test system . . . . . . . . . . . . . 55

3.62 Steel sample used for system verification . . . . . . . . . . 57

3.63 Graphical comparison of data collection methods . . . . . . . 57

3.64 Chopped fiber tension data . . . . . . . . . . . . . . . 59

3.65 Chopped fiber compression data . . . . . . . . . . . . . . 59

3.661 direction tension results . . . . . . . . . . . . . . . . . 59

3.672 direction tension results $\ldots \ldots \ldots \ldots \ldots$

3.681 direction compression results $\ldots \ldots \ldots \ldots \ldots$

3.692 direction compression results . . . . . . . . . . . . 60

3.70 Experimental setup for discrete strain measurements using wheatstone bridge . . . . . . . . . . . . . . . . . . . 61

3.71 Data used to calculate chopped fiber poisson's ratio . . . . . . . . 62

3.721 direction compression results . . . . . . . . . . . . 62

3.732 direction compression results $\ldots \ldots \ldots \ldots \ldots \ldots$

3.74 Chopped fiber tension failure . . . . . . . . . . . . . . 64

3.75 Chopped fiber compression failure . . . . . . . . . . . . 65

3.76 Alternative chopped fiber compression failure . . . . . . . . . 65

3.77 Woven 1 direction tension edge . . . . . . . . . . . 66

3.78 Woven 1 direction tension failure . . . . . . . . . . . 66

3.79 Woven 1 direction tension failure on opposite edge . . . . . . . 66

3.80 Woven 1 direction compression failure . . . . . . . . . . 67

3.81 Woven 2 direction tension failure side view . . . . . . . . . 67

3.82 Woven 2 direction tension failure . . . . . . . . . . . 67

3.83 Woven 2 direction compression failure . . . . . . . . . . 68 
3.84 Gauge used for specimen vertical alignment . . . . . . . . . . . 69

3.85 Arbitrary geometry for machining testing . . . . . . . . . . . 70

3.86 Schematic of tool differences (Harvey, n.d.-b) . . . . . . . . 71

3.87 Compression spiral cutter schematic (Harvey, n.d.-b) . . . . . . 72

3.88 Ball end mill schematic (Harvey, n.d.-a) . . . . . . . . . . . 72

3.89 Compression spiral end mill . . . . . . . . . . . . . . . 73

3.90 Ball end mill . . . . . . . . . . . . . . . . . 73

3.91 Haas Mini-Mill test operation . . . . . . . . . . . . . . 74

3.92 Machined chopped fiber brick sample . . . . . . . . . . . . 75

3.93 Machined triaxially woven brick sample . . . . . . . . . . . . 75

4.1 Connecting rod CAD . . . . . . . . . . . . . 78

4.2 Definition of regions on $\operatorname{rod} \ldots \ldots \ldots$. . . . . . . . . 79

4.3 Mesh on geometry . . . . . . . . . . . . . . . . 80

4.4 Mesh convergence study . . . . . . . . . . . . . . . . 80

4.5 Boundary conditions imposed on geometry . . . . . . . . . . . . . 81

4.6 Coupling constraints imposed . . . . . . . . . . . . . 81

4.7 Axial strain results . . . . . . . . . . . . . . . . . . 82

4.8 Location of interest probed strain . . . . . . . . . . . . . . 82

4.9 Crank end fixture . . . . . . . . . . . . . . . . 83

4.10 Piston end fixture . . . . . . . . . . . . . . . . 83

4.11 Boundary conditions imposed on geometry . . . . . . . . . . . . . 84

4.12 Coupling constraints imposed . . . . . . . . . . . . . . . . 84

5.1 Flange modifications . . . . . . . . . . . . . . . . . 87

5.2 Modified bolt mount area . . . . . . . . . . . . . . 87

5.3 CAD geometry comparison . . . . . . . . . . . 88

$5.4 \quad$ OP1 roughing path . . . . . . . . . . . . . . . . . . 90

5.5 OP1 finishing path . . . . . . . . . . . . . . . 90

5.6 Expected geometry after $\mathrm{OP} 1 \ldots \ldots . \ldots 90$

$5.7 \quad$ OP2 roughing path . . . . . . . . . . . . . . . . 91

$5.8 \quad$ OP2 finishing path . . . . . . . . . . . . . 91

5.9 Aluminum soft jaw used to hold composite component for OP2 . . 92 
5.10 Aero Hangar TM-1 Haas mill . . . . . . . . . . . . . . . . . . 92

5.11 Completed OP1 roughing . . . . . . . . . . . . . . . . . . 93

5.12 Completed OP1 . . . . . . . . . . . . . . . . . . . . 93

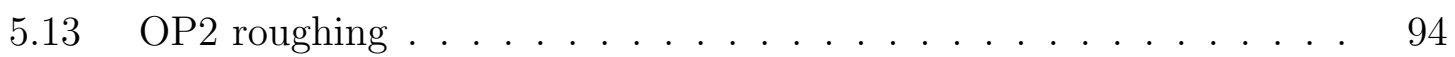

5.14 Failed machining attempt $\ldots \ldots \ldots \ldots \ldots$

5.15 Machined connecting rod prior to cleanup . . . . . . . . 95

5.16 Cleaned woven $\operatorname{rod} \ldots \ldots \ldots \ldots$. . . . . . . . . 96

5.17 Cleaned chopped fiber rod . . . . . . . . . . . . . . 96

5.18 Strain gauge located on connecting rod . . . . . . . . . . 97

5.19 Composite connecting rod experimental setup . . . . . . . . . 98

5.20 Data check conducted on all rods . . . . . . . . . . . . . . . 99

5.21 Failure test data . . . . . . . . . . . . . . . . . 100

5.22 Flange failure of chopped fiber connecting rod . . . . . . . . . . . 101

5.23 Woven rod flange failure . . . . . . . . . . . . . . . . . 102

5.24 Woven rod opposite flange . . . . . . . . . . . . . . . . . 102

6.1 Comparison of linear regions of connecting rods tested . . . . . 105

$7.1 \quad$ Sample problem mesh . . . . . . . . . . . . . . . . 108

7.2 Boundary conditions and load applied . . . . . . . . . . . 109

7.3 Ply stack plot of laminate . . . . . . . . . . . . . . . . . 110

7.4 Normal stresses through laminate thickness of 4 ply simulated specimen 111

7.5 Actual taper angle of I-beam geometry . . . . . . . . . . . . . 112

7.6 Simplified "I" geometry applied in Abaqus . . . . . . . . . . . . . 113

7.7 Shell I-beam . . . . . . . . . . . . . . . . . . . . . . . . . . . . . . 114

7.8 Shell geometry with thickness rendered . . . . . . . . . . . . . 114

7.9 Load and boundary conditions on I-beam . . . . . . . . . 114

7.10 Meshed shell I-beam . . . . . . . . . . . . . . . . . . . . 115

7.11 I-beam mesh convergence study . . . . . . . . . . . . . . . . 115

7.12 Web laminate ply stack plot . . . . . . . . . . . . 116

7.13 Flange laminate ply stack plot . . . . . . . . . . . . . . 116

7.14 Axial stress results in $0^{\circ}$ ply of laminates . . . . . . . . . . . 117

7.15 I-beam web stresses . . . . . . . . . . . . . . . . . . 118 
7.16 I-beam flange stresses f . . . . . . . . . . . . . . . . . . . 118

A.1 Top plate dimensions . . . . . . . . . . . . . . . . . . 126

A.2 Push plate dimensions . . . . . . . . . . . . . . . 127

A.3 Short bar dimensions . . . . . . . . . . . . . . . . . . . . . . 128

A.4 Long bar dimensions . . . . . . . . . . . . . . . . . . 129

A.5 Bottom plate dimensions . . . . . . . . . . . . . . 130 


\section{LIST OF NOMENCLATURE}

\begin{tabular}{|c|c|}
\hline $\mathrm{A}$ & Cross-sectional Area \\
\hline$\Delta$ & Change in \\
\hline $\mathrm{E}$ & Elastic Modulus \\
\hline$\epsilon$ & Strain \\
\hline $\mathrm{F}$ & Force \\
\hline G & Shear Modulus \\
\hline $\mathrm{L}$ & Gauge Length \\
\hline$\mu \epsilon$ & Microstrain \\
\hline$\nu$ & Poisson's Ratio \\
\hline$\sigma$ & Stress \\
\hline 1 & 1 direction \\
\hline 2 & 2 direction \\
\hline 3 & 3 direction \\
\hline CAD & Computer Aided Design \\
\hline CAM & Computer Aided Manufacturing \\
\hline CFRP & Carbon Fiber Reinforced Polymer \\
\hline CLT & Classical Lamination Theory \\
\hline CR & Connecting Rod \\
\hline DAQ & Data Acquisition \\
\hline DOF & Degree(s) of Freedom \\
\hline FEA & Finite Element Analysis \\
\hline $\mathrm{HDF}$ & High Density Foam \\
\hline $\mathrm{MDF}$ & Medium Density Fibreboard \\
\hline $\mathrm{OP}$ & Cutting Operation \\
\hline UD & Unidirectional \\
\hline
\end{tabular}


Chapter 1

INTRODUCTION

\subsection{Overview}

The rising impact of human technologies on the global ecosystem has dire ramifications should new approaches not be investigated. The life expectancy of consumer products and available methods of safe disposal of many items has contributed heavily to growing waste and negative impact to our planet's climate. Furthermore, the dependence on fossil fuels and combustion vehicles has expedited the positive feedback loop of climate change through greenhouse gas emissions. Although many companies are now exploring alternative fuel options, the infrastructure requirements of these progressive vehicles slows the popular transition. However, there is similar interest in exploring alternative materials for current vehicle architectures. Lightweight material substitution in a combustion engine serves to improve the overall efficiency of the vehicle by reducing mass. One of the most costly systems within a typical road vehicle is the engine block. By examining ways to reduce the mass of inherently heavy components comprising the engine block, the economy of internal combustion vehicles can be improved, and thereby the impact on environment.

\subsection{Literature Review}

The connecting rod is a linkage within the cranktrain assembly which translates the linear motion of a piston's displacement from gas pressure into the rotational motion which drives the crank shaft. These components and their coupled motion are depicted in Figure 1.1 taken from Design of Machinery (Norton, 1999). 


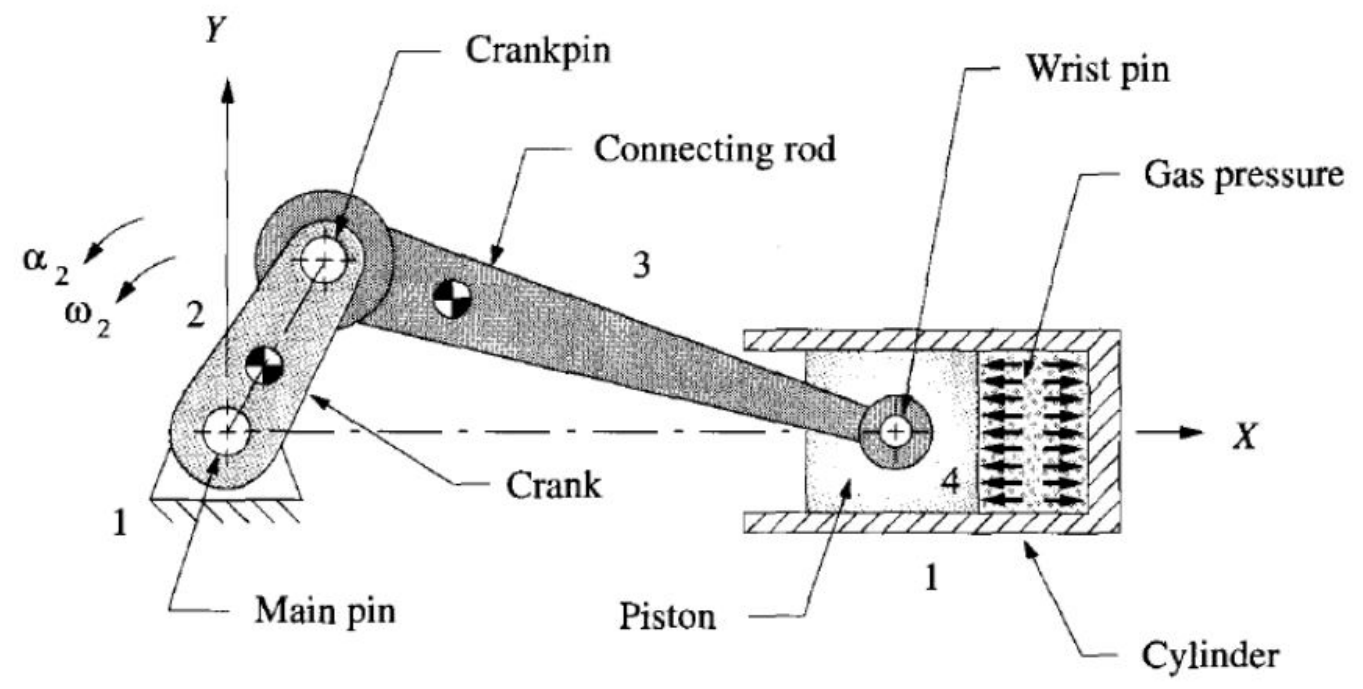

Figure 1.1: Cranktrain assembly schematic (Norton, 1999)

Due to the role of the connecting rod in the engine assembly it is subject to complex loading. In a discussion of the kinetics and kinematics of the system Norton breaks this loading into pin forces, inertia torque, and torque from cylinder pressure (Norton, 1999). As the connecting rod travels through a single cycle it experiences a maximum compression load due to the gas pressure exerted at the piston, and a maximum tension load due to its inertia. The culmination of dynamic forces, vibrations, and high thermal loading from combustion create an extreme environment which stresses the part immensely. These forces in conjunction with fatigue from cycles on the order of $10^{8}$ to $10^{9}$ thereby require high durability components (Khan and Dolas, 2017). The compiling of all of these environmental factors makes it difficult to fully assess and decompose load cases on the connecting rod.

Dynamic Analysis of Loads and Stresses in Connecting Rods explored applying both static and quasi-dynamic FEA to assess the loading on a connecting rod (Shenoy and Fatemi, 2006). Eleven critical failure points on the connecting rod geometry were identified and used for exploring results from analysis conducted. In doing this 
the maximum loading expected with respect to compression was found at about a $22^{\circ}$ crank angle. Location 8, shown in Figure 1.2, was used to establish an overall operating stress range from an overall load range. It was found that the stress range at the maximum speed represents a $36 \%$ decrease from the extremes of the overall range examined. Therefore using the maximum and minimum stresses provided by the overall operating load range provides an overly conservative design which can add an order of magnitude to the expected fatigue life of the component.

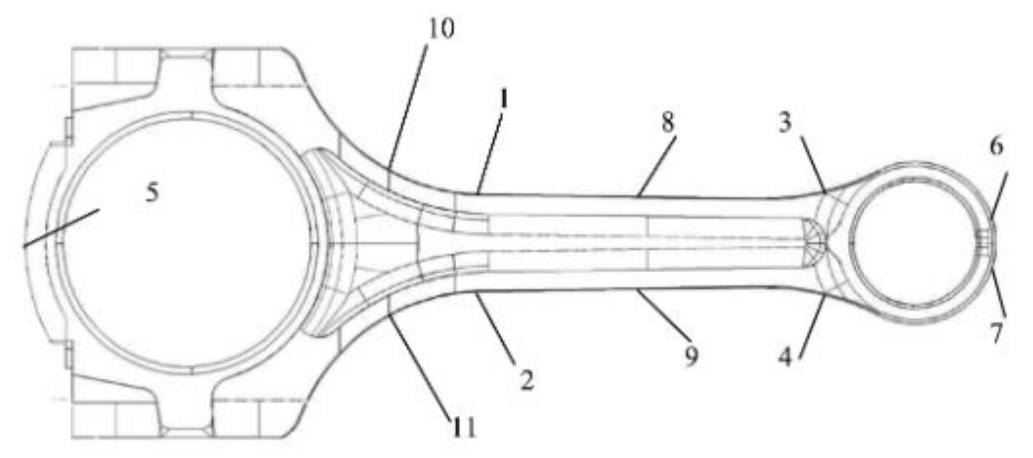

Figure 1.2: Failure locations provided in Dynamic Analysis of Loads and Stresses in Connecting Rods (Shenoy and Fatemi, 2006)

Finite Element Analysis of a Diesel Engine Connecting Rod for Shape Optimization modeled the connecting rod of a Kirloskar TV1 diesel engine to conduct FEA and optimize shape to mitigate stress concentrations (Bhavi and Kurbet, n.d.). After running initial stress analysis the geometry was altered to redistribute and minimize the induced maximum stress by filleting and chamfering. The resultant geometry showed a $24.912 \%$ reduction in maximum stress when chamfered, and a $4.921 \%$ reduction when filleted.

Both A Comparative Study of Fatigue Behavior and Life Predictions of Forged Steel and PM Connecting Rods (Afzal and Fatemi, 2003) and Optimized Connecting Rods to Enable Higher Engine Performance and Cost Reduction (Repgen, 1998) explored powder metal for material selection over forged steel in connecting rod man- 
ufacturing. In both cases it was found that although the cost of a powder metal is cheaper as a function of the high tolerance part and ease of post-processing, the strength and fatigue properties of forged steel are superior. Afzal and Fatemi explicitly state that because the cost effective attributes of powder metals are voided by materials such as C-70 and MA splittable steels, automotive manufacturers are switching back to forged steel connecting rods.

In Dynamic Analysis of Connecting Rods Using MSC ADAMS Modal Sythesis Method for Flexible Bodies Bradaric explored modeling a flexible connecting rod dynamically by coupling ADAMS and Patran/Nastran (Bradaric, 2017). A connecting rod was modeled in CAD based on a physical component retrieved from a Ford Vulcan engine assembly. Dynamic FEA results were compared with static load cases and experimental data, ultimately showing a tolerable percent difference between the sources of data.

Prakash et. al explored weight reduction in a connecting rod geometry through a study of material alternatives analyzed in ANSYS (Prakash, Prabhahar, Jeshuran, and Manish, 2017). The study found that the strain, shear stress, and overall factor of safety experienced by the carbon fiber case were comparatively closer to the performance of stainless steel than other materials, and therefore called for further investigation into high strength composites for application.

Composites are defined as materials consisting of two or more distinct parts. In the context of fiber reinforced polymers (FRP) these parts are composed of a matrix and a fiber. Typical matrix materials include epoxy and vinyl-ester. Fiber types include carbon fiber, fiberglass, or recycled bio-materials. These fibers can either be oriented unidirectionally, woven as a plain or more complex weave, or left as short fibers in a discontinuous and random orientation. Fibers can either be acquired as dry material and infused with resin (the matrix), or purchased as pre-impregnated material which 
has a specified ratio of resin to fiber and is typically cured via autoclave or oven under vacuum pressure. Examples of a plain weave and random orientation fibers are presented in Figures 1.3 and 1.4 respectively. Woven and unidirectional materials can be cut and stacked to form high strength laminates. Manufacturing defects such as voiding or delamination can severely impact the matrix to fiber interface of a composite and result in significant losses of structural integrity. For every $1 \%$ of void content in a composite volume there is a $2 \%-10 \%$ drop in mechanical behaviors (Agarwal, Broutman, and Chandrashekhara, 2018).

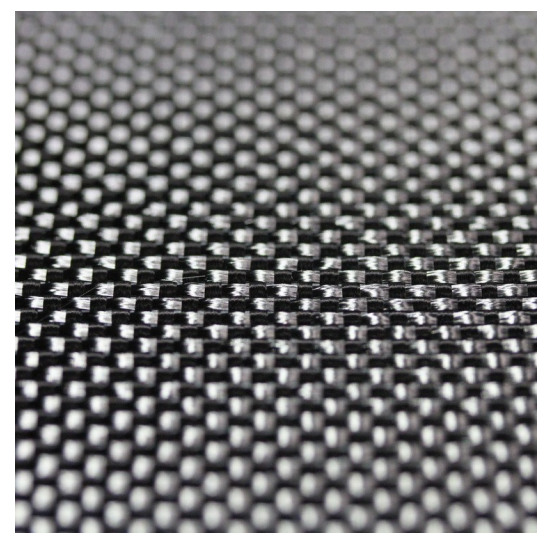

Figure 1.3: Plain weave (Rockwest, 2019)

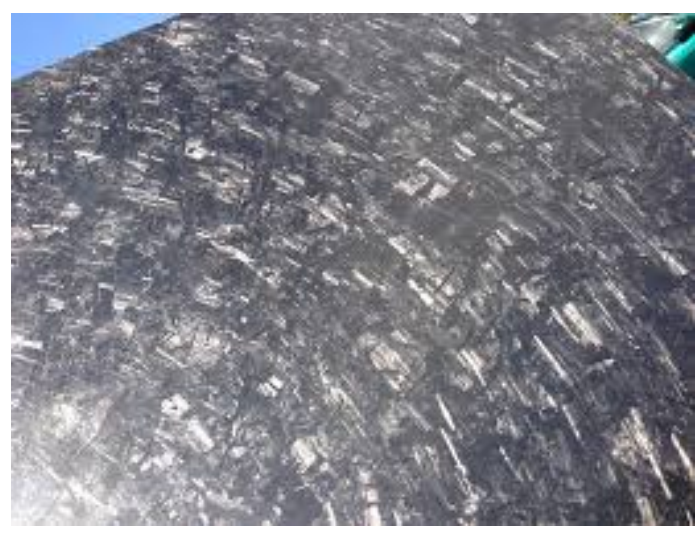

Figure 1.4: Short fiber material (Adams, 2013)

Mechanical Properties of Chopped Carbon Fiber Reinforced Epoxy Composites explored experimentation on chopped fiber materials and found trends resulting from fiber to resin ratio (Ozsoy, Ozsoy, and Mimaroglu, 2016). The study conducted tensile, bending and impact tests which showed a peak performance when $8 \%$ of the composite was constituted by carbon fibers. After this ratio composites became too dry without enough matrix to hold the constitution of the material. This called attention to the importance of fiber to resin ratio, as well as the manufacturing procedure to limit voiding and maximize material properties.

Composite materials offer incredible advantages in mechanical material properties with respect to their high stiffness, low density, and thermal resistance. This 
makes them an excellent candidate for the criteria driving connecting rod design. For this reason performance vehicle companies have begun exploring the technology. In 2016, Lamborghini opened a Seattle based carbon fiber research facility deemed the Advanced Composite Structures Laboratory (ACSL) (Milberg, 2017). One of the primary foci of this lab is developing a compression molded connecting rod which the company hopes to apply in a V-12 engine by 2020 or 2021 . The $60 \%$ weight reduction and rapid production cycle of their research efforts show great promise for the implementation of the replacement material. Several academic papers based on research at the lab have been made available online and cover subjects such as chopped fiber material testing and composite replacement of metal vehicle structures. Startup company Naimo is similarly manufacturing carbon fiber connecting rods, but independent of a production vehicle (Christensen, 2018). Their design is based on the dimensions of a standard LS engine. This approach could provide the high end components to consumers and applications outside of the luxury performance car clientele.

Feraboli et. al discloses the process used at Lamborghini's ACSL to manufacture control arms for a Sesto Elemento using Forged Composite ${ }^{\circledR}$ (Feraboli et al., n.d.). The research focuses on the development of the component capable of taking the expected combined loading with a goal of a 30\% reduction in weight, as well as time reduction in manufacturing compared to the baseline forged hardware. The composite redesign showed an average weight saving of $27 \%$ and a streamlined six minute production cycle from raw material to finished part.

\section{Design and Analysis of a Compression Molded Carbon Composite Wheel Center} details the process by which a wheel hub is manufactured from a composite and compares to the existing aluminum component (Dhananjayan, 2013). The study goes into great detail on prior processes established and the heritage established by industry on the subject. The study highlights the importance of closed mold processes and random fiber composites to improve production volumes, reduce cost of parts, 
provide near net shape parts eliminating secondary operations, and produce parts with near isotropic properties due to random fiber orientation.

In Integration of Carbon Fiber Composite Materials into Air-Cooled Reciprocating Piston Engines for UAV Applications the strength to weight benefit over metal components was explored in the context of a composite connecting rod and crankcase (Trunzo, 2012). Experimental testing was successful in dynamic testing and failure modes were not purely composite defects. Weight savings for the crankcase and connecting rod were $80 \%$ and $26 \%$ respectively.

In Design $\&$ Analysis of Connecting Rod by Composite Material FEA is conducted on a designed connecting rod geometry composed of aluminum (6061) based material reinforced with boron carbide (B4C) (Sydanna and Kumar, n.d.). It was found that the composite reinforced aluminum exhibited lower stress and deformations than compared to an aluminum alloy, verifying the higher strength provided by the composite.

Joshi and UmairZaki utilized FEA in Ansys to explore different materials in a connecting rod geometry. The study examined stainless steel, aluminum alloy 7075 , and high strength carbon fiber in the analysis (Joshi and UmairZaki, n.d.). Conclusions pointed to carbon fiber as an excellent alternative material as modeling showed a comparatively lower stress and strain intensity. The carbon fiber is asserted as easier and more convenient to work with than the metals studied, and a high strength, low weight alternative capable of more design flexibility.

In Process Study on Compression Moulding of SMC using Factorial Design issues with compression molding of sheet compounds are explored (Olsson, 2008). The effects of vacuum on compression molding in conjunction with high temperatures is found to yield a better finish product with fewer surface defects. However, the conclusion was drawn that no significant reduction in void content was found when 
compared to standard pre-preg compression molding.

Teti discusses the difficulties of machining composite materials due to their anisotropic and non-homogenous structure (Teti, n.d.). The study explores the impact of the abrasiveness of composite materials on tool life. Tool selection is explained and explicitly cites that PCD (polycrystalline diamond) tools are ideal for machining. It is found that in the case of cutting carbon fiber reinforcement the cutting tool material dominates the tool selection.

The Ford Vulcan V6 engine was released in vehicles from 1986 to 2008. It was utilized in a number of Ford vehicles, but most notably acted as the standard engine for the Ford Taurus for a number of years. The engine is a pushrod design with 2 valves per cylinder. Both its block and heads were constructed from cast iron. For this reason it is hypothesized Ford selected its name in homage to the mythological Roman god of fire and iron-working ("Ford Vulcan engine," 2019). A render of the full engine is provided in Figure 1.5.

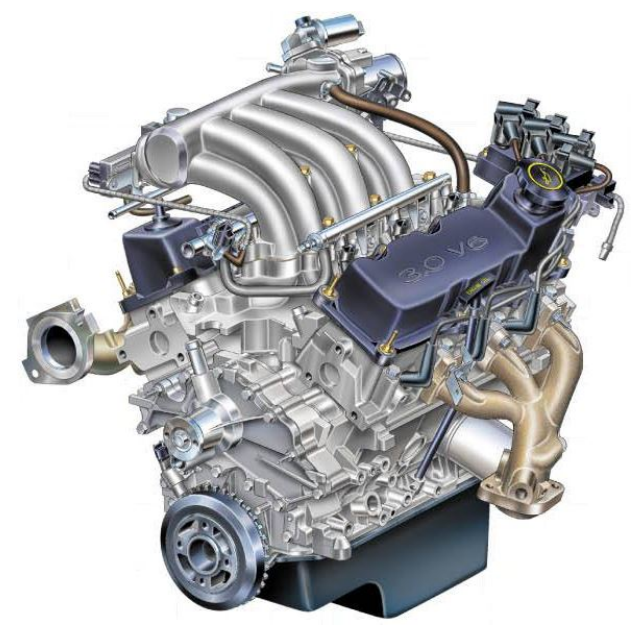

Figure 1.5: Vulcan V6 engine ("Ford Vulcan engine," 2019) 


\subsection{Inspiration}

This project was inspired by current investigations being conducted within the automotive industry by companies such as Lamborghini. Although the context is limited to a particular component, application of the same process to an expanded scope of mechanical designs holds great potential for efficiency boosts in a spectrum of vehicles. Success in composite replacement of traditional mechanical systems would have widespread implications for industries such as automotive and aerospace where systems are subject to high load cases and driven at high operating speeds. By proving feasibility with alternative materials there is potential for gains in efficiency and mass reduction in systems, ultimately allowing for new concepts and design spaces to be accessed.

\subsection{Objective}

The objectives of this research are to explore the material options, manufacturing process, and testing of a composite connecting rod. Verification via FEA provides a basis by which experimental process and results can be determined viable and accurate.

As a result of the broad scope involved in developing a process to produce the physical component, a number of concurrent efforts were necessary. Material exploration and selection required evaluating different composite options from the perspectives of ease of handling for layups, machinability, and mechanical strength properties. Mold selection presented trades with regards to the difficulty of manufacturing and the ability to apply the highest pressure to the material layup. Machining of the composite material required an understanding of the recommended tools and machining specifications for the best end product. Conducting FEA for composite plates and 
more complex geometries required an understanding of software case setup and the translation of physical testing conditions into simulation settings. Experimental testing required an understanding of proper instrument installation, data acquisition, and safe hardware working procedures. The holistic reach of these efforts allowed for a number of new and previously taught skills to be applied, expanded on, and mastered, fully capturing the "Learn by Doing" motto of Cal Poly.

\subsection{Scope of Thesis}

This document describes the development of a consistent manufacturing process for a selected material, setup of theoretical calculations and FEA for verification, and finally experimental testing. Chapter 2, Process Overview, provides a high level discussion of the factors examined for the manufacturing process based on prior research. This gives context necessary for understanding the decision making in Chapter 3, which steps through material tests and mold techniques used to decide a path forward. Chapter 4 follows with numerical analysis and experimental setup used for verification of data. Chapter 5 details the machining process and testing of the composite connecting rods, while Chapter 6 discusses the results from destructive testing. Chapter 7 explores a study on FEA applied to a unidirectional composite I-beam ge-

ometry. Finally, Chapter 8 summarizes the conclusions drawn from the body of work conducted. 


\section{Chapter 2}

\section{PROCESS OVERVIEW}

This chapter outlines the approach and methods considered in developing a process for construction of a composite connecting rod. The scope of the work within process development included material selection, compression molding, and material machinability. Figure 2.1 exhibits the geometry being examined, with Figure 2.1a showing the original steel component, and Figure $2.1 \mathrm{~b}$ being the composite result of efforts discussed in this research.

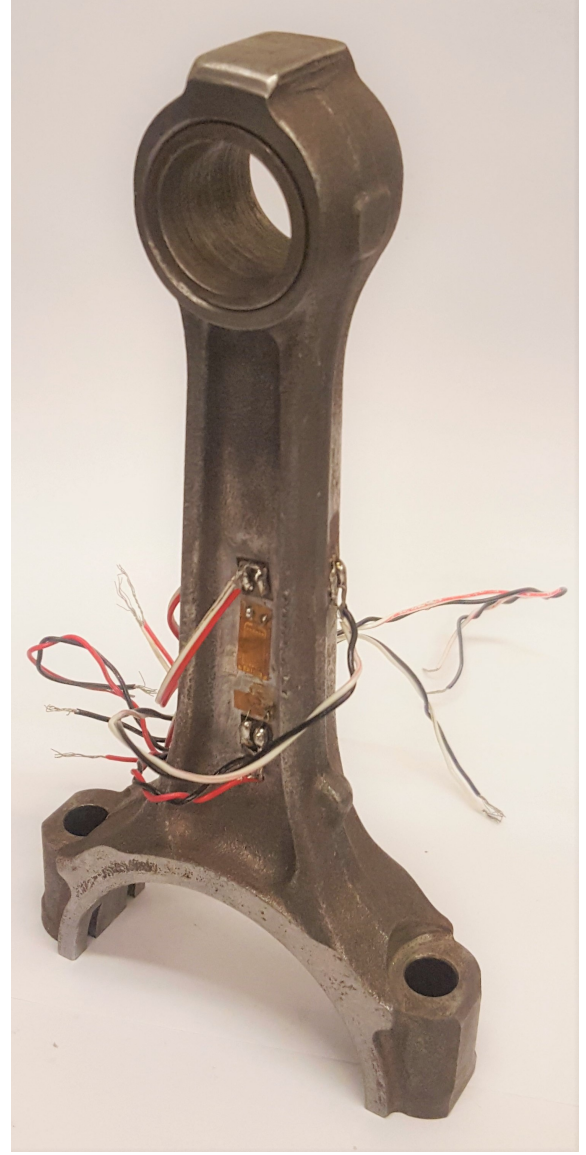

(a) Steel connecting rod

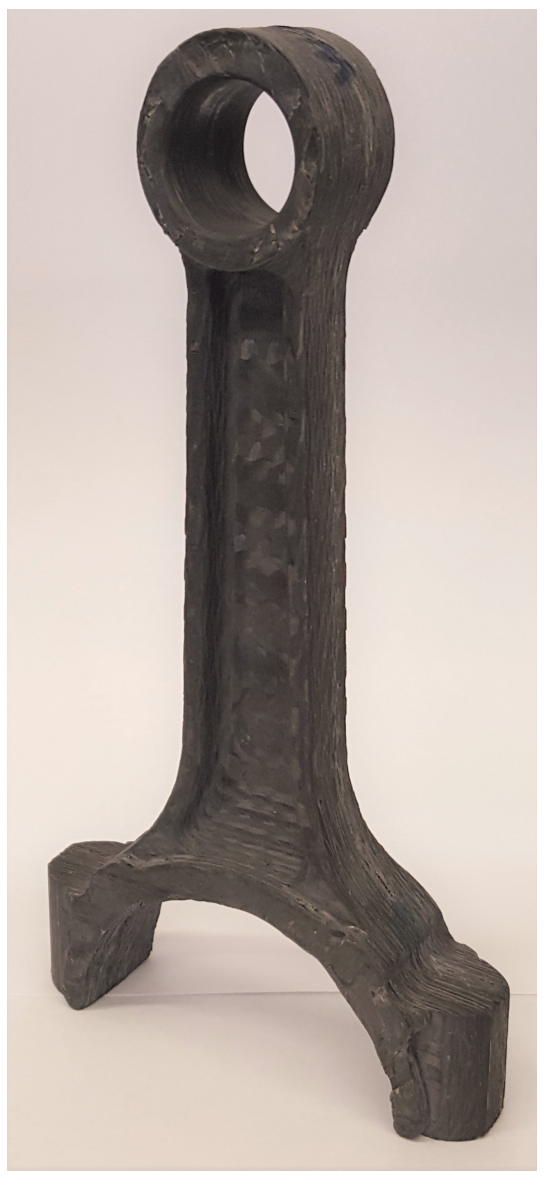

(b) Composite connecting rod

Figure 2.1: Geometry of interest 
Multiple composite options were examined with consideration for their quality after curing, bleed-out of resin, and machinability. The three primary candidates examined included carbon fiber plain weave with an epoxy matrix, pre-impregnated chopped carbon fiber with a vinyl-ester matrix, and carbon fiber tri-axial weave with an epoxy matrix. Each material's quality was inspected visually after curing for attributes which would benefit a compression molding process and provide desirable mechanical properties in the context of the connecting rod geometry being designed for.

Compression molding was pursued based on heritage in high performance, high strength manufactured components. The compression molding process ensures a maximization of material volume and limiting of void content when executed properly. However, due to facility limitations and the complexity of designing a well toleranced six part compression geometric mold, alternative compression molding options were explored. In order to maintain the maximum amount of material composing the final component, a brick geometry compression mold was elected for a path forward. This would allow for minimal void content, cured shape control, and a consistent composite product which would be machined into the desired geometry.

Exploration of machining composites required an understanding of the tools necessary to ensure good surface finish, minimize delamination, and prevent overall weakening of the matrix-fiber interface. Machining of a composite for structural cases would typically be limited to smaller operations on a part, but the elected path of a brick geometry necessitated full machining of the connecting rod geometry, providing insight on the effectiveness of a heavier reliance on machined contours from composite "stock".

The I-beam of the connecting rod became the primary area of interest for machinability and stress distribution as it contains multiple points for failure and has a ten- 
dency to buckle under compression depending on stiffness parameters. This assertion focused the scope of work to the strength performance of the composite in this region and eliminated concerns about fittings necessary for integration into an operable system. 
Chapter 3

\section{MATERIAL SELECTION AND PROCESS DEVELOPMENT}

\subsection{Overview}

This chapter surveys the material options to be machined into the final connecting rod geometry. Mechanical properties as quoted by the manufacturer were examined for preliminary context. Preliminary layups were conducted to evaluate the ease with which each material could be handled and cured. Experimental values for elastic modulus and ultimate strengths were taken. Tool selection for machining is discussed, and initial machinability results of materials are presented. Methods for layup of composite bricks are described and iterated upon. These elements of material selection were conducted in parallel with each other and drove the decision to the primary material for application. The design and manufacturing of the final compression mold are presented. Preliminary bricks were cured to verify the success of the process established.

\subsection{Materials of Interest}

Multiple materials were examined for ease of handling and quality results post cure. Two materials were elected to be tested in tension and compression, as well as for machinability to characterize material behaviors.

\subsubsection{HexPly $^{\circledR}$ F-155}

The HexPly ${ }^{\circledR}$ F-155 is a plain woven composite material (Hexcel, 2016). The system investigated was composed of carbon fiber fabric (Toho $300^{\circledR}$ ) and an epoxy matrix. 
Initial consideration for the material was founded on manufacturer claim of high laminate strengths. The manufacturer quotes the material to have $40 \%-44 \%$ resin content exhibiting a favorable ratio of resin to fiber. A sample of the uncured material is pictured in Figure 3.1.

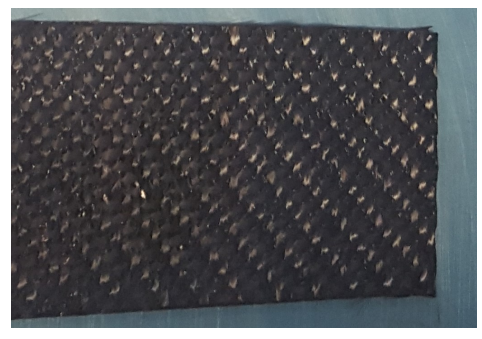

\section{Figure 3.1: HexPly ${ }^{\circledR}$ F-155 uncured sample}

\subsubsection{Cure Cycle}

The cure cycle for the plain weave material can be seen in Figure 3.2. The minimum recommended vacuum pressure for curing is $22 \mathrm{inHg}$ (10.1 psi).

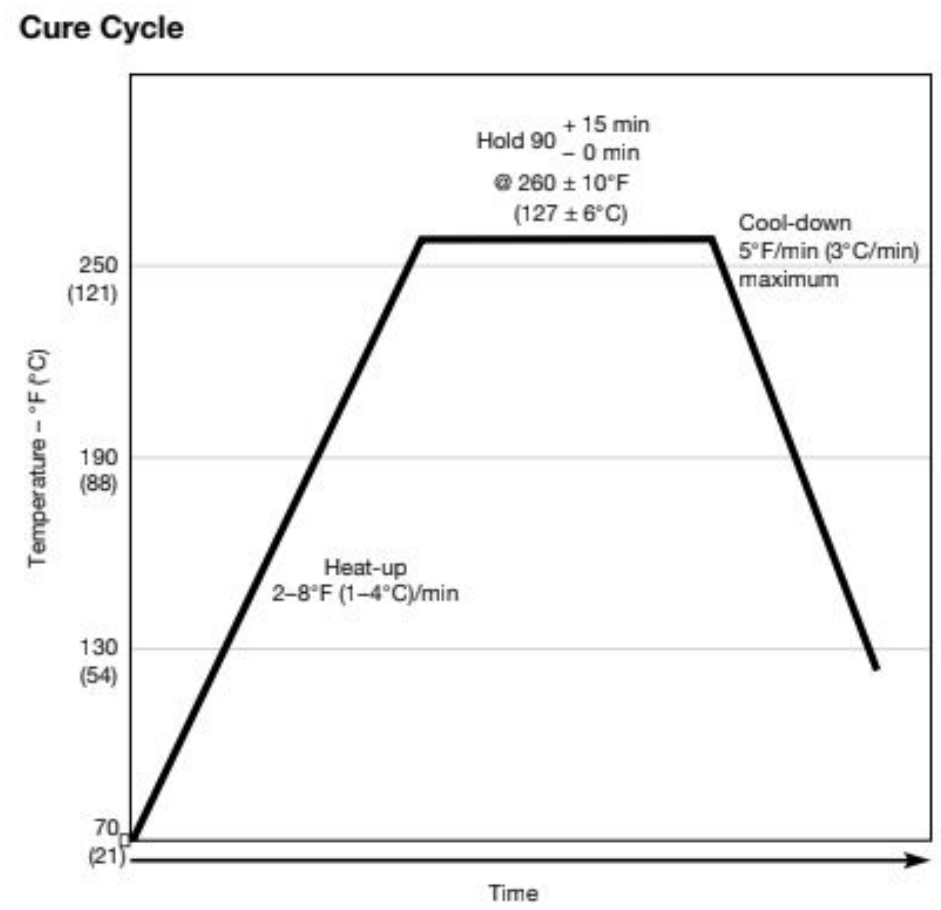

Figure 3.2: HexPly ${ }^{\circledR}$ F-155 Cure Cycle (Hexcel, 2016) 
An initial cure was conducted in the Cal Poly Mechanical Engineering composite oven pictured in Figure 3.3. The layup constructed was symmetric with the $0^{\circ} / 90^{\circ}$ fibers aligned for each layer, and consisted of three ply as a control to verify the manufacturer quoted cured thickness of 0.015 inches per ply. Release film and a smaller aluminum plate mirroring this were placed on top of the specimen. Breather cloth was placed on the top sheet of aluminum. This allowed for a vacuum bag to be taped surrounding the material layup using thermally resistant gum tape stuck to the bottom plate, thereby applying vacuum and distributed pressure to the sample via the top aluminum sheet. With full vacuum pulled on the sample 14.7 psi would be imparted to the layup coupon area. The layup schedule used to prepare the specimen for curing is displayed in Figure 3.4. The layup sitting on the bottom plate and sandwiched in release film is pictured in Figure 3.5. The result of the cure can be seen in Figure 3.6. The final cured sample had a measured thickness of 0.0451 inches, well within tolerance of the expected value.

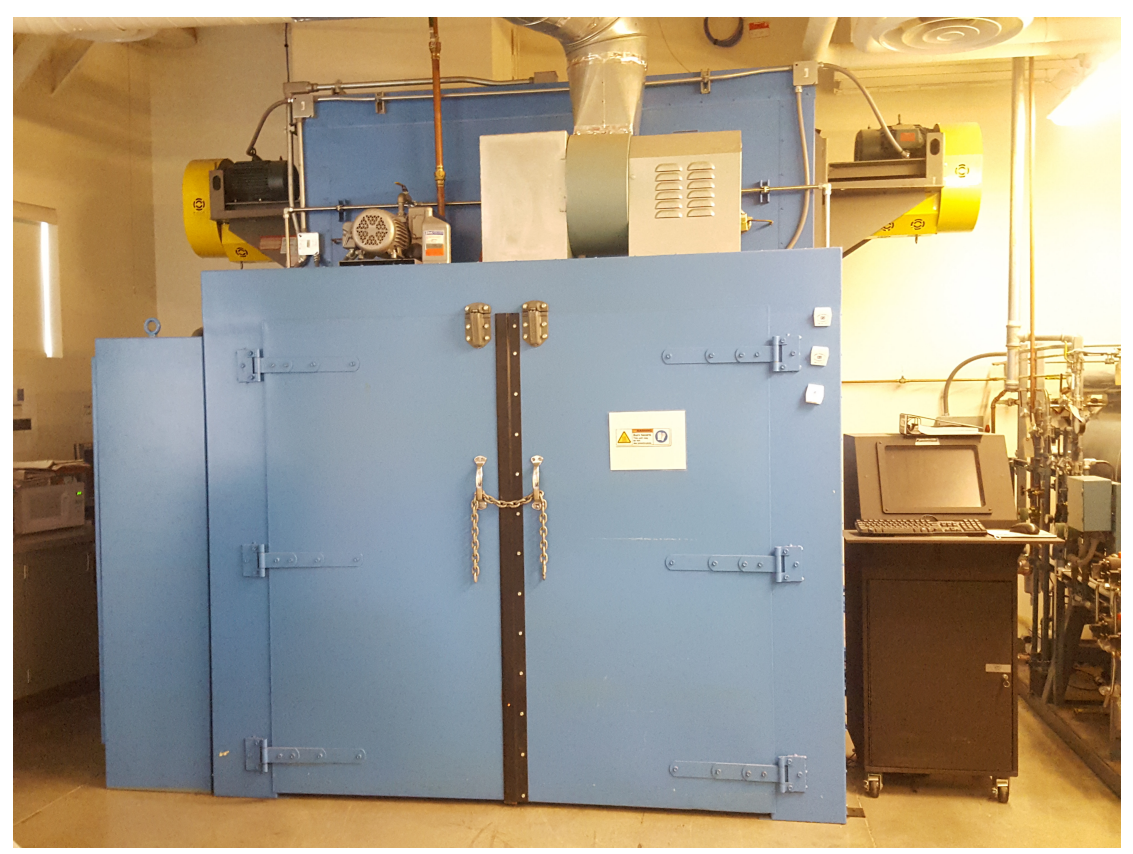

Figure 3.3: Mechanical Engineering composite oven 


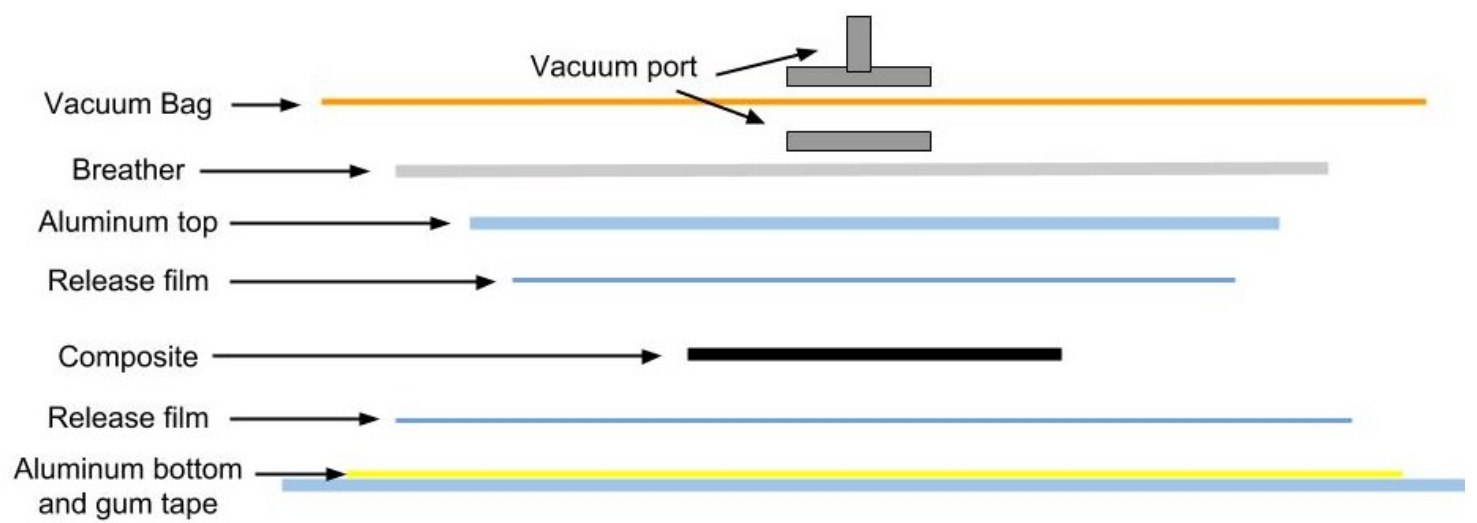

Figure 3.4: Bagging schedule for oven cured material

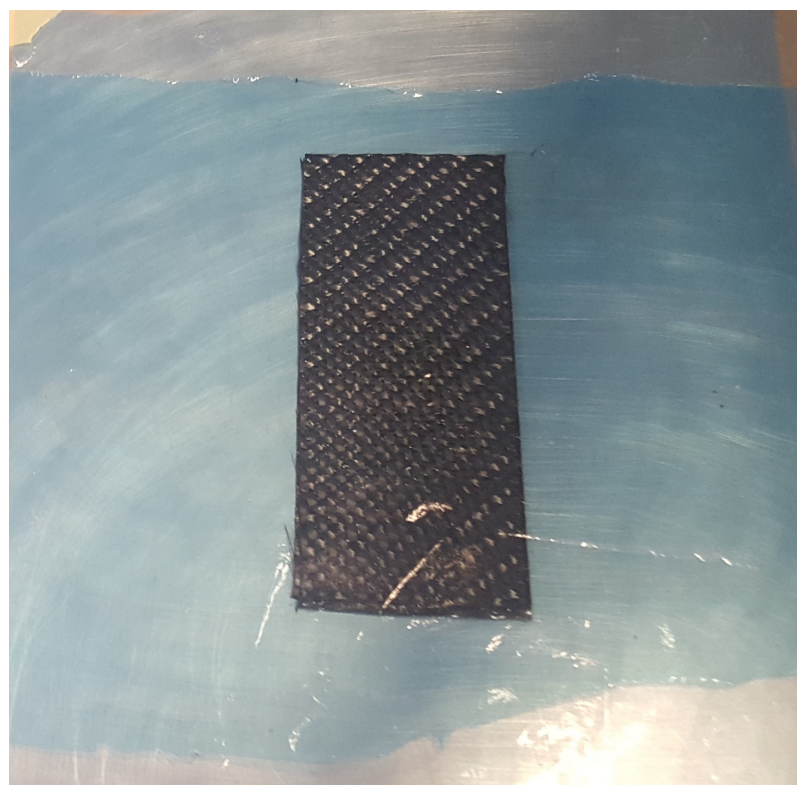

Figure 3.5: Prepping for cure

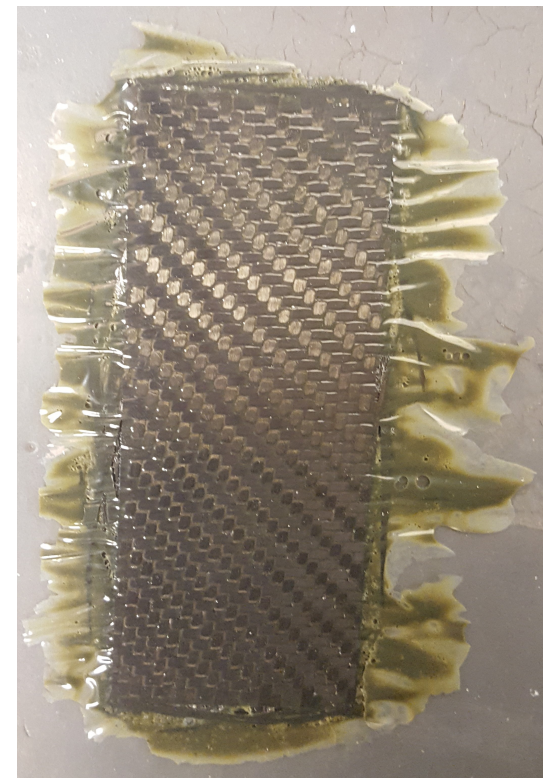

Figure 3.6: Sample post cure

Although the sample exhibited an ability to maintain predicted final thickness, the significant run of resin brought about concerns for use in a compression mold application. 


\subsubsection{AMC $^{\circledR}$ Chopped Fiber Pre-preg}

The Quantum AMC ${ }^{\circledR} 8593$ material is a pre-impregnated chopped carbon fiber and vinyl-ester Engineering Structural Compound (ESC $\left.{ }^{\circledR}\right)$ molding compound (Schulman, n.d.-b). It was selected based on its high resin content (50\%) and the benefits of discontinuous fiber orientation providing quasi-isotropic material properties. The manufacturer additionally highlights that it is easily moldable and provides parts that are high strength, fatigue resistant, heat resistant and possessing low density. The thickness of the material prior to curing added the advantage of achieving a high laminate stack thickness without exhausting material supply. An uncured sample of the material is presented in Figure 3.7.

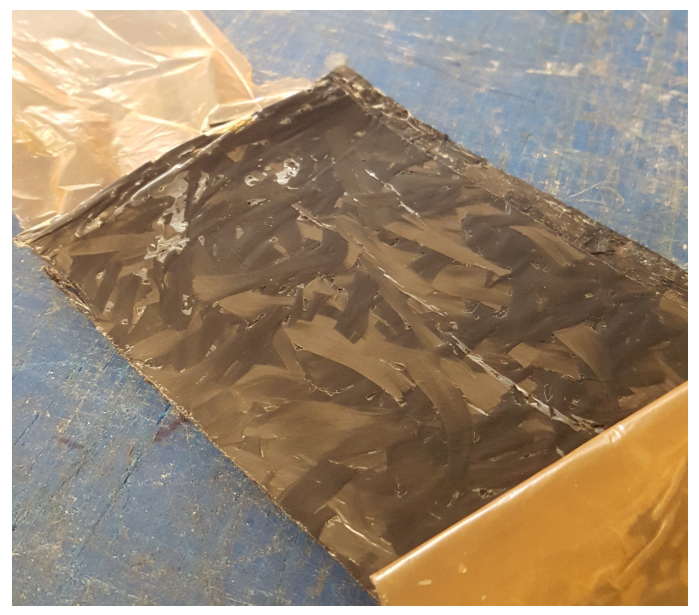

\section{Figure 3.7: AMC ${ }^{\circledR} 8593$ uncured material}

\subsubsection{Cure Cycle}

The cure cycle used for the chopped fiber pre-preg can be seen in Figure 3.8. The manufacturer specifies that the material is intended for matched metal die compression molding. 


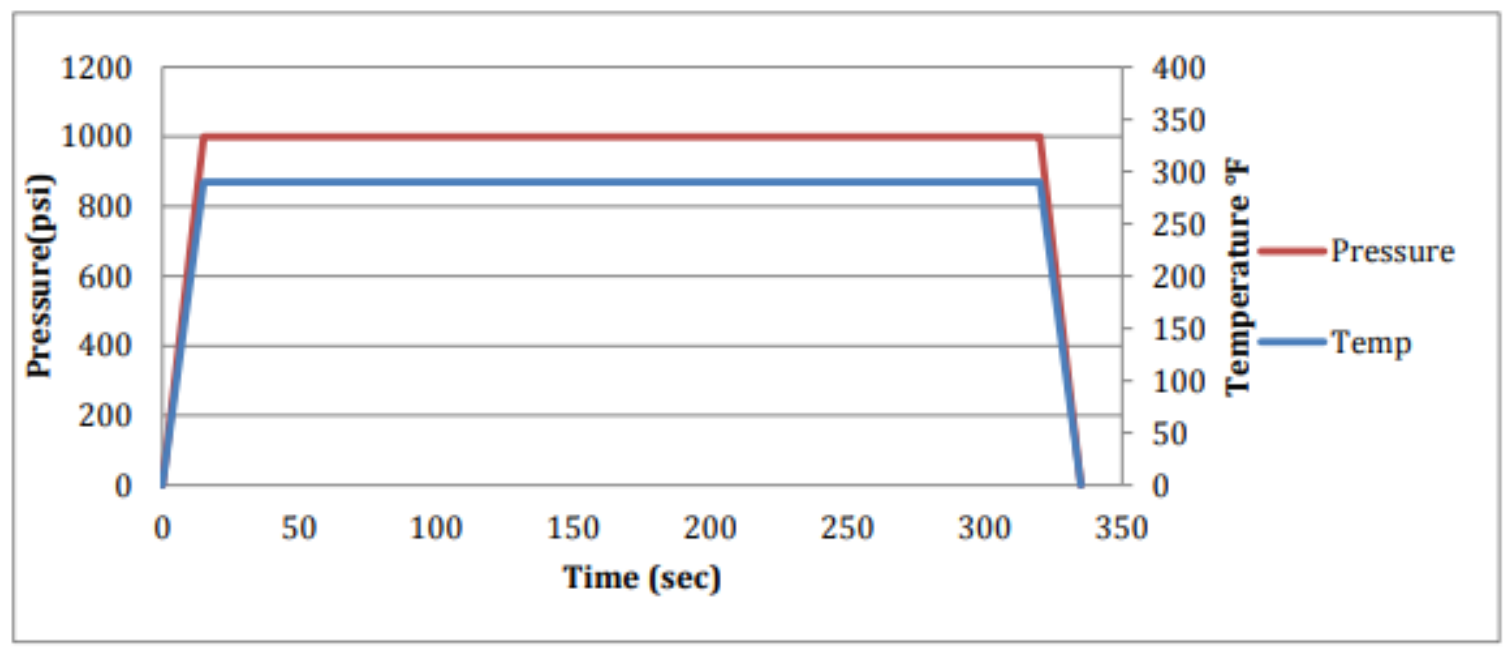

Figure 3.8: $\mathrm{AMC}^{\circledR} 8593$ cure cycle (Schulman, n.d.-a)

This cycle was applied to cures conducted within the Cal Poly Mechanical Engineering oven, as well as using the Cal Poly Aerospace Engineering heat press. Small samples of three ply each were constructed and prepped according to the requirements of each machine. The oven sample was prepared using the bagging schedule depicted in Figure 3.4, while the other sample was prepped for the heat press using the material layup pictured in Figure 3.9. The hot press used is shown in Figure 3.10, while the sample for the oven without its top aluminum sheet can be seen in Figure 3.11. In the context of all curing the maximum available pressure was applied, although this was significantly less than that recommended by the manufacturer data sheet. The oven pressure was provided by vacuum applied on the bagged specimen allowing 14.7 psi from the atmosphere to act on the 4.5 inch by 4.5 inch top plate area. The hot press applied around 1000 lbf onto a 3 inch by 6 inch top plate, ultimately imparting 55 psi across the composite specimen. Maximizing pressure with the available machines for curing was recognized as a high priority for chopped fiber cures to limit void content and maximize strength of the laminate samples. 


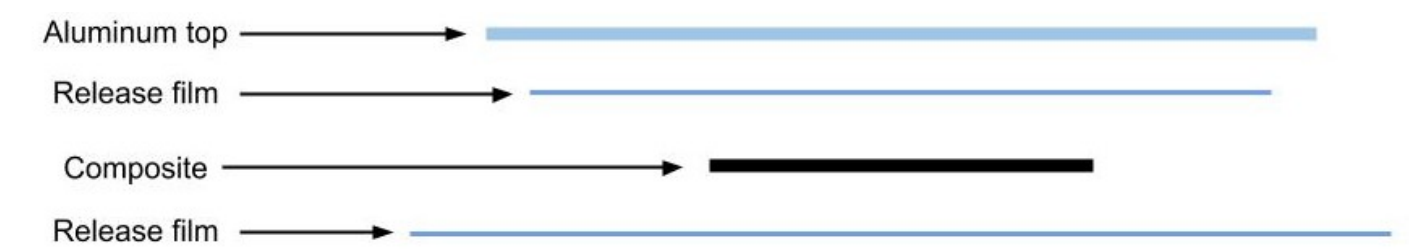

Aluminum bottom

Figure 3.9: Hot press material layup schedule

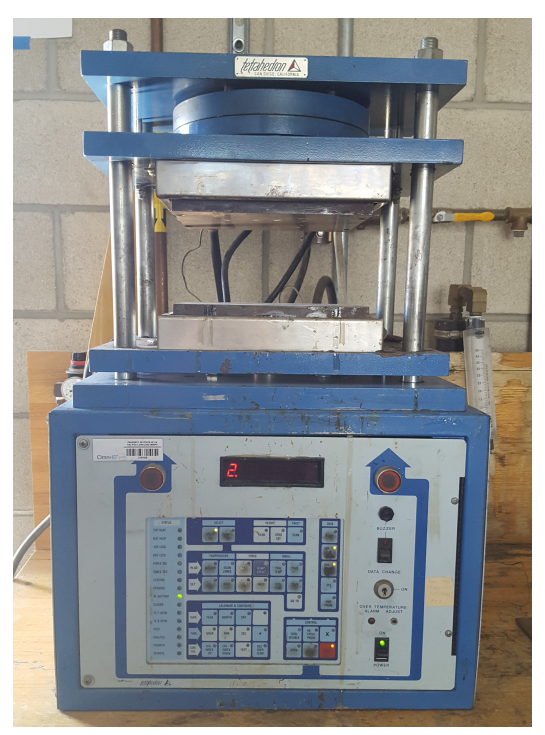

Figure 3.10: Cal Poly Aerospace Engineering composite press

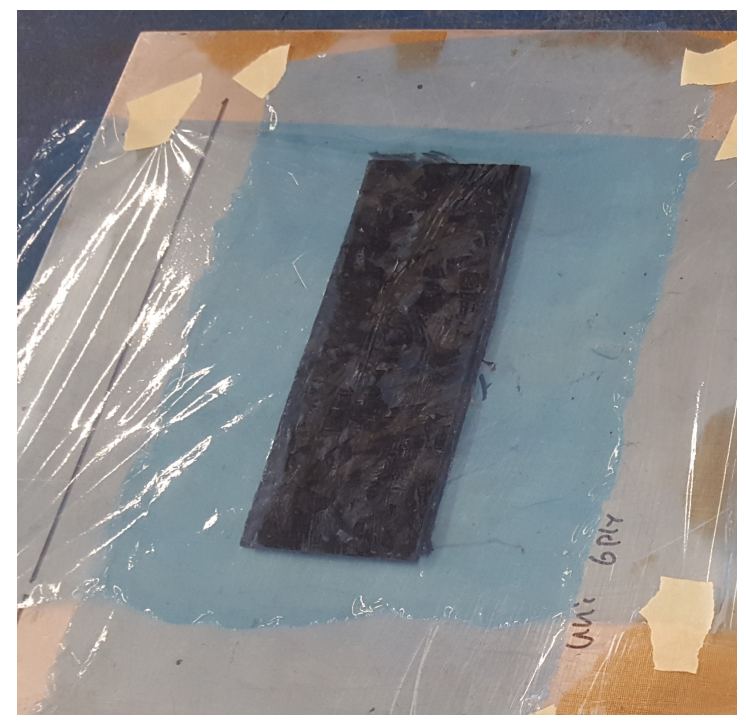

Figure 3.11: Prepped chopped fiber sample

The result of initial flat coupon cures of the discontinuous fiber material are exhibited in Figures 3.12 and 3.13. As is evident there is a visible difference in the surface finish and flow of material dependent on the curing methodology used. 


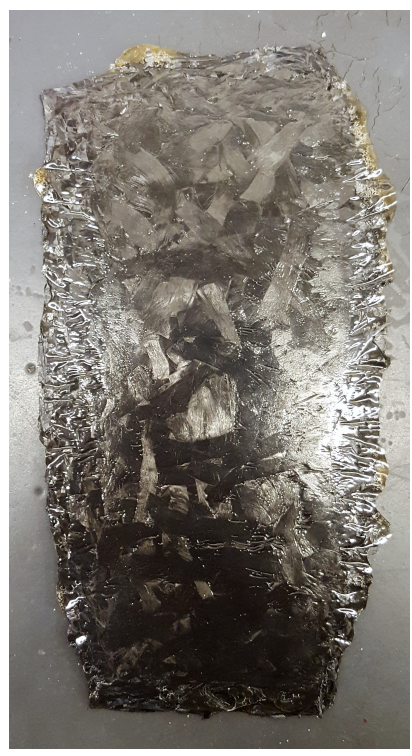

Figure 3.12: Oven cured sample

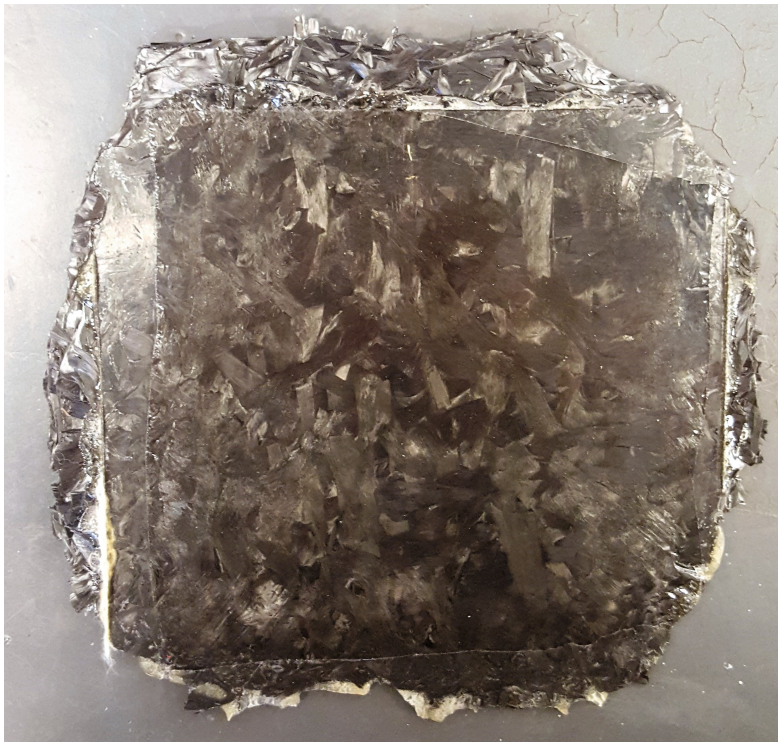

Figure 3.13: Hot press cured sample

There was little predictability in the final cured thickness of the chopped fiber material. Once the resin was heated, the short fibers were unconstrained and flowed freely. This coupled with the pressure being applied forced material well outside of the original size areas which were stacked. The surface finish also exhibited some minor defects due to the discontinuity of fibers. However, the material exhibited better resin retention than the HexPly F-155, giving it some favor in the selection process.

\subsubsection{TenCate Ambertool ${ }^{\circledR}$ HX42 Tooling Prepreg}

TenCate Ambertool ${ }^{\circledR}$ HX42 is a woven composite consisting of $12 \mathrm{k}$ tow carbon fiber and an epoxy matrix (Tencate, n.d.). Rather than being a plain weave, it uses a triaxial weave with fibers in the $0^{\circ}$ and $\pm 60^{\circ}$ directions. An example of a triaxial fiber weave pattern, as well as the axis convention established is shown in Figure 3.14. The specific angular dispersion of fibers gives it quasi-isotropic in-plane behavior meaning regardless of the orientation of loading the material will react with the nearly the same 
elastic properties. For this reason, as well as the manufacturer assertion of proven pedigree in aerospace and high strength applications, the material was investigated. The available roll had a $35 \%$ resin content and weight of $650 \mathrm{gsm}$. A sample of the uncured material is presented in Figure 3.15 .

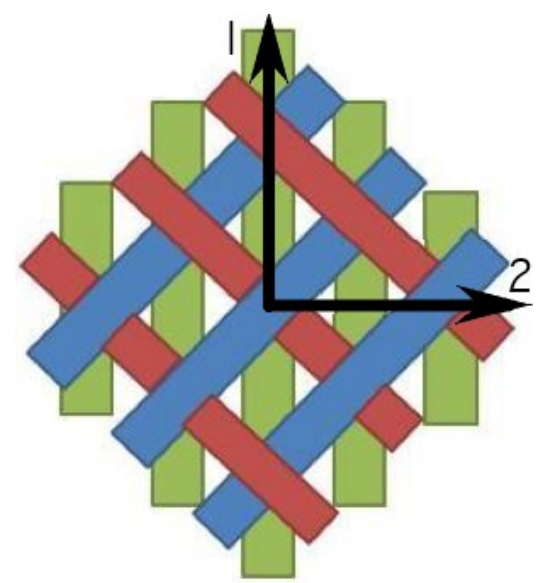

Figure 3.14: Triaxial weave diagram and convention ("3D composites," 2019)

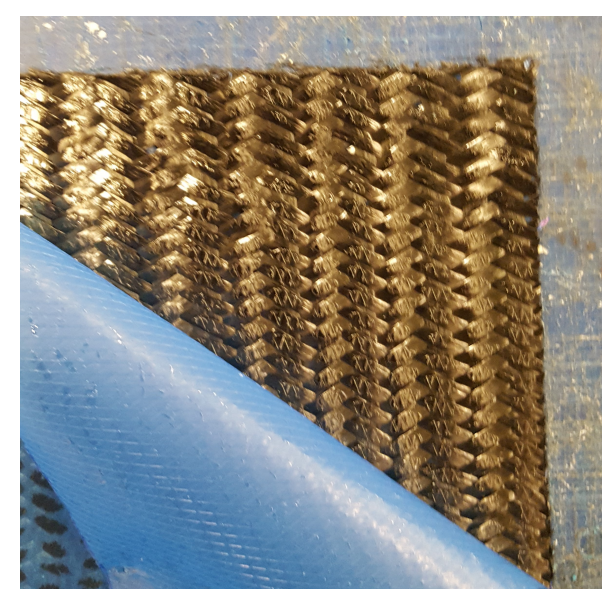

Figure 3.15: Uncured HX42 material

\subsubsection{Cure Cycle}

The cure cycle options for the triaxially woven material can be seen in Figure 3.16. The profile utilized within this research is represented by the blue line exhibiting the shortest cure time. A post cure schedule was provided in the data sheet as well, but it was elected to only apply the initial minimum cure to represent worst case and allow for a faster process turnaround. The material is capable of being oven cured under vacuum pressure. 


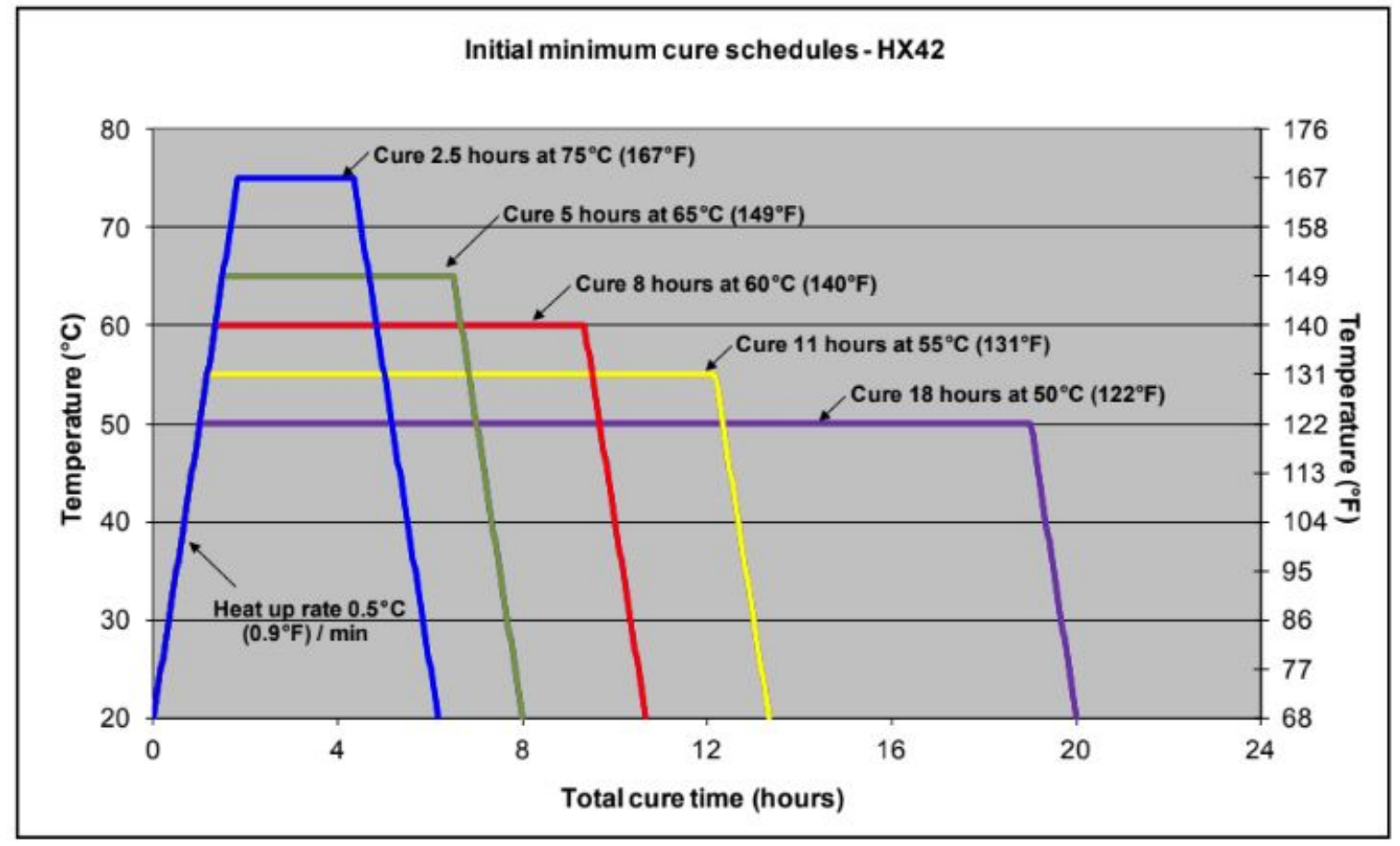

Figure 3.16: HX42 Cure Cycle (Tencate, n.d.)

An initial cure was conducted in the Aerospace Engineering hot press. A small plate of three ply with identical orientation was constructed. The sample was separated from its base aluminum plate with teflon release material and vacuum bag to protect the plate from any potential resin bleed out. The prepped sample is pictured in Figure 3.17. The release film and accompanying protective vacuum bag were then mirrored and an aluminum plate was placed on top of the layup as shown in Figure 3.18. This closely mimics the provided layup schedule presented in Figure 3.9. 


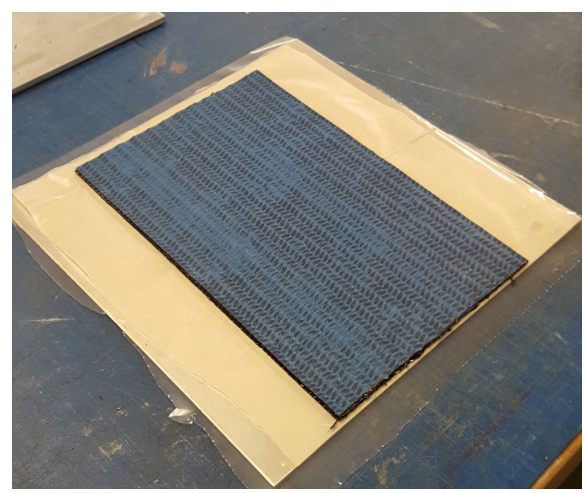

Figure 3.17: Woven flat plate

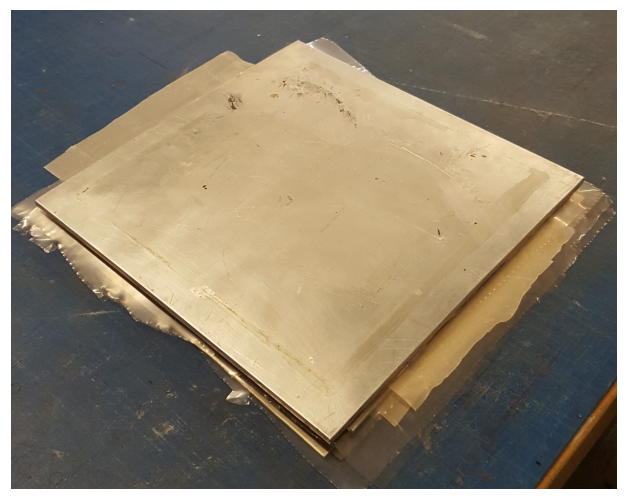

Figure 3.18: Prepped for press cure

A section of the cured plate is shown in Figure 3.19. The specimen exhibited excellent finish qualities with regard to consistent thickness and little to no loss of resin. The final measured thickness of the material was 0.0710 inches as compared to the calculated thickness of 0.0697 inches, showing an excellent ability to come close to predicted laminate height.

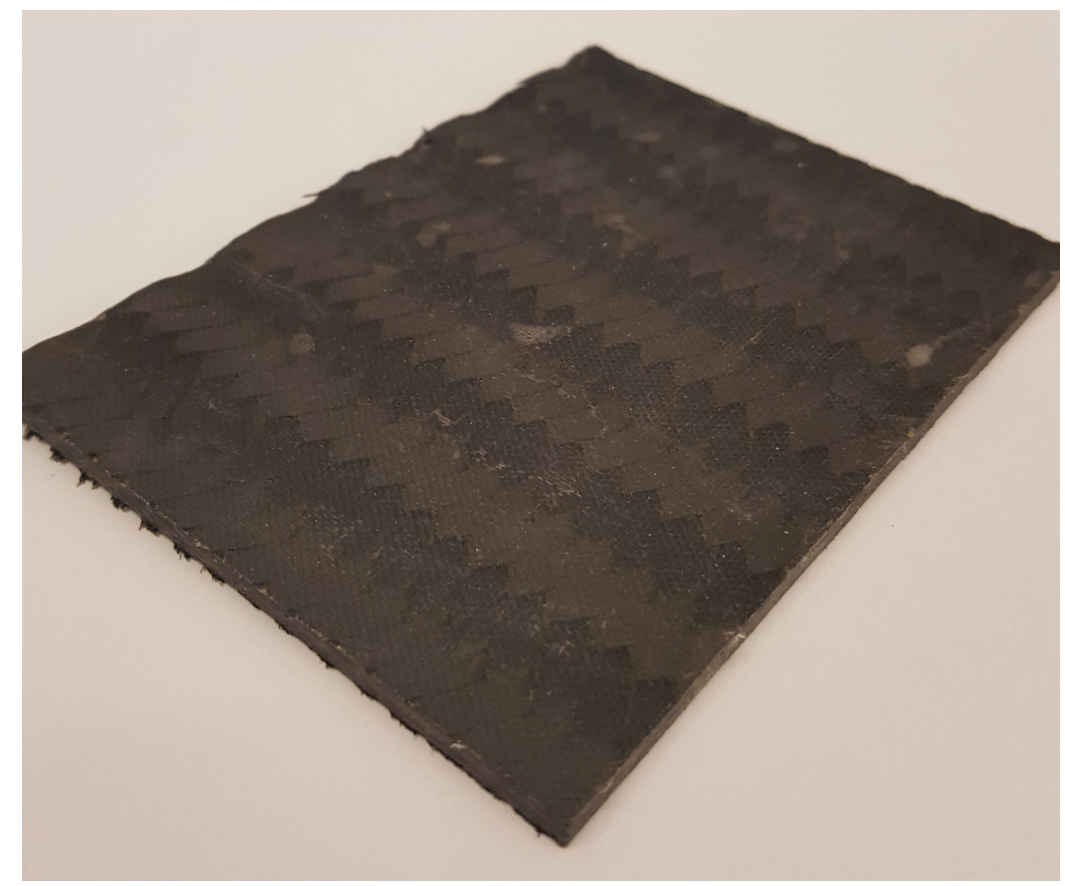

Figure 3.19: Cured HX42 sample 


\subsection{Manufacture Methodology Iterations}

After electing a composite brick geometry from which the connecting rod geometry would be machined, several attempts to cure a brick of thickness corresponding to that of the desired geometry were attempted. The chopped fiber material exhibited the least controllable cure behavior and is intended for compression molding, therefore driving the decision to utilize the material to prove the concept.

\subsubsection{Early Concepts}

Initial block cure tests conducted utilized high density foam (HDF) to create a constrained perimeter around material in an attempt to maintain post-cure shape. Temperature resistant vacuum bag tape was used to secure strips of foam to each other and an aluminum base plate. Each of the walls were sanded to within 0.01 of 0.86 inches, which corresponds to the final thickness of a brick necessary for the composite connecting rod geometry. The assembly along with the first layup can be viewed in Figure 3.20. The composite was isolated from the upper and lower face aluminum

plates using a non-porous teflon sheet. All early concept cures were conducted using the Aerospace Engineering composite hot press. 


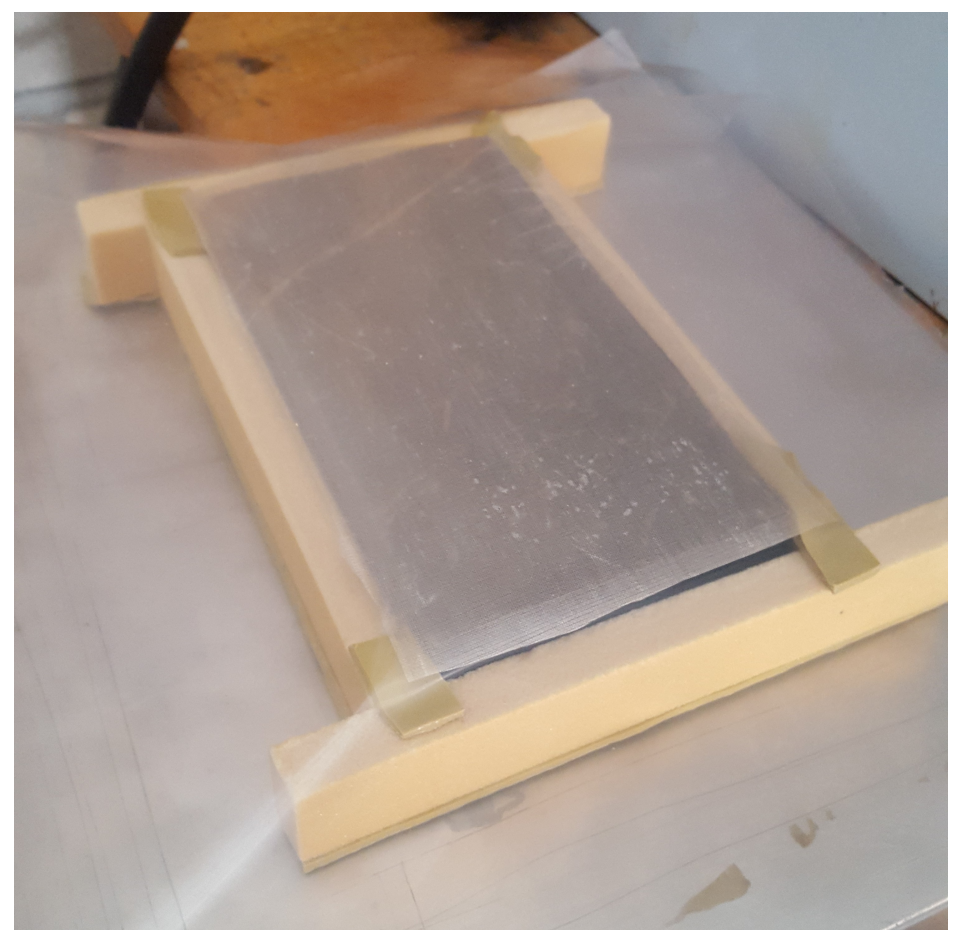

Figure 3.20: HDF mold setup and chopped fiber layup

This iteration revealed that the chopped material ran significantly due to high volume of material and discontinuous nature of the fibers. Additionally, the pressure exerted on the heated vacuum tape and foam segments rotated the mold walls, thereby allowing the structure to be crushed edgewise and demolish the perpendicularity between the HDF segments. The vertical pressure of the hot press forced material out horizontally putting further pressure on the unconstrained walls and exacerbating the destruction of the perimeter as seen in Figure 3.21. The post cure result is presented in Figure 3.22. 


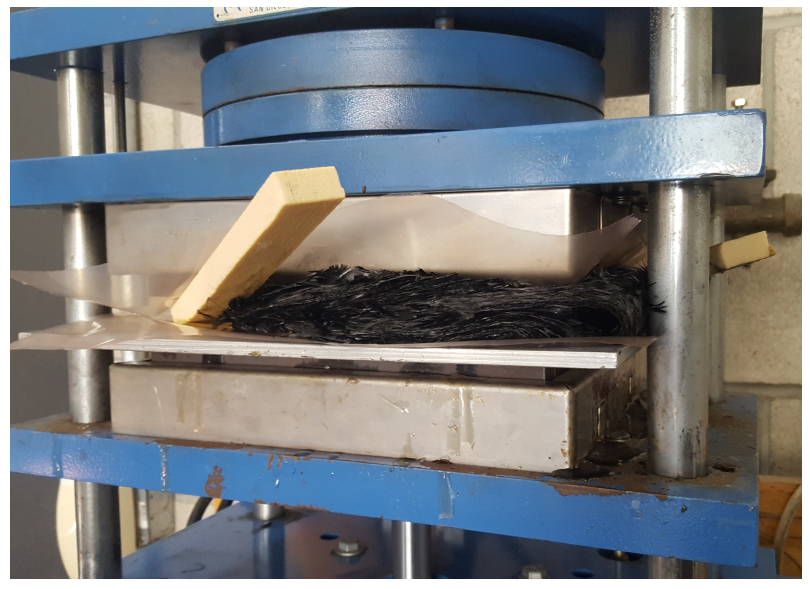

Figure 3.21: HDF cure failure

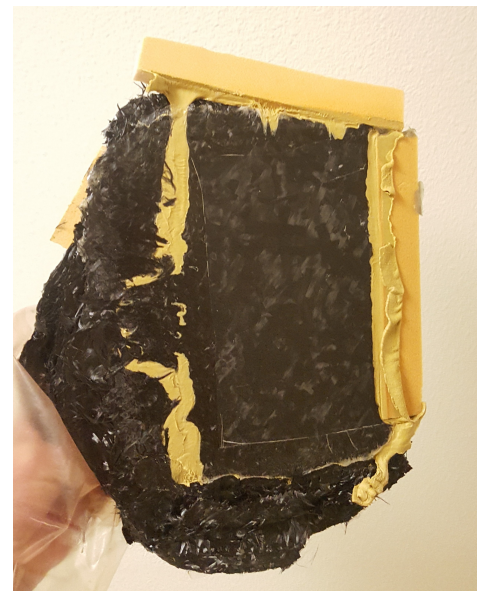

Figure 3.22: $\quad$ First HDF cured result

To better the understanding of the resultant cure properties, especially with respect to void content, the "brick" sample was cut to the uniform section using the Aerospace Engineering tile saw, pictured in Figure 3.23.

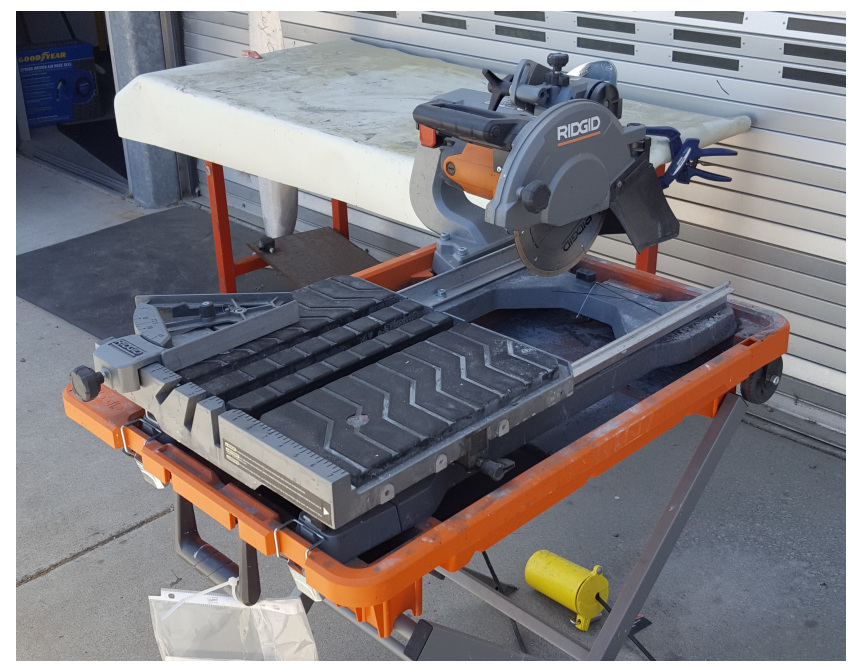

Figure 3.23: Aerospace Engineering tile saw

By exposing the cross section of the more consistent portions of the cure attempt visual inspection could be conducted for defects. Figure 3.24 shows the portion cut from the failed cure, while Figure 3.25 shows a side view of the sample. 


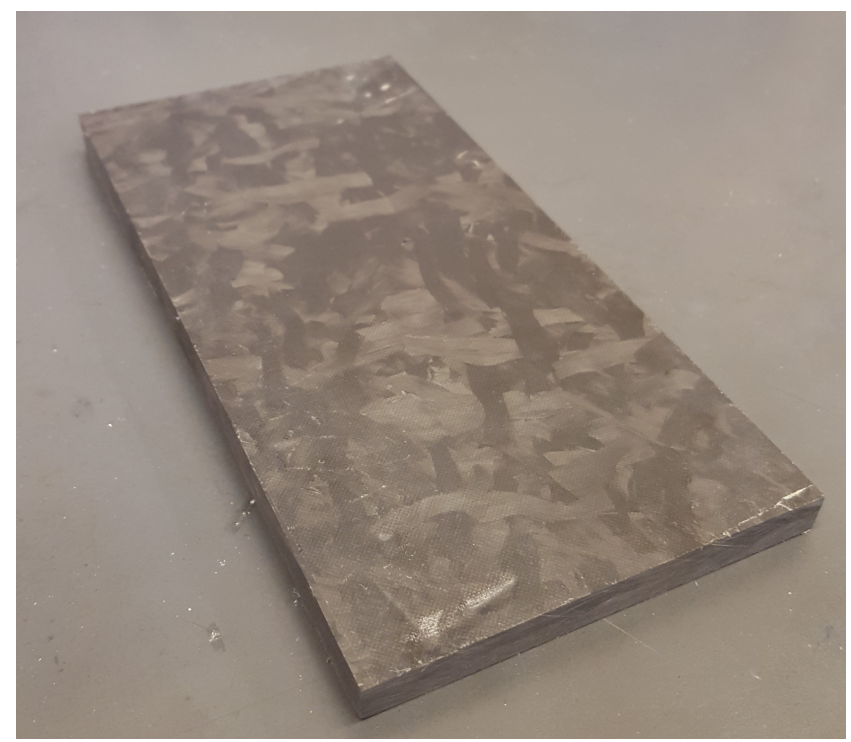

Figure 3.24: Chopped fiber sample cut

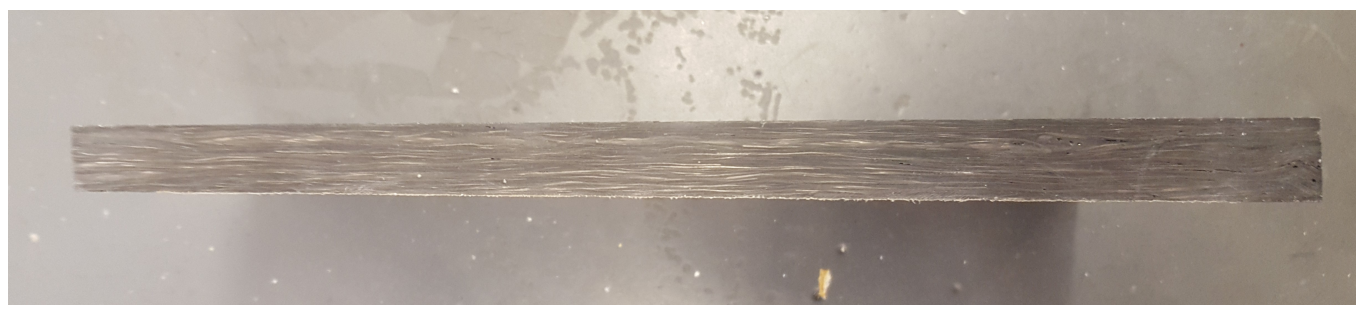

Figure 3.25: Side view of sample cut

Inspection revealed that the thickness was not uniform throughout the sampled section. This made sense as the top push plate would have become unlevel based on the resistance and direction of material flow. However, because this section experienced the most pressure and retention of material, the level of voiding was low. As a result, the perimeter based concept was continued with a focus on utilizing the chopped fiber material.

The next iteration of a perimeter mold utilized HDF once again, but this time applied epoxy at the joints of the wall sections in hopes of eliminating separation. Once again foam segments were sanded to within 0.01 of 0.86 inches. The segment 
lengths were then cut with $45^{\circ}$ joints at each end which could be epoxied and clamped. The final construction along with its corresponding uncured layup are depicted in Figure 3.26. The layup schedule of materials isolating the composite and brick from aluminum face sheets matched that used prior as this did not appear to have a negative effect on the cure result.

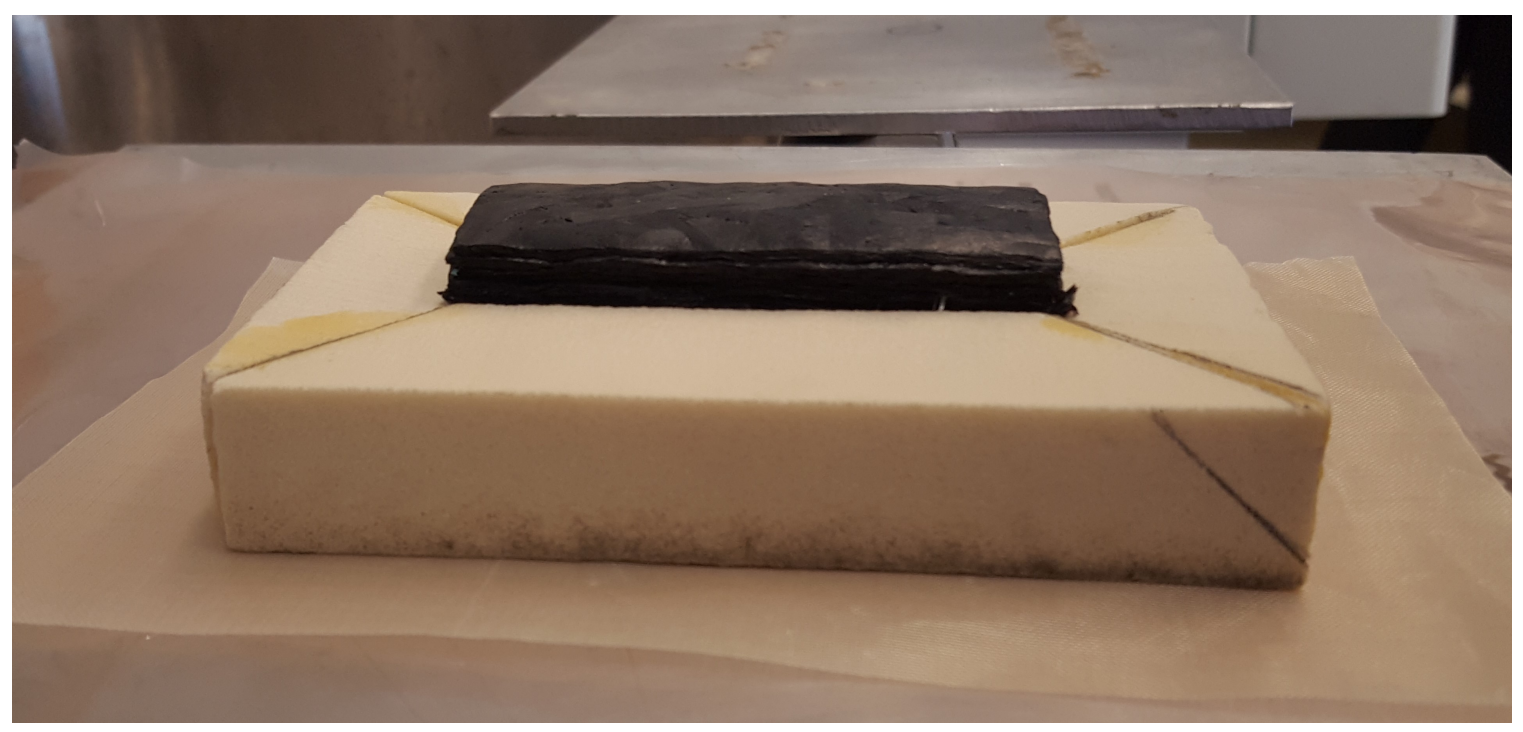

\section{Figure 3.26: Second HDF perimeter mold attempt}

By increasing the footprint of the walls to be greater than their height the issue of rotation was eliminated. However, the epoxy was still unable to counteract the internal pressure accumulated as the chopped fiber material became compressed into the cavity. The result of this is pictured in Figure 3.27. It was concluded that because of the foam's porosity, the epoxy bonding area was compromised resulting in the separation of the HDF segments. 


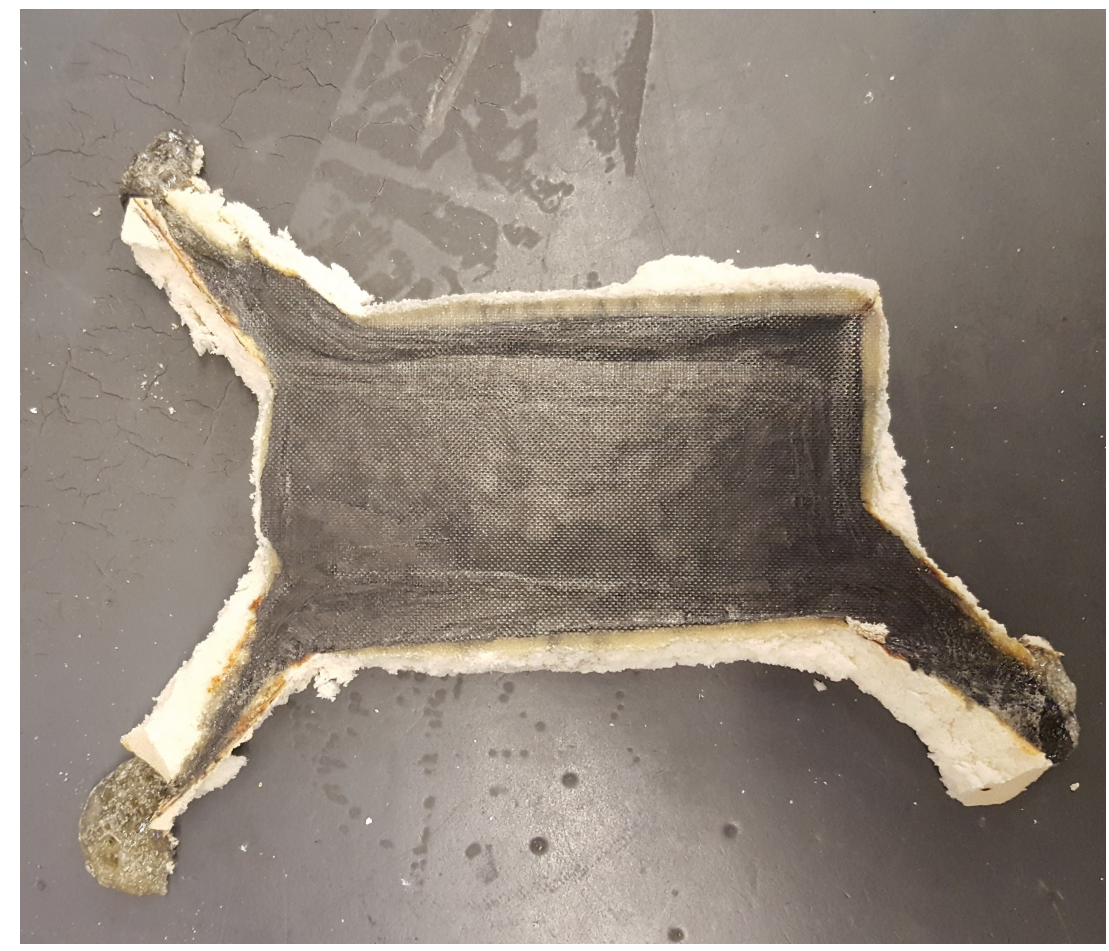

Figure 3.27: HDF perimeter second attempt result

Due to issues with fully constraining the foam segments in the first two iterations of perimeter methods a medium density fiberboard (MDF) option was elected as a path forward. This would allow for hardware to be used as a constraint thereby providing significantly more resistance to the internal pressure accumulation during the cure. Segments of MDF were cut to length and sanded flat to an arbitrary height of 1.10 inches. A pilot hole was then drilled to mitigate any damage to the segments when a screw was inserted to join them. Because MDF is primarily composed of glue small cracks did form when screws were inserted despite the pilot holes. The layup sequence of aluminum face sheets, vaccuum bag, and teflon material matched that of prior iterations. The result of the MDF perimeter cure is available in Figure 3.28. 


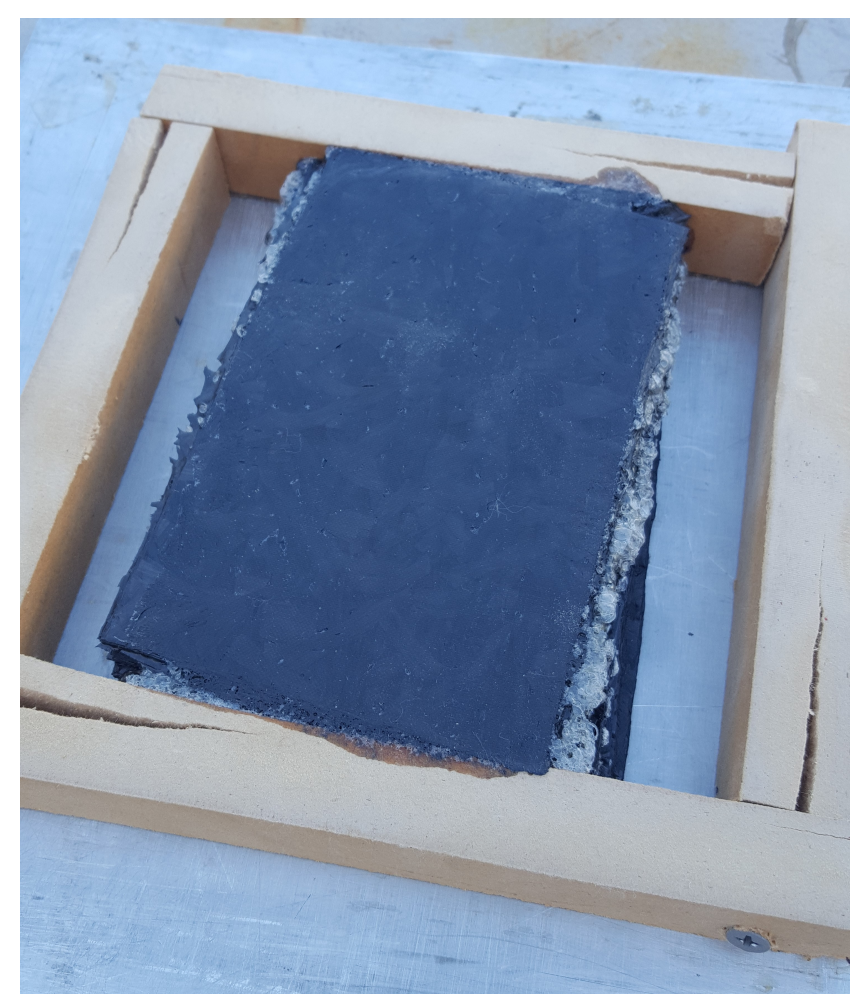

Figure 3.28: MDF perimeter result

The product of using a MDF perimeter showed greater success than previous attempts which utilized HDF. The lack of unmanaged material flow showed that the MDF had succeeded in gauging the final height rather than continually compressing the material and forcing it outside the extents of the mold. Some sliding of plies did occur, but the containment of the material was overall better as the height of the press had remained constant. However, the propagation in cracks along where screws had been placed implied deformation and proved that the solution was not sustainable. After the cure, the sample was freed from the MDF and cut on the tile saw to expose a cross section close to the center of the brick. Although the thickness consistently measured 1.0625 inches (showing a slight compression from original perimeter height), the void content was visibly unsatisfactory. This was most certainly due to the significantly lower pressure applied than the recommended 1000 psi. The sample cut from the brick is exhibited in Figures 3.29 and 3.30. 


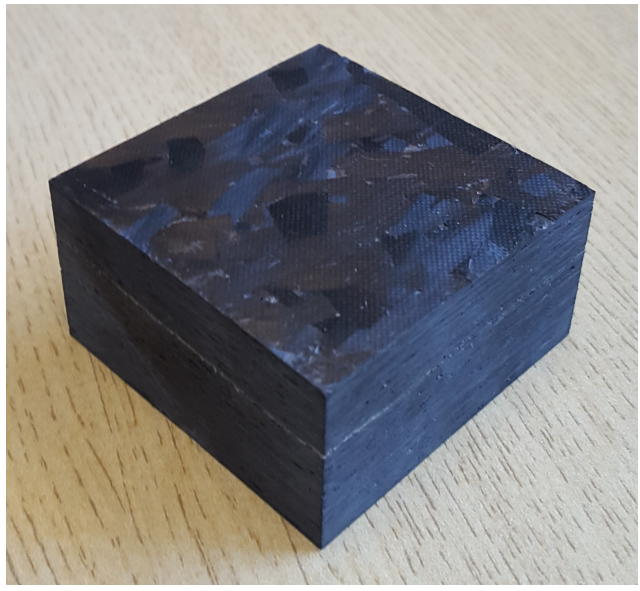

Figure 3.29: MDF sample cut

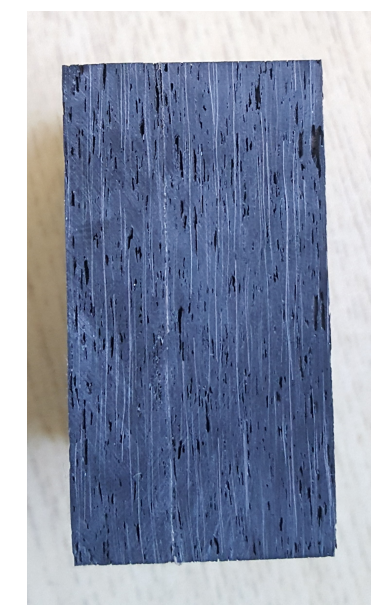

Figure 3.30: Sample cut side view

Because the cut sample yielded a consistent thickness it was asserted that it could be used in preliminary tests for machinability. The void content made it undesirable in a structural application, but in proof of concept for process the specimen provided a viable start point.

The result of the MDF perimeter attempt proved that if constant height could be maintained and a well constrained perimeter be constructed the chopped fiber material cured shape could be controlled. From this it was decided an aluminum compression mold for the brick geometry would fare best for repeatability in results and integrity of the mold. In the interest of prototyping, aluminum materials which mocked the concept were found in the Mechanical Engineering Composite Laboratory. These materials are pictured in Figure 3.31. The aluminum plates were stacked to attempt to offset the depth of the mold cavity and control the final height of the cured composite brick. Knowing that the chopped fiber would not perform well without a fully enclosed mold, this iteration applied the triaxially woven material. This meant a sample of the same dimensions as the chopped fiber sample cut for machinability trials could be manufactured from the HX42. 


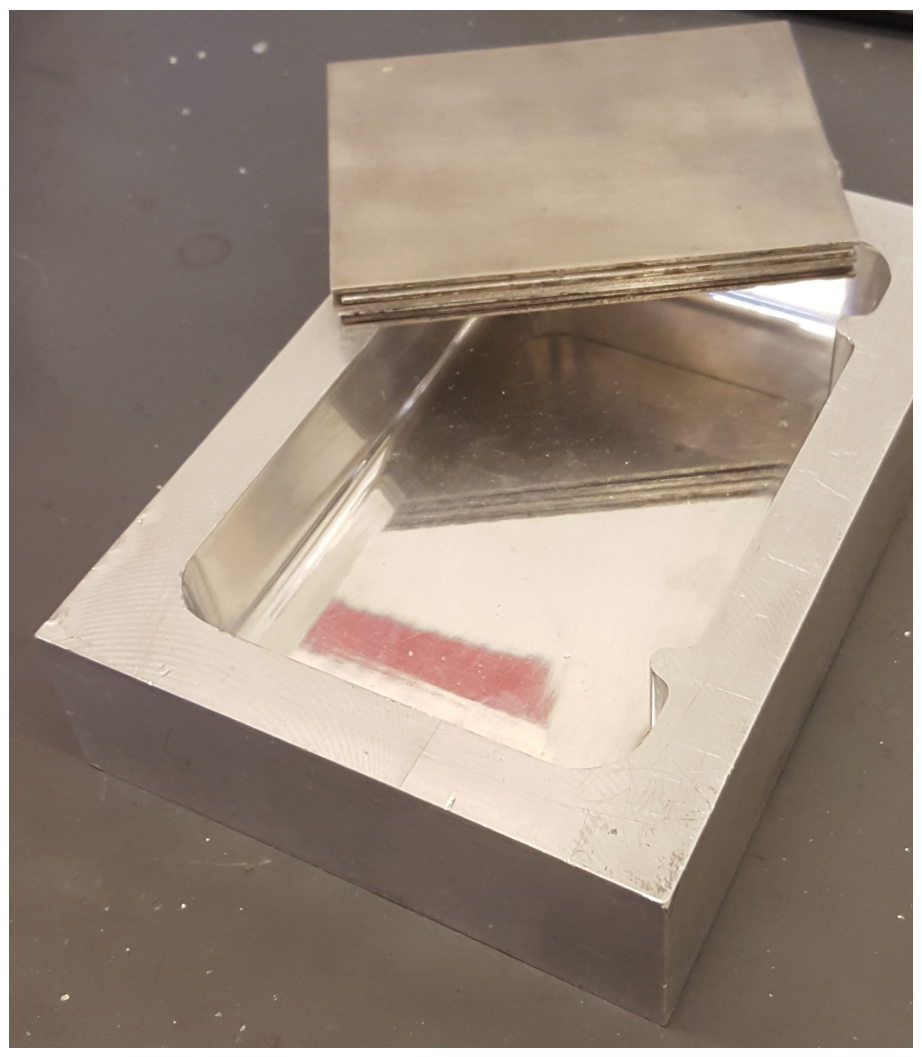

\section{Figure 3.31: Aluminum mold mockup materials}

As expected, the success of using repurposed materials for the mold was limited. As the woven material was compressed, fillets in the cavity of the mold curled and distributed the material unevenly. This yielded a less than satisfactory brick product, but samples were still salvaged from sections centered on the cure. Figures 3.32 and 3.33 exhibit the best recovered segment for machining. From the side view the effects of curling and ply distortion induced by the fillets and walls in the mold are apparent. As a result of this sliding effect the final thickness was nowhere close to the intended 0.86 inches, measuring closer to 0.625 inches. 


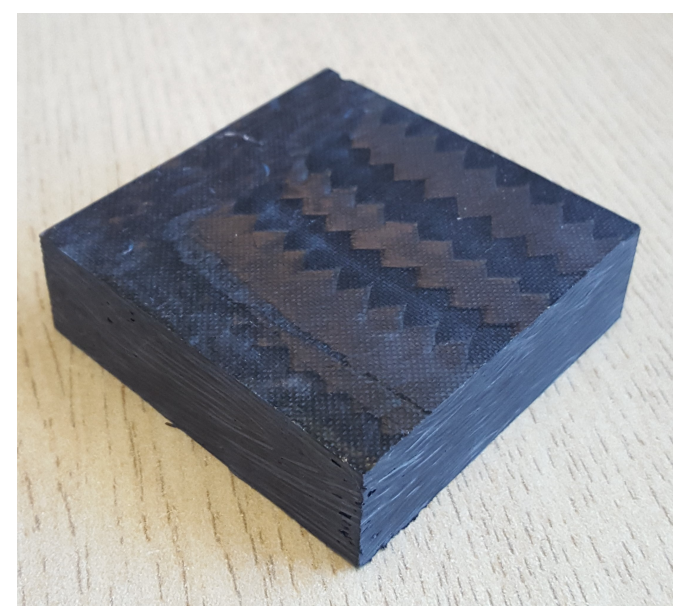

Figure 3.32: Woven sample cut

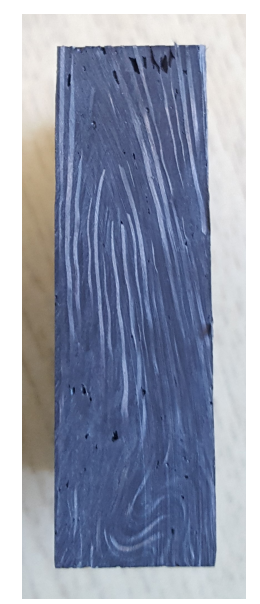

Figure 3.33: Woven block side view

Having samples prepared for machinability testing allowed for concurrent efforts to occur. As building a well toleranced aluminum mold was not a trivial task, having small brick samples available for machining tests was beneficial to the project timeline.

\subsubsection{Final Mold Design and Composite Manufacture Method}

Based on the early iterations of molding attempts it was decided a fully constrained, aluminum mold was necessary to maximize the quality of cured product. Stock 6061 aluminum was collected based on what was readily available, which in turn drove certain decisions on mold construction. A 1 inch thick plate of ample length was found and dedicated to constructing the mold walls. Similarly, plates of the adequate area were found to use for face plates and a push plate. Figure 3.34 exhibits the primary components of the mold system. 


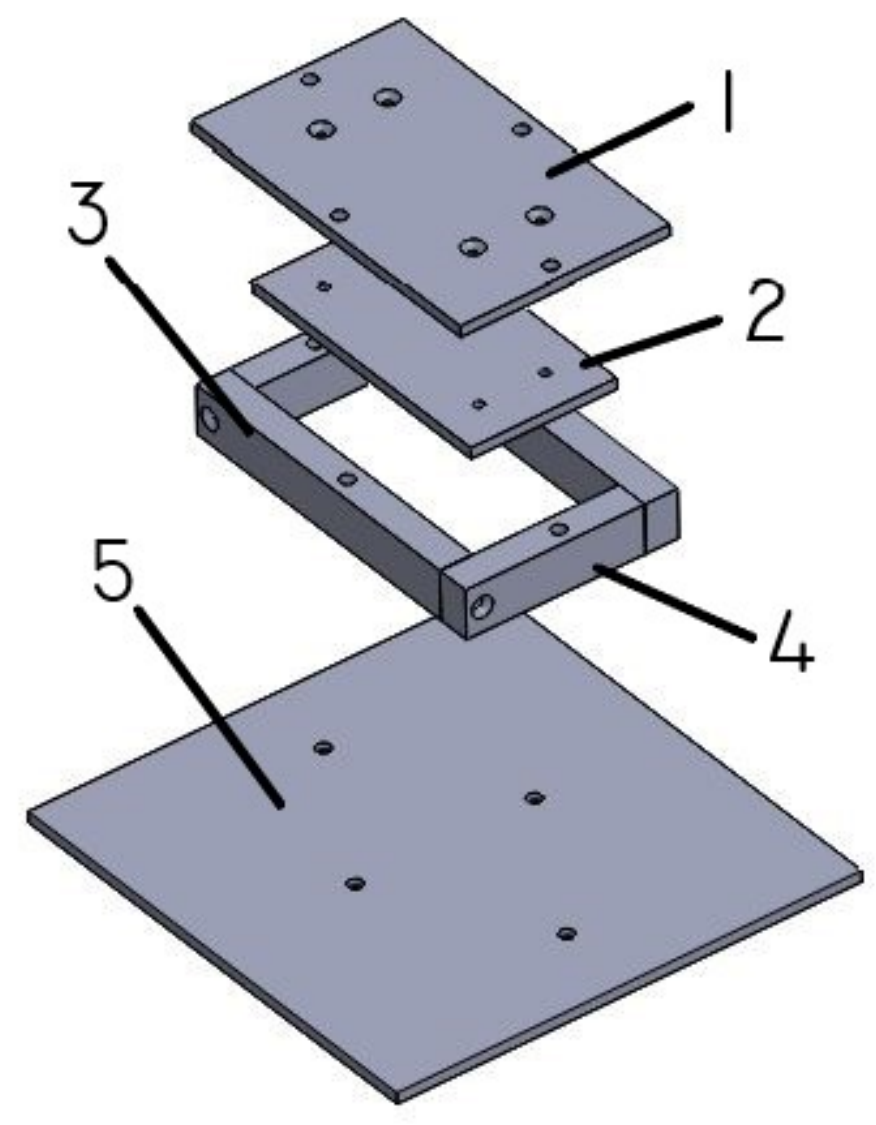

Figure 3.34: Exploded view of aluminum mold concept

Item 1 is a top plate with unthreaded through holes. The four outermost holes accommodate through bolts which extend past the thickness of the mold, while the center four are for attachment item 2, the push plate. To allow for attachment to the top plate, the four holes on the push plate are threaded, but do not go through the full depth of the plate to maintain a closed surface to press on the composite. The push plate acts as a thickness offset from the height set by items 3 and 4, the long and short side bars respectively. Item 5 is the bottom plate which includes four through holes for the through bolts which extend the thickness of the mold. An assembled CAD model is exhibited in Figure 3.35. The orientation and placement of each of the parts of the mold is based on fully constraining all DOF when the mold is assembled, 
while still facilitating easy part removal post cure.

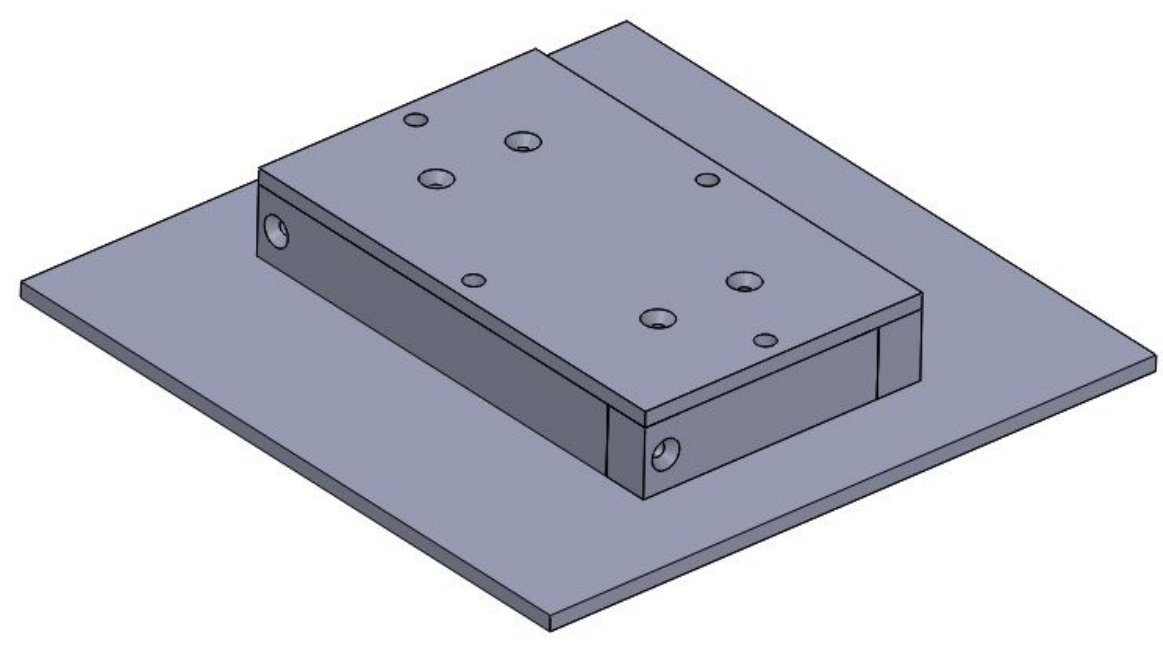

Figure 3.35: Assembled aluminum mold concept CAD

Hardware used to constrain the mold components was purchased from McMaster Carr. Table 3.1 lists the components purchased and quantities applied for mold assembly.

\begin{tabular}{c|c|c|c|c}
\multirow{2}{*}{ Type } & Material & Length & Thread Size & $\begin{array}{c}\text { Quantity } \\
\text { in Mold }\end{array}$ \\
\hline Flat Head Bolt & Stainless Steel & $3 / 8 "$ & $1 / 4 "-28$ & $\mathrm{x} 4$ \\
\hline Flat Head Bolt & Stainless Steel & $1 "$ & $1 / 4 "-28$ & $\mathrm{x} 4$ \\
\hline Flat Head Bolt & Stainless Steel & $2 "$ & $1 / 4 "-28$ & $\mathrm{x} 4$ \\
\hline Hex-Nut & High-Strength Steel & - & $1 / 4 "-28$ & $\mathrm{x} 4$
\end{tabular}

The four $3 / 8$ inch bolts are used to attach the push plate to the top plate. The four 1 inch bolts pass through one side wall and secure it to a perpendicular wall, thereby ensuring the corners of the brick will be square with one another. The four 2 inch bolts are passed from beneath the bottom plate vertically so that they travel the 
through holes and extend above the upper surface of the top plate. This constrains all parts of the mold horizontally, prevents rotation of the side bars, and allows for hex nuts to be tightened from the top. When the hex nuts are torqued, they compress the top and push plates toward the cavity until the top plate lower surface is flush with the upper faces of the side bars.

Dimensions of the design were driven by two major constraints: the dimensions of available stock, and the desired final cure geometry. Plate thicknesses were set based on the provided materials, and therefore the only way to achieve the desired brick thickness of 0.86 inches was to set the side wall height to force the proper offset. Using the smallest stock plate for the push plate set this wall height to 1.11 inches. This determined that the 1 inch thick stock would have to be cut using a ban saw to a nominal height and faced down to the precise dimension required. The other major driver of mold dimensions were the length and width of the cured brick. It was asserted that some additional area on the brick could be beneficial to avoid any edge effects of the composite cure effecting the final machined part. Instead of sizing the inside area of the mold to the exact 6.25 by 3.2 inches of the connecting rod extents, dimensions were set to 6.35 by 3.3 inches to allow for 0.05 inches of margin around the perimeter. By setting this inner area's dimensions, all other dimensions were derived. Fully dimensioned detail drawings of each component are available in Appendix A. Note that all threads were specified to $1 / 4 "-28$ to limit the number of tool changes in machining and utilize a tap that was already available. After stock materials were cut to nominal sizes they were faced using the Haas mill located in the Aerospace Engineering Machine Shop. The mill used is pictured in Figure 3.36. 


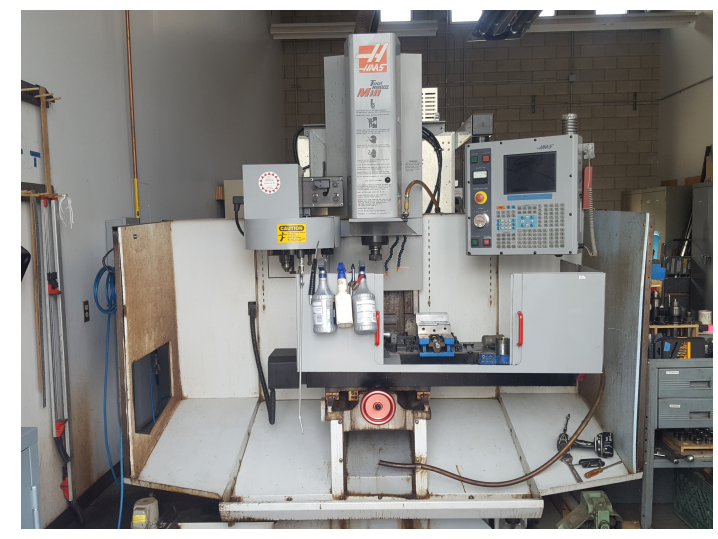

Figure 3.36: Aerospace Engineering Haas mill

After roughing, finishing, hole placement, and tapping was completed the machined aluminum parts still had a rough surface finish. This is exhibited in Figures 3.37 and 3.38 with the side bars and bottom plate respectively.

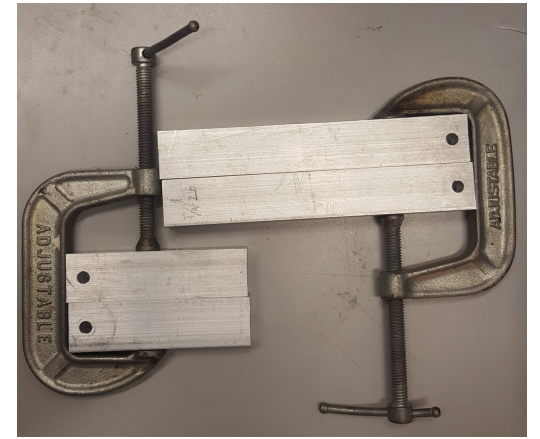

Figure 3.37: Walls before polish

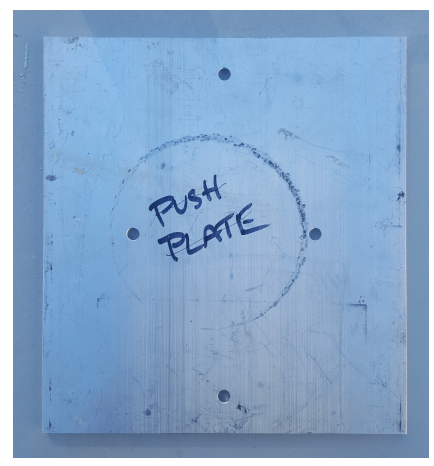

Figure 3.38: Plate before polish

Polishing the inner surface of aluminum parts which are exposed to contact with carbon during a cure is important. A near mirror finish ensures that the surface finish on the carbon part is good, as well as significantly simplifies the freeing process. Polishing each of the components started by roughing each part with dry 80 grit sandpaper to remove any oxidation and major blemishes i.e. scratches or dings. This was followed by aggressive wet sanding with 120, 220, 320, 600, 800, and 1000 grit sand paper successively. The result was a near mirror finish on the inside surfaces of 
the mold components as shown by the examples in Figures 3.39 and 3.40.

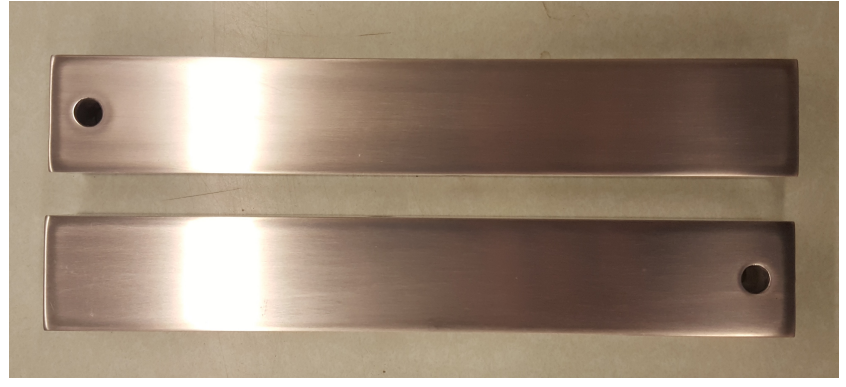

Figure 3.39: Bars after polish

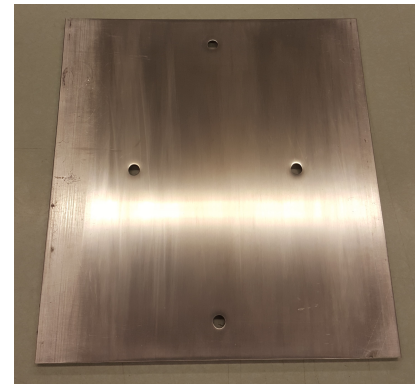

Figure 3.40: Plate after polish

After all of the surfaces had been polished to satisfaction, the mold was ready to receive its first layup. For a principle test the chopped fiber composite was utilized to test the success of the new concept. To guarantee that the brick could be freed from the mold a wax release agent was applied liberally to all surfaces of the mold. This would ensure not only that the part could be removed easily, but the components of the mold could be disassembled without damage for cleaning. A layup of 34 ply of chopped fiber material was prepared. Once the sections had been assembled and the composite layup placed inside the cavity of mold, considerable pressure had to be applied to get any engagement from the 2 inch through bolts. The extensive pressure required was due to the height of the layup as a result of wanting to maximize the amount of material being forced into the final cured part. When ample thread engagement was available the hex nuts were applied and tightened using a socket wrench. Each nut was incrementally tightened to ensure the push plate forced material down evenly and did not cause slipping between the layers. The nuts were tightened until the top plate lay flush with the side bars. The assembled mold ready for a cure cycle is exhibited in Figure 3.41. As pressure was applied via the mold itself the Mechanical Engineering oven was utilize. As the bottom plate was not properly cut to size, the mold could not be used in any of the available composite presses on campus. However, using the oven had the added benefit of a more even heating 
environment over an open heat press system.

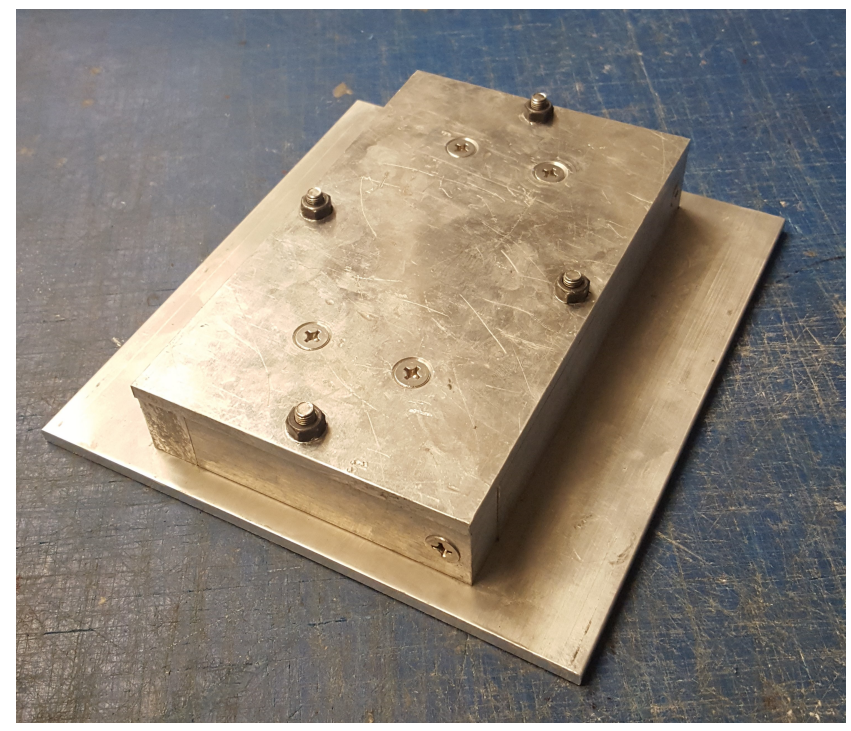

Figure 3.41: Mold ready for cure

The bleed of material from the mold seen in Figure 3.42 shows a significant reduction prior perimeter molding attempts. Although there is some loss, the overall containment of the volume of material compressed into the mold when compared to the previously uncontrolled results previously is promising. The brick after removal from the mold is exhibited in Figure 3.43. In a mass production environment having a clean product straight from the mold would be ideal for time and cost of a process, but in the context of this prototype cleanup of excess material is a trivial task. First the excess cured fibers outside the bricks extents were removed using a tile saw and a guide to ensure cuts were kept square. This was followed by sanding with 120 grit sandpaper to remove any protrusions which might interfere with machine tools or cause chipping of the primary brick. The first cleaned sample can be found in Figure 3.44 . 


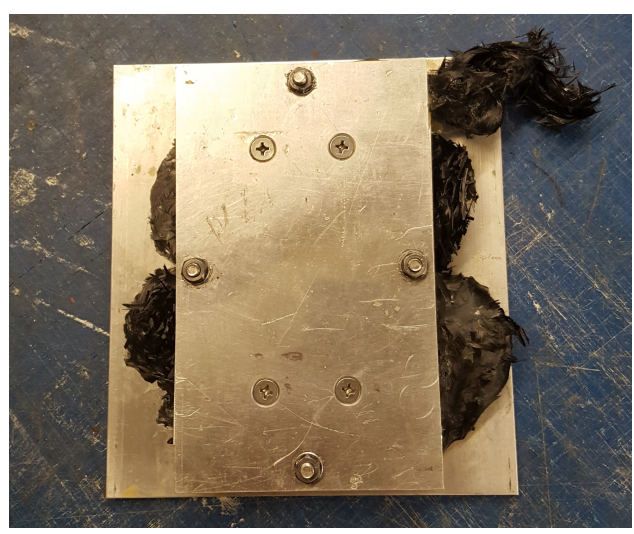

Figure 3.42: Mold top view after cure

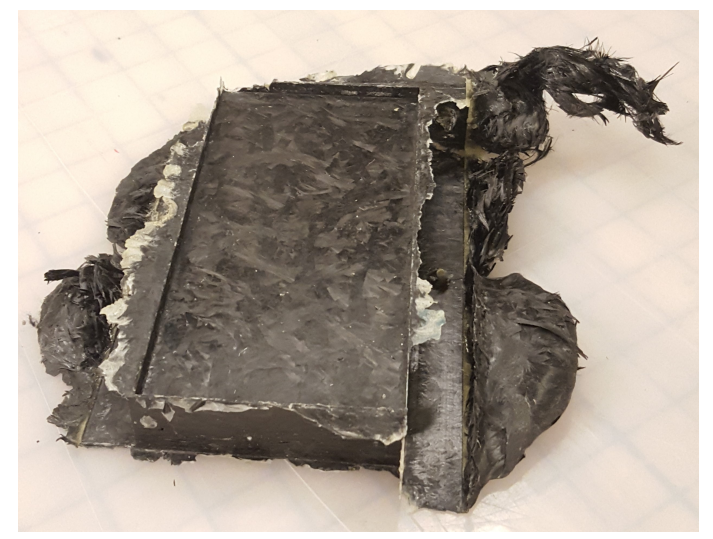

Figure 3.43: Uncleaned chopped fiber brick

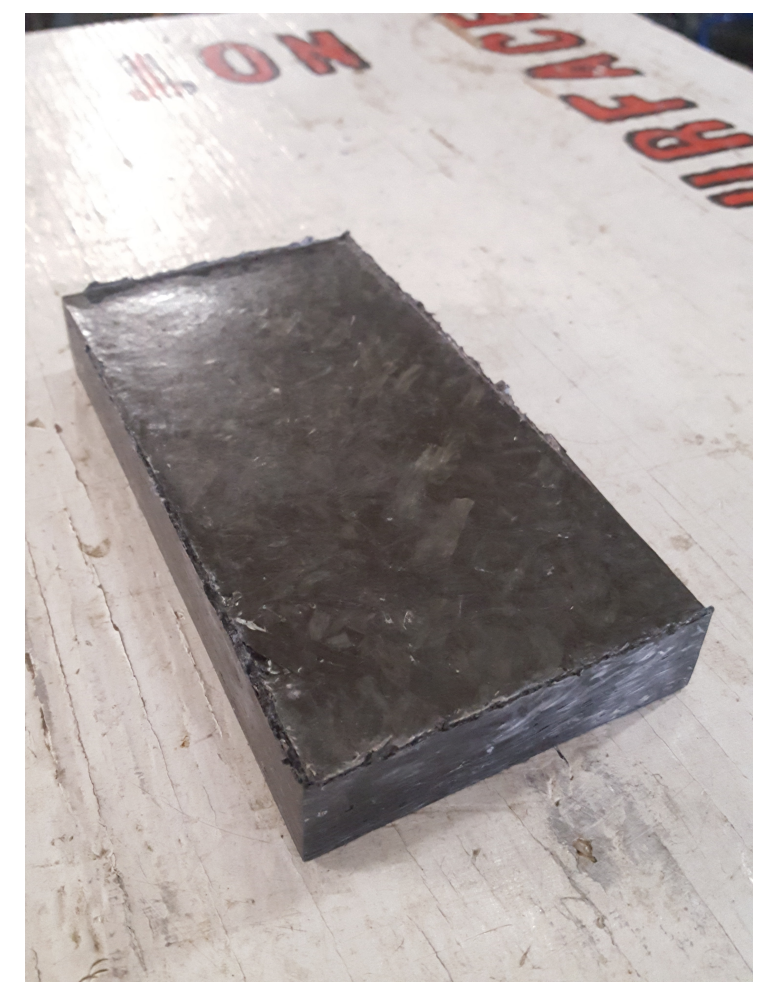

Figure 3.44: Chopped fiber block after cleaning

After removal of the specimen from the mold it was found a significant amount of epoxy had bled into threaded areas making mold deconstruction difficult. Although the bolts and segments were eventually separated, putting a fresh bolt into a threaded hole still proved challenging, suggesting that there was resin buildup in the threaded holes. In order to clean the entire mold and restore it back to its original functionality 
the threaded hole ends of side bars and surfaces of face plates were soaked in paint stripper for twelve hours. After letting soak overnight the epoxy easily dripped from the threads, and the flat plate surfaces cleaned with ease using a plastic scraper. This process was conducted inside a fume hood.

After the success of the chopped fiber brick cure it was asserted that two more bricks would be constructed out of the triaxially woven material. One brick would feature a layup of plies all with the $0^{\circ}$ fiber (or 1 direction as denoted in Figure 3.14) oriented in the lengthwise direction of the brick, and a second featuring all plies with the fiber 2 direction in the lengthwise axis of the brick. Each layup consisted of 23 ply, a significant overshoot of the required 14 ply for the desired cure thickness. This was done in an attempt to maximize the amount of woven material constituting the final brick. The layup and prepared mold for the 2 direction brick is featured in Figure 3.45 .

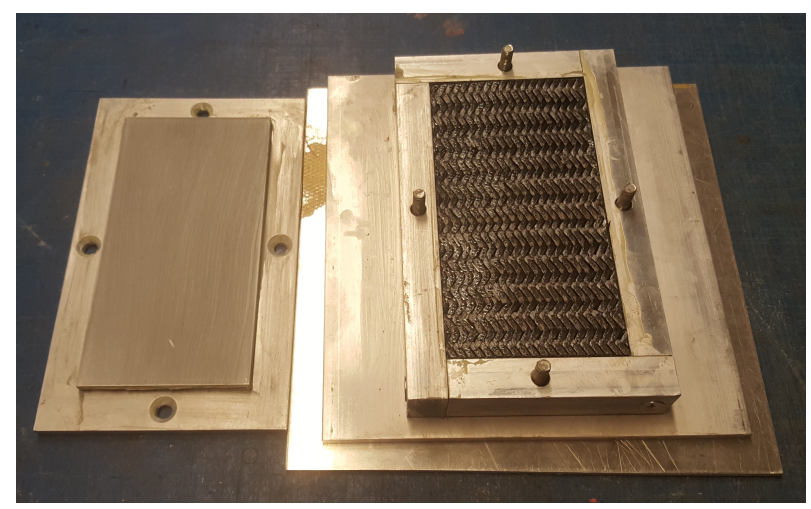

Figure 3.45: Triaxial weave 2 direction brick prepared for curing

The woven material exhibited far less bleed out of material than the chopped fiber brick as was expected based on prior experiences. Tile saw edge cleaning was not necessary as was with the chopped fiber brick, but sanding with a high grit sand paper was still required to clean small excess bleed on edges seen in Figure 3.46. 


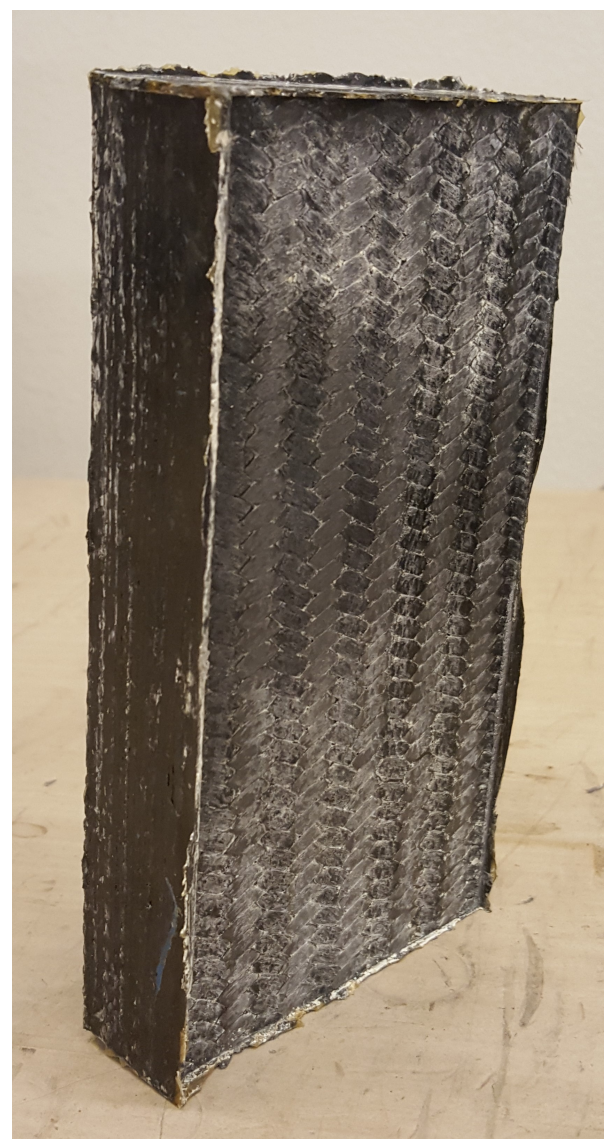

Figure 3.46: Triaxial weave 1 direction brick prior to edge sanding

After cleaning all bricks from excess edge material, accurate measurements could be made using digital calipers to asses the preciseness of each dimension compared to the desired geometry. Four measurements were taken for each dimension and averaged. Some of these measurements showed significant deviation from each other, but still exhibited a range which would allow for a brick to be machined into a consistent geometry as the average tends to overshoot the desired. The expected measurements and average dimensions of the individual bricks are tabulated in Table 3.2, while the full array of measurements can be found in Appendix B. 
Table 3.2: Average measurements of first three brick attempts Averaged Dimensions

\begin{tabular}{cc|c|c}
\cline { 2 - 4 } & Length [in.] & Width [in.] & Thickness [in.] \\
\hline Expected & 0.635 & 3.3 & 0.86 \\
\hline First Woven 1 Dir. & 6.4033 & 3.62 & 0.866 \\
\hline First Woven 2 Dir. & 6.3698 & 3.353 & 0.8643 \\
\hline Chopped Fiber & 6.38 & 3.38 & 0.871
\end{tabular}

\subsection{Material Mechanical Characteristics}

Material testing of the elected composites sought to characterize the tensile and compressive elastic moduli as well as the ultimate strengths in both load directions. This was accomplished by applying the suggested procedures from ASTM-D3039 (ASTM, 2016a) and ASTM-D3410 (ASTM, 2016b) corresponding to tensile and compressive testing of polymer matrix composite materials. By gathering the stress-strain relationship of each material the modulus can be calculated from the slope of the linear elastic region of the curve. Loading to failure provides the ultimate strength of the material. These two concepts are exemplified in Figure 3.47.

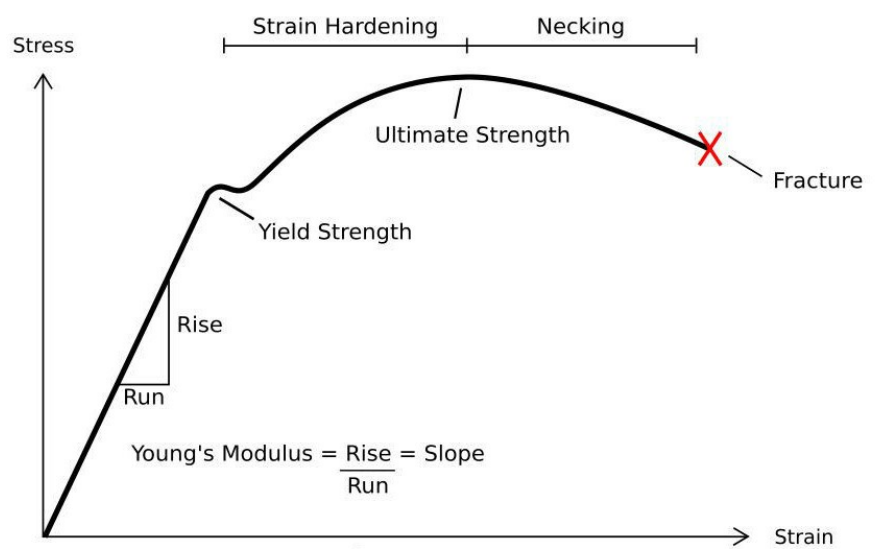

Figure 3.47: Example of a stress strain relationship (Instructables, 2017) 


\subsubsection{Sample Manufacture and Preparation}

Test specimen for strength and modulus testing were manufactured from flat plates of each material. Based on the constraints imposed by the ASTM recommended dimensions, target lengths, widths, and thicknesses were asserted. These values are presented in Table 3.3. Special care was taken to adhere to the geometry requirements provided by the standards, while asserting dimensions which could be achieved based on the prior knowledge of working with the materials.

Table 3.3: Asserted dimensions for test specimen

\begin{tabular}{c|c|c|c} 
Test Specimen & Length [in.] & Width [in.] & Thickness [in.] \\
\hline Tension & 10 & 1 & 0.1 \\
\hline Compression & 5 & 1 & 0.1
\end{tabular}

Flat plates were cured using the Aerospace Engineering hot press, and plates were sized to maximize the available cure area and allow for maximum number of specimen to be cut. Figure 3.48 shows initial flat plate attempts for the chopped fiber material. These plates showed little uniformity and poor surface finish. For this reason the cure was repeated, this time using aluminum plates as a stop around the perimeter of the layup to get a final plate thickness of approximately 0.1 " from 4 ply of material. Only one plate of permissible quality was produced and is displayed in Figure 3.49. The difficulties associated with producing good quality chopped fiber flat plates resulted in a lower sample size for the material. 


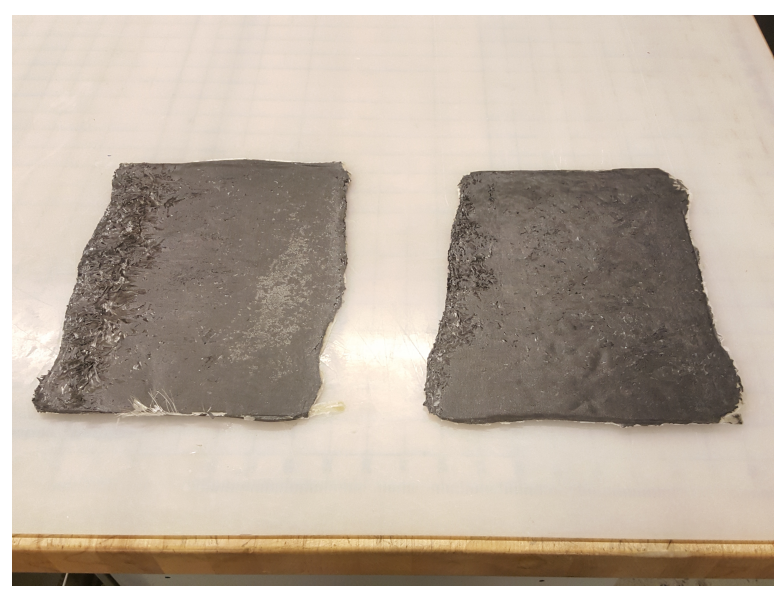

Figure 3.48: Unusable chopped fiber flat plates

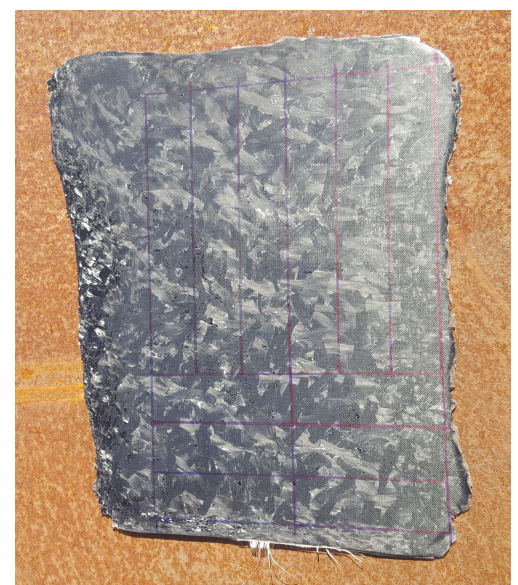

Figure 3.49: Usable chopped fiber flat plate

Four flat plates of the triaxially woven composite were constructed. Two plates featured the 1 direction of the weave in the plates dominant dimension, while the other two plates oriented the 2 direction in the dominant dimension. A total of 4 ply were used in each plate to achieve the desired cure thickness. Examples of these layup orientations are provided in Figure 3.50.

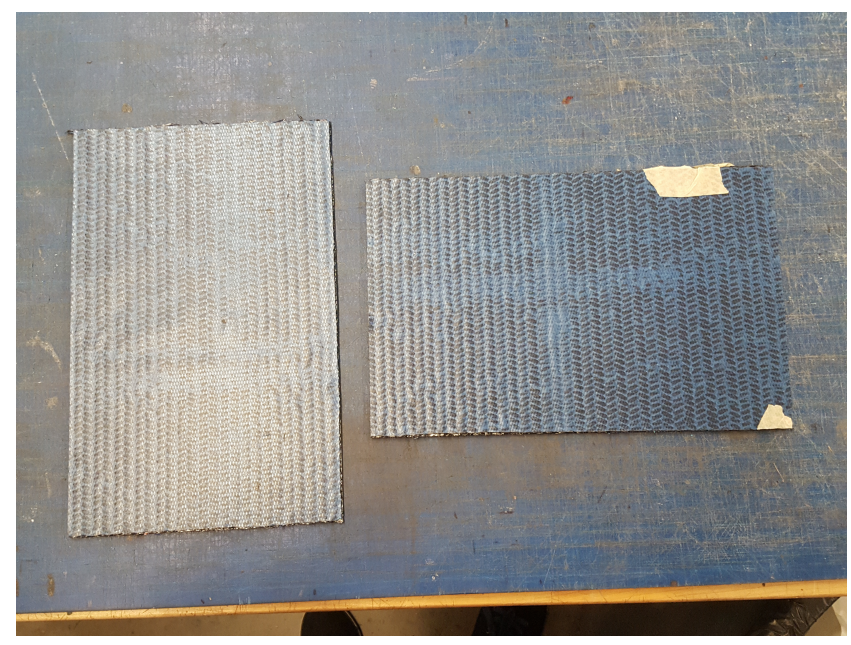

\section{Figure 3.50: HX42 specimen plate layups}

Specimen dimensions were drawn onto cured flat plates using a dark blue Sharpie ${ }^{\circledR}$. These lines accounted for the $1 / 8$ " saw blade thickness to ensure that cuts were as 
accurate as possible. Due to the limited plate area of the chopped fiber cure accommodations were made to fit six specimen of each test type onto the plate. This meant deviating from the originally asserted dimensions. Similarly with the woven material the excess of plate area provided slightly larger specimen than originally expected. The nominal dimensions of the specimen cut from the plates are specified in Table 3.4. Although the actual lengths of specimen varied between tests, tabs were installed to provide a more consistent gauge length and create similarity between tests. The raw dimensions of all specimen tested are available in Appendix C.

\begin{tabular}{c|c|c|c|c|c}
\multicolumn{2}{c}{ Table 3.4: Nominal dimensions for cut specimen } \\
\multicolumn{2}{c}{ Test Specimen } & $\begin{array}{c}\text { Length } \\
{[\text { in.] }}\end{array}$ & $\begin{array}{c}\text { Width } \\
{[\text { in.] }}\end{array}$ & $\begin{array}{c}\text { Thickness } \\
{[\text { in.] }}\end{array}$ & $\begin{array}{c}\text { Gauge Length } \\
{[\text { in.] }}\end{array}$ \\
\hline Woven 1 & Tension & 10.75 & 1 & 0.1 & 8.6 \\
\cline { 2 - 6 } Direction & Compression & 5 & 1 & 0.1 & 1 \\
\hline Woven 2 & Tension & 9.75 & 1 & 0.1 & 7.6 \\
\cline { 2 - 6 } Direction & Compression & 5 & 1 & 0.1 & 1 \\
\hline \multirow{2}{*}{ Chopped } & Tension & 10 & 1 & 0.1 & 8 \\
\cline { 2 - 6 } Fiber & Compression & 3 & 1 & 0.1 & 1
\end{tabular}

Unfortunately, the chopped fiber plate only yielded a total of two tensile specimen and three compressive specimen which fulfilled the relative tolerance requirements between each sample. A total of fourteen tensile specimen and twelve compressive specimen were cut for the woven material samples.

Several types of tabs were tried across many scrap samples generated, but ultimately the elected type were epoxy-fiberglass adhered with 3M Scotch-Weld ${ }^{\mathrm{TM}}$ Structural Adhesive Film AF 163-2 (3M, 2009). The fiberglass tabs provided an excellent surface for test apparatus grips, while the film adhesive provided ample shear strength for tests and was easy to apply to specimen, although some slipping did occur during 
curing which caused a small variance in gauge lengths between specimen. Contact surfaces for the film adhesive were roughed using 120 grit sandpaper and cleaned with acetone. The film was then applied and all specimen along with their tabs placed on an aluminum sheet. Tab curing was conducted using the Mechanical Engineering hot press, pictured in Figure 3.51, at $225^{\circ} \mathrm{F}$ and max press pressure (approximately 3000 lbf) for 90 minutes. An example of a tab cured with the film adhesive is available in Figure 3.52. Some light sanding was necessary to remove excess adhesive and ensure the tab faces were unobstructed from the test fixture grips.

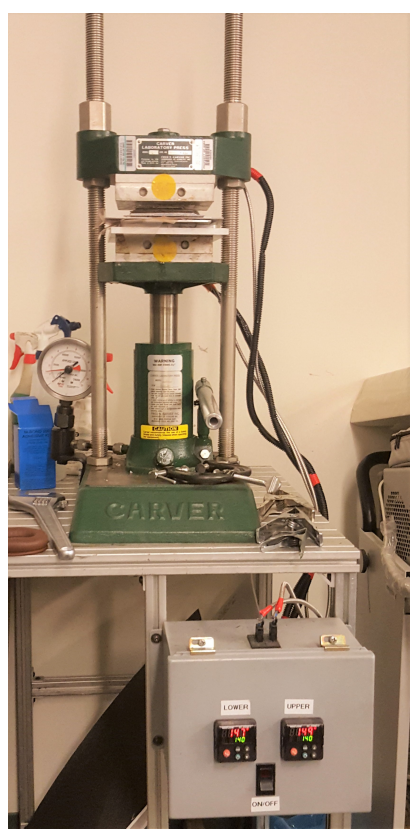

Figure 3.51: Mechanical Engineering hot press

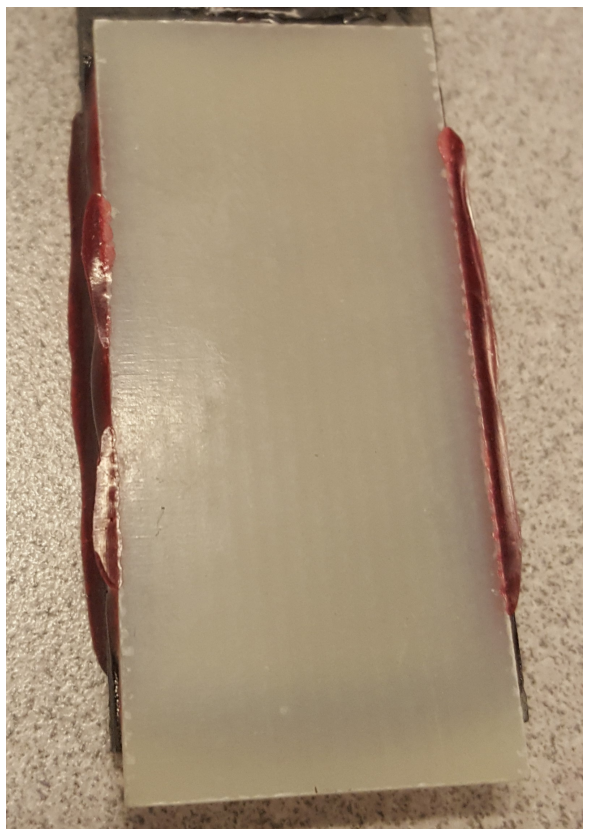

Figure 3.52: Glass tab cured with structural film adhesive

After tabs were installed on all test specimen strain gauges were applied in the axial loading direction. These would allow for data to be recorded during tensile and compressive testing and used in calculation of the material properties of interest. Strain gauges used were Micro-Measurements CEA-06-240UZ-120 with a grid resistance of $120.0 \pm 0.3 \%$ Ohms and a nominal gage factor of 2.14. An example of one of these strain gauges is seen in Figure 3.53. 


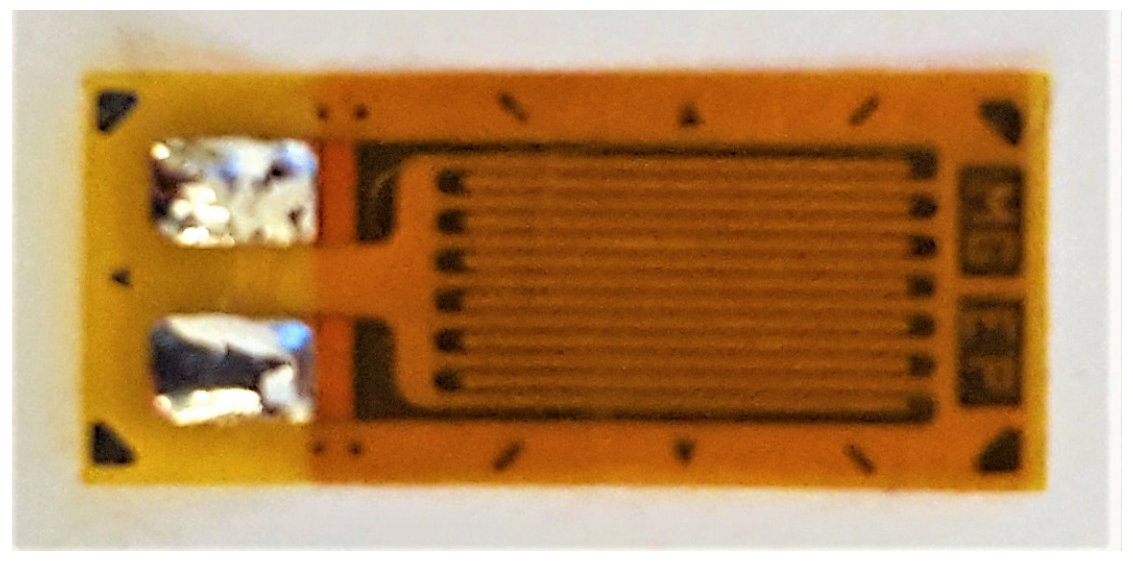

Figure 3.53: Micro-Measurements strain gauge

The procedure followed for strain gauge application was provided with the MBond 200 Adhesive Kit (Vishay, n.d.) used and was executed as follows:

1. First the sample was thoroughly degreased in the gauge area with CSM-2 degreaser.

2. Degreasing was followed by dry abrading with 220 and 320 grit sandpaper. Final abrading was done with 320 grit sandpaper and M-Prep Conditioner A. The surface was then dried thoroughly.

3. Next a score mark was made within the gauge area for alignment during installation. The surface was cleaned with Conditioner A repeatedly until all residue was removed.

4. Next a liberal amount of M-Prep Neutralizer 5A (seen in Figure 3.54) was applied to the same section and carefully dried using some gauze. 


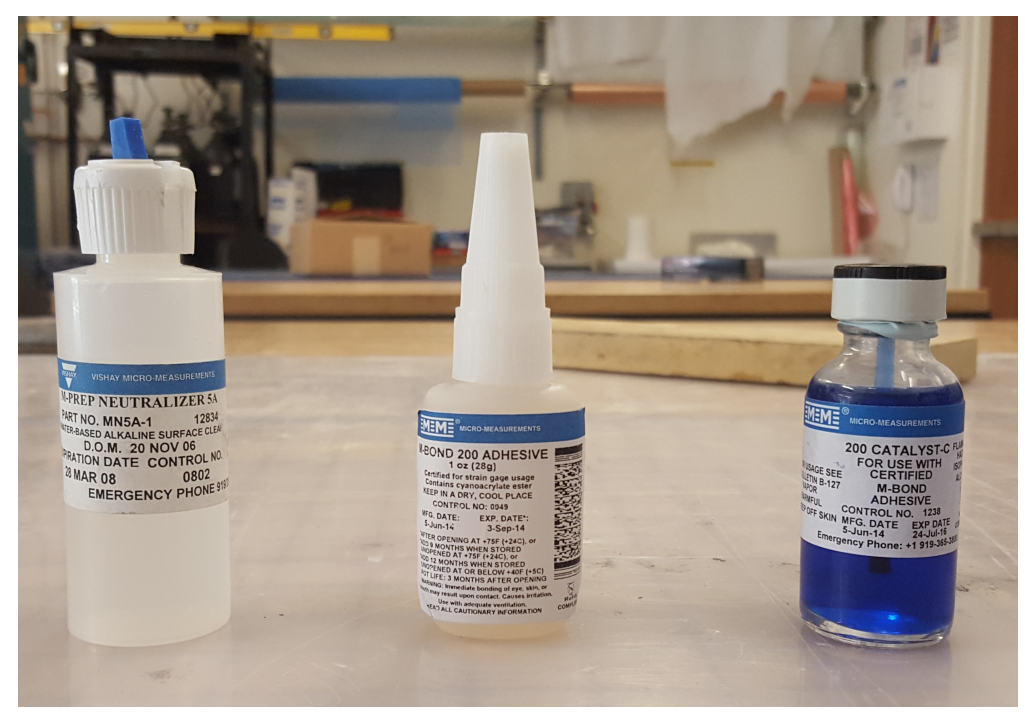

Figure 3.54: M-Bond kit adhesive materials

5. A strain gauge was removed from the original packaging, and the plastic slide containing it was torn to expose the upper surface of the instrument. A 3 inch strip of PCT-2M Installation Tape was then used to remove the gauge from its plastic slide, ensuring that it was centered on the tape and the pulling angle for removal was shallow as demonstrated in Figure 3.55.

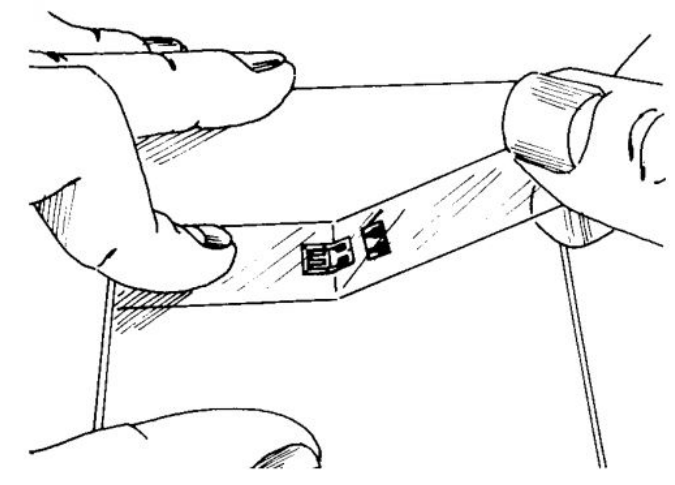

Figure 3.55: Removal of gauge from slide (Vishay, n.d.)

6. After lifting the gauge from the plastic slide the gauge was placed and aligned according to the score made on the test specimen. 
7. Once properly aligned, the tape was left adhered at one end, lifted at a shallow angle, and folded back so that its adhesive face was exposed and the gauge lay flat on the surface of the specimen. A terminal was then dropped onto the tape face down.

8. M-Bond 200 catalyst, pictured in Figure 3.54, was then applied to both the terminal and gauge surfaces facing up. Very little catalyst was applied as a thin coat is all that is necessary.

Note: The next steps were completed in under 5 seconds to ensure proper bonding.

9. The end of the tape folded over was removed from the specimen. While holding the tape at a steep angle 1 or two drops of M-Bond 200 adhesive, pictured in Figure 3.54, were applied at the base of the tape meeting the specimen.

10. The tape was then brought to approximately a 30 degree angle with the specimen to ensure alignment with the original score mark.

11. While holding the the tape taught, a slow and firm stroke was used to place the strain gauge on the surface at the desired position. This stroking motion forces the adhesive at the base of the tape to distribute evenly as pressure is applied.

12. After asserting alignment firm thumb pressure was applied for one minute.

13. The gauge was then left to rest for 5 minutes to ensure complete curing of the M-Bond adhesive. After 5 minutes the tape was removed.

Once gauges were placed on specimen, a thin strip of tape was placed between the bonding terminal and strain gauge. This was done to isolate leads from the surface of the carbon as the material is conductive and would short the circuit collecting data. An example of the tape's placement is visible in Figure 3.56. Leads were then soldered 
to all the bonding terminals. The leads were stripped and a single uninsulated wire was used between each bonding terminal and strain gauge terminal. A completed specimen with both axial and transverse gauges installed is exhibited in Figure 3.57, while the full array of instrumented triaxially woven specimen is shown in Figure 3.58 .

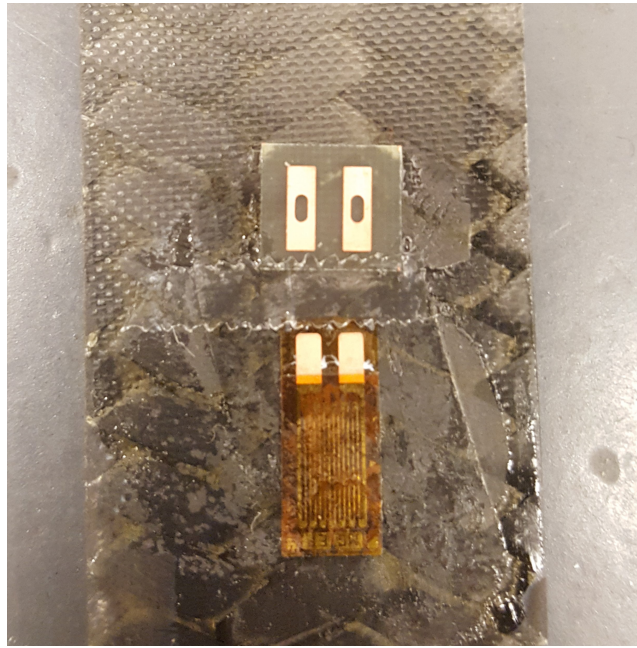

Figure 3.56: Isolation tape between bonding terminal and gauge

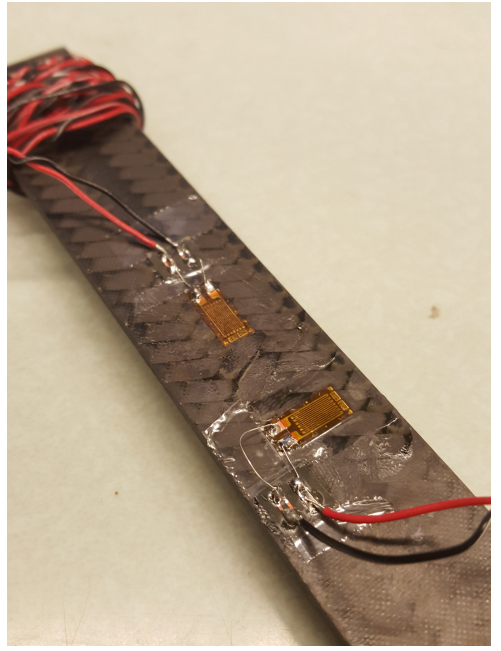

Figure 3.57: Example of completed gauge installation

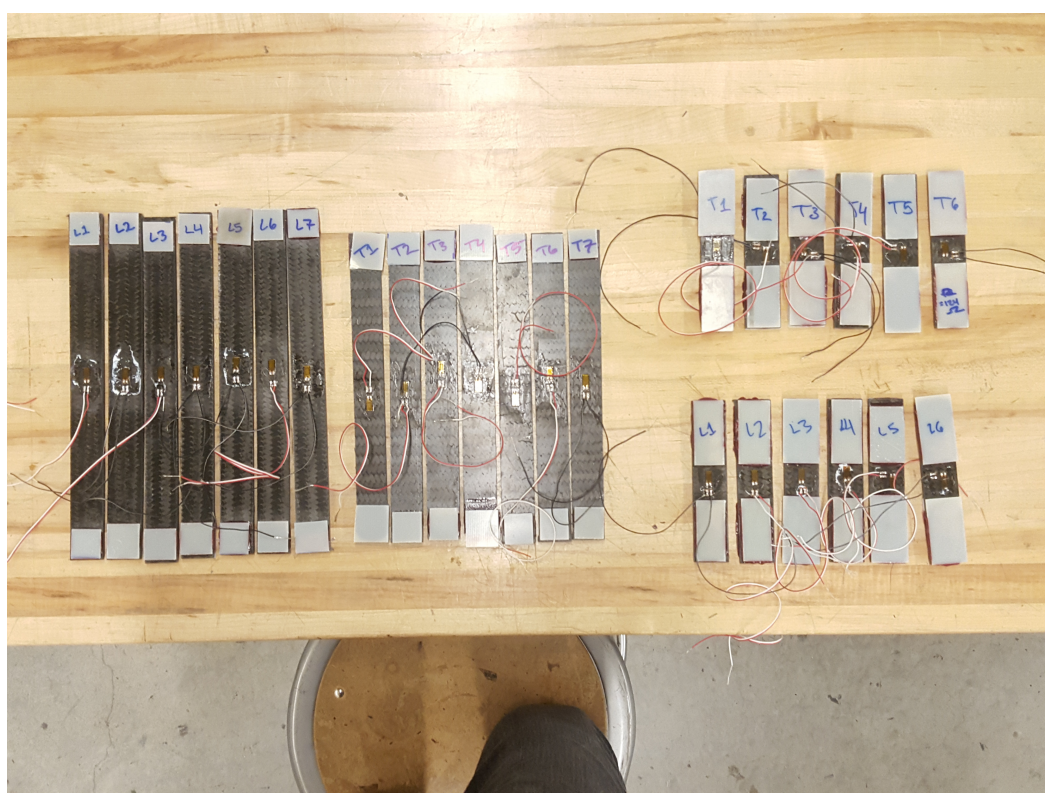

Figure 3.58: Fully prepared woven material specimen 


\subsubsection{LD-50 Tensile Tester}

Testing was initiated on the newly acquired Ametek ${ }^{\circledR}$ LD-50 bench mounted testing apparatus, shown in Figure 3.59, located in the Cal Poly Mechanical Engineering Composite Lab. This testing machine was selected for the elegant user interface provided through manufacturer software.

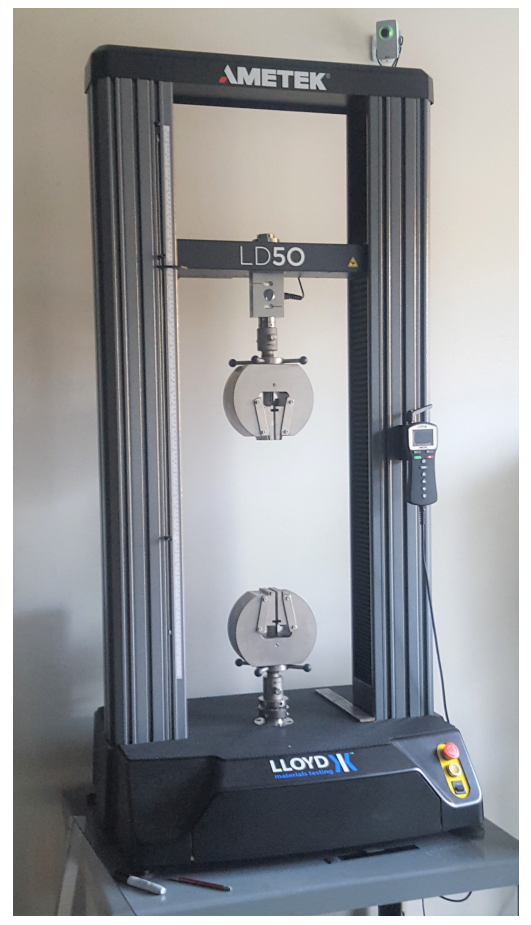

\section{Figure 3.59: Ametek $^{\circledR}$ LD-50}

Although the user experience was favorable over other available machinery, some flaws arose mechanically which complicated the procedure. One fundamental flaw in the system was that the vice grips had to be hand tightened. This required a tremendous amount of effort which pushed the limits of safety to get a proper hold on the test specimen. Even with a high level of exertion the grips would loosen across the time span of a test. This resulted in a non-linear stress-strain trend, and made failure of the specimen near impossible. Additionally, the provided grips were limiting in the types of tests that could be run. Compression testing was not feasible with the 
current configuration as the wedges composing the grips were designed only to resist pulling motion. The geometry of the wedges is exhibited in Figure 3.60.

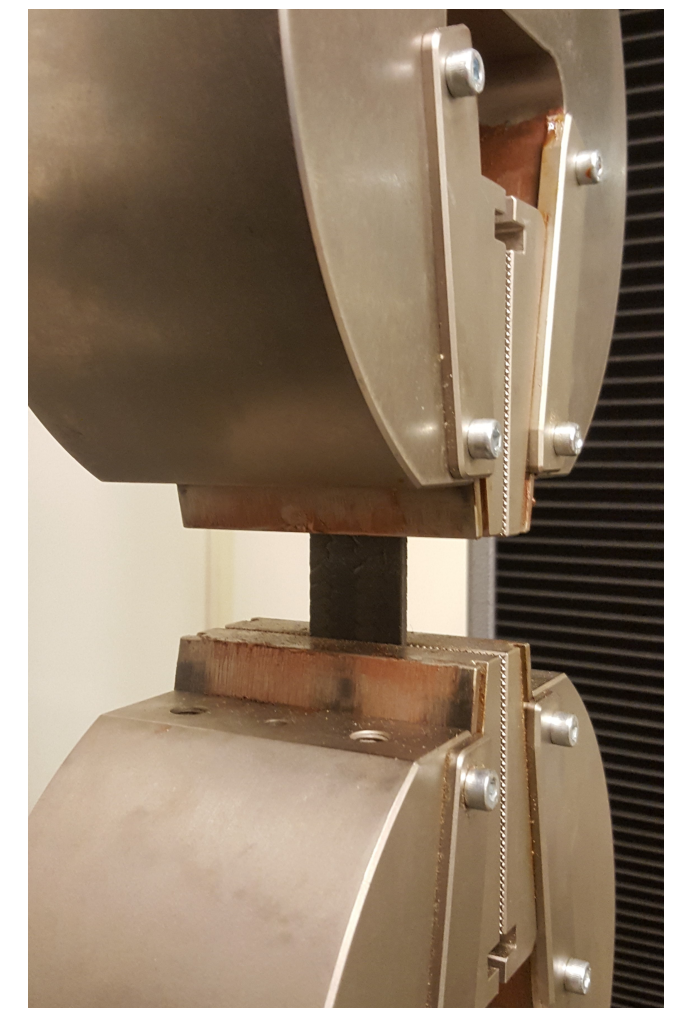

Figure 3.60: Vice grips on LD-50 machine

Alternative compression test fixtures were explored, but the LD-50 machine could not accommodate any that were procured. For this reason compression testing could not be conducted, and it was elected to switch machines so that all data collection came from a uniform testing environment.

\subsubsection{Instron 1331 Hydraulic Tester}

The Instron 1331 Hydraulic testing machine is located in the Cal Poly Mechanical Engineering Composite Lab and is pictured in Figure 3.61. The system features a control panel where a calibration sequences can be initiated, as well as a readout of cross-head position and force measured by the load cell. The control panel sources a 
DAQ which can be accessed through LabVIEW on an accompanying computer. The LabVIEW interface was configured to store data collected in .txt files during testing.

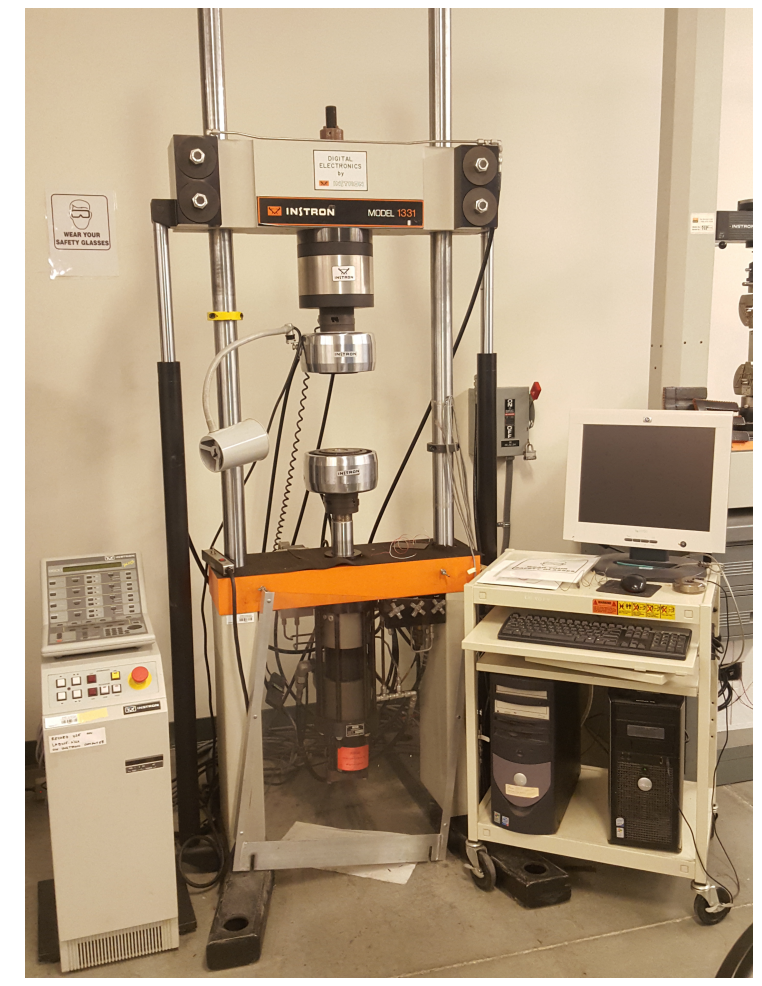

Figure 3.61: Instron 1331 Hydraulic test system

The first tests run on the system consisted of a batch of test specimen which had not been instrumented with strain gauges. This became a key indicator of a fundamental problem existing in the system's DAQ. A full batch of triaxially woven samples as well as the three available chopped fiber compression samples were tested to failure before the noticing the subtle problem. Rather than using strain guages on this prior batch of test specimen, the guage length and cross-head displacement were used to calculate strain. However, when the calculated elastic modulus from the Instron was compared with prelimary tensile tests conducted on the LD-50 the results did not agree. This pointed to either machine having a flaw in the way data was being recorded. To troubleshoot the Instron's data two approaches could be taken: examine the accuracy of the load cell or verify that the cross-head position was accurate. As 
diagnosing issues with the load cell required expertise from the machine manufacturer the path forward required examining the measurements used to calculate strain.

To test the accuracy of strain measurements three data collection methods were applied: a strain gauge, an extensometer, and crosshead position measurements. While the first method directly reported strain values, the extensometer and crosshead position simply provide a change in length for calculating strain. Using a gauge length established by the initial distance between the vice grips the change in length could be calculated from the crosshead position data and then applied to find strain. Similarly, the change in length provided by the extensometer could be used to calculate strain using Equation 3.1 taken along with all other equations presented from Analysis and Performance of Fiber Composites (Agarwal et al., 2018).

$$
\epsilon=\frac{\Delta L}{L}
$$

Where the variable $L$ represents the gauge length, and $\Delta L$ the extension of the sample. $\epsilon$ is the resultant strain. The stress for all testing methods is calculated using Equation 3.2.

$$
\sigma=\frac{F}{A}
$$

Where $F$ is the force recorded from the load cell and $A$ is the cross sectional area in the gauge length of the specimen being tested. $\sigma$ is the resultant stress.

A steel specimen with a known elastic modulus of 29 Msi was used as a control variable. The specimen loaded into the vice grips of the Instron can be seen in Figure 3.62 . 


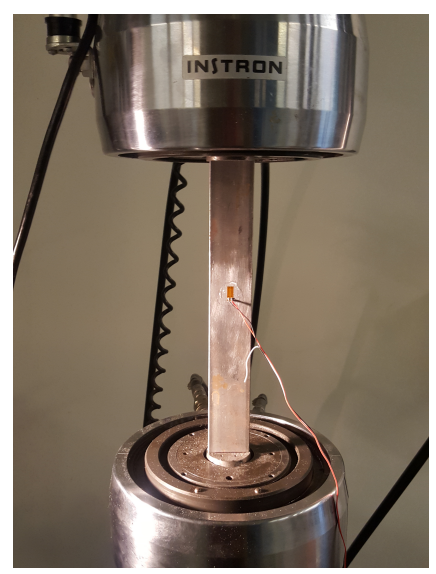

Figure 3.62: Steel sample used for system verification

The data collected via the three methods applied is shown graphically in Figure 3.63. Running this experiment proved that neither of the collection methods unique to the DAQ system were properly calibrated. The errors associated with each method when compared to the assumed modulus of steel are tabulated in Table 3.5.

Instron Steel Elastic Modulus

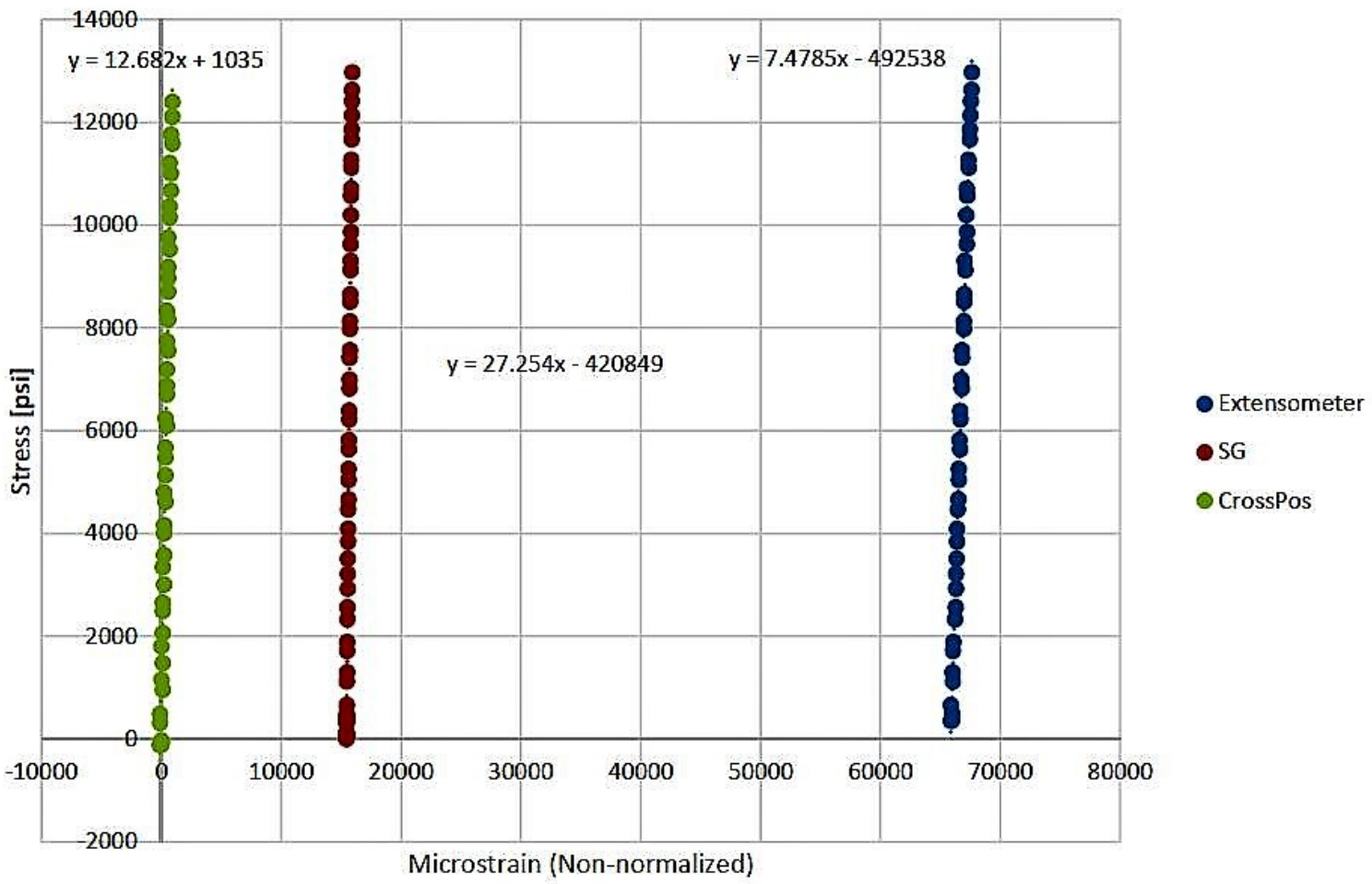

Figure 3.63: Graphical comparison of data collection methods 


\begin{tabular}{c|c|c|c} 
& \multicolumn{3}{|c}{ Table 3.5: Strain measurement errors } \\
& Strain Gauge & Extensometer & Crosshead Position \\
\hline$\%$ Error & 6.02 & 74.21 & 56.27
\end{tabular}

As the strain gauge provided results within a reasonable margin of error, it was confirmed that the load cell was not the problem. The gauge was the only measurement method which provided tolerable data, therefore all failed woven specimen had to be re-manufactured and instrumented with strain gauges. Based on the difficulties associated with manufacturing good tolerance chopped fiber samples, the data from the failed chopped fiber compression specimen was accepted as ultimate strengths gathered from testing were still valid and could provide a relative comparison against the woven sample compressive failure strength. It was decided that should the chopped fiber outperform the woven samples it would be necessary to reopen investigation of that sample type.

\subsubsection{Elastic Moduli and Ultimate Strengths}

The elastic or Young's modulus $(E)$ of each material was calculated from testing data using Equation 3.3. Ultimate strengths were found from the max stress value achieved by each sample. Testing was run at a rate of $0.0005 \mathrm{in} / \mathrm{min}$. It was assumed that the specimen acted with only plane strain.

$$
E=\frac{\Delta \sigma}{\Delta \epsilon}
$$

The tension and compression test results for the chopped fiber samples are displayed in Figures 3.64 and 3.65. 

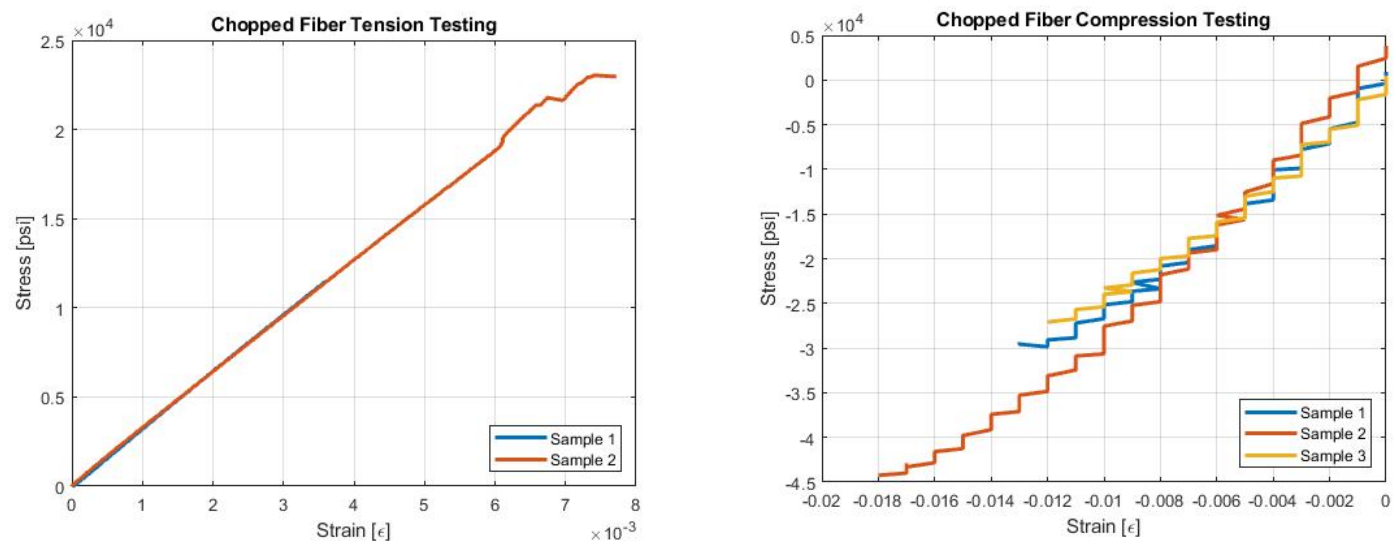

\section{Figure 3.64: Chopped fiber tension Figure 3.65: Chopped fiber com- data pression data}

The tension results for both orientations of the triaxially woven composite are shown in Figures 3.66 and 3.67 .

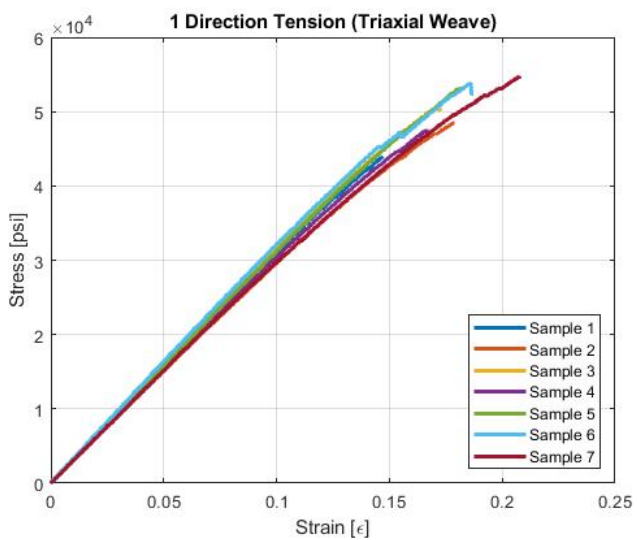

Figure 3.66: 1 direction tension re- Figure 3.67: 2 direction tension results

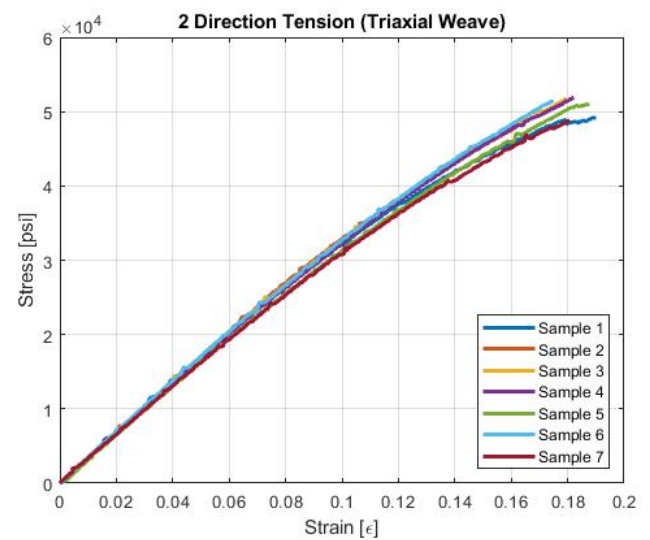
sults

The compression results for both orientations of the triaxially woven composite are shown in Figures 3.68 and 3.69. The elastic moduli and ultimate strengths for all samples tested are summarized in Table 3.6. 


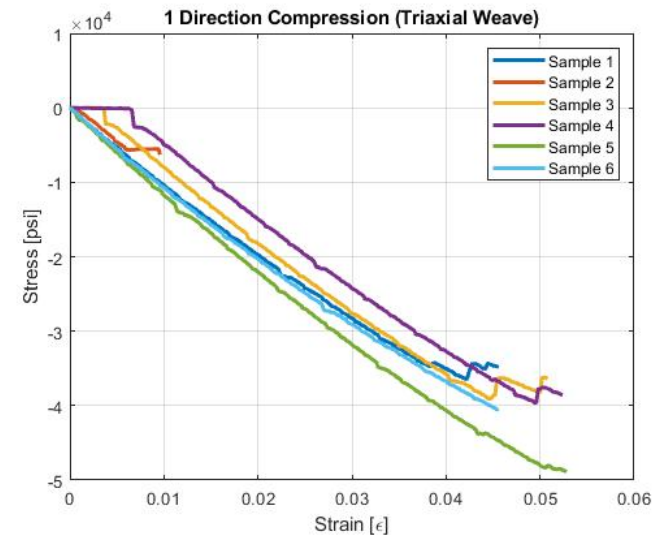

Figure 3.68: 1 direction compres- Figure 3.69: 2 direction compression results

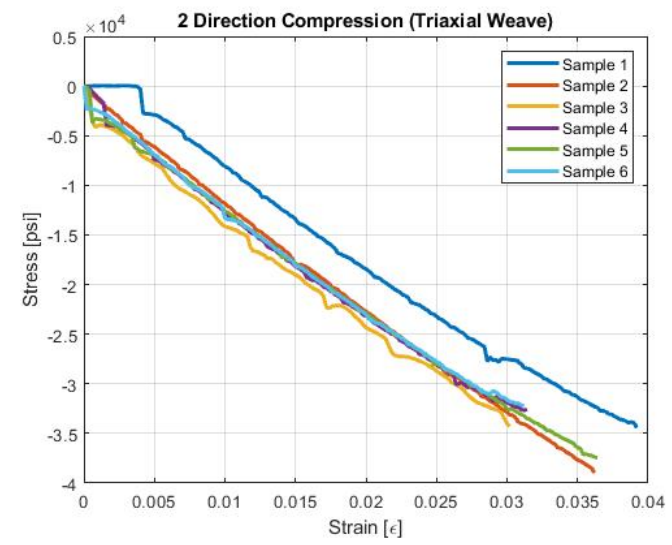
sion results

Table 3.6: Elastic modulus and ultimate strength averages

\begin{tabular}{c|c|c|c|c|c|c} 
& \multicolumn{2}{|c|}{ Tension } & \multicolumn{2}{c|}{ Compression } & Tension & Compression \\
\cline { 2 - 7 } & $\begin{array}{c}\text { Woven 1 } \\
\text { Direction }\end{array}$ & $\begin{array}{r}\text { Woven 2 } \\
\text { Direction }\end{array}$ & $\begin{array}{c}\text { Woven 1 } \\
\text { Direction }\end{array}$ & $\begin{array}{c}\text { Woven 2 } \\
\text { Direction }\end{array}$ & \multicolumn{2}{|c}{$\begin{array}{c}\text { Chopped } \\
\text { Fiber }\end{array}$} \\
\hline $\begin{array}{c}\text { Avg. E } \\
\text { [Msi] }\end{array}$ & 0.29 & 0.29 & 0.84 & 1.02 & 3.18 & 2.58 \\
\hline $\begin{array}{c}\text { Std. Dev. } \\
\text { [Msi] }\end{array}$ & 0.01 & 0.01 & 0.09 & 0.04 & - & 0.25 \\
\hline $\begin{array}{c}\text { Avg. Ult. } \\
\text { [ksi] }\end{array}$ & 50.35 & 50.32 & 40.94 & 35.00 & 23.04 & 33.73 \\
\hline $\begin{array}{c}\text { Std. Dev. } \\
\text { [ksi] }\end{array}$ & 3.91 & 1.64 & 4.72 & 2.69 & - & 9.21
\end{tabular}

Table 3.6 presents the average results of tests conducted on the composite specimen. It should be noted that Sample 2 of the 1 direction woven material compression testing was omitted as an outlier from the ultimate strength average due to premature failure. Additionally, the elastic modulus obtained from chopped fiber compression testing should be considered void as these results use strain calculated from the In- 
stron crosshead position rather than a strain gauge. Errors considered in the process of recording and calculating this data included instrument errors of the load cell and strain gauges, as well as alignment errors in the strain gauge, specimen placement in vice grips, and recorded specimen dimensions.

\subsubsection{Poisson's Ratio}

To further apply the data collected and create comparisons of the materials being tested poisson's ratio was evaluated. Poisson's ratio was calculated from Equation 3.4 .

$$
\nu_{12}=-\frac{\epsilon_{2}}{\epsilon_{1}}
$$

In this equation $\epsilon_{2}$ represents the strain measured by the transverse (perpendicular to the loading axis) strain gauge, while $\epsilon_{1}$ is strain measured in the axial direction. The resulting poisson's ratio is $\nu_{12}$. It should be noted that the chopped fiber data was achieved using the DAQ system equipped to the Instron, while the woven samples were measured discretely using the LD-50 and a strain gauge box with a quarter bridge configuration. This experimental setup for the wheatstone bridge is presented in Figure 3.70 .

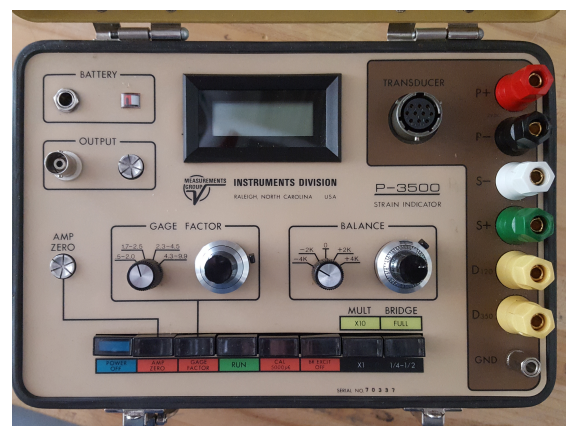

Figure 3.70: Experimental setup for discrete strain measurements using wheatstone bridge 
Figure 3.71 exhibits the data used for chopped fiber poisson's ratio. Note that only a single set of usable data for this calculation was available as the transverse data from sample 1 became corrupted after failure of the specimen. Figures 3.72 and 3.73 show the discrete measurements in each strain gauge direction for the two orientations of woven samples. The results for the poisson's ratio of each material are tabulated in Table 3.7.

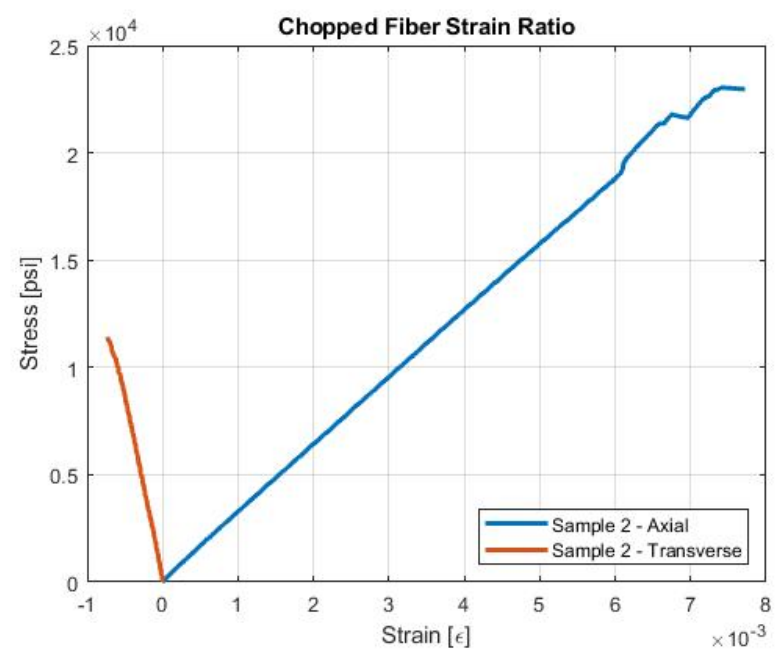

\section{Figure 3.71: Data used to calculate chopped fiber poisson's ratio}

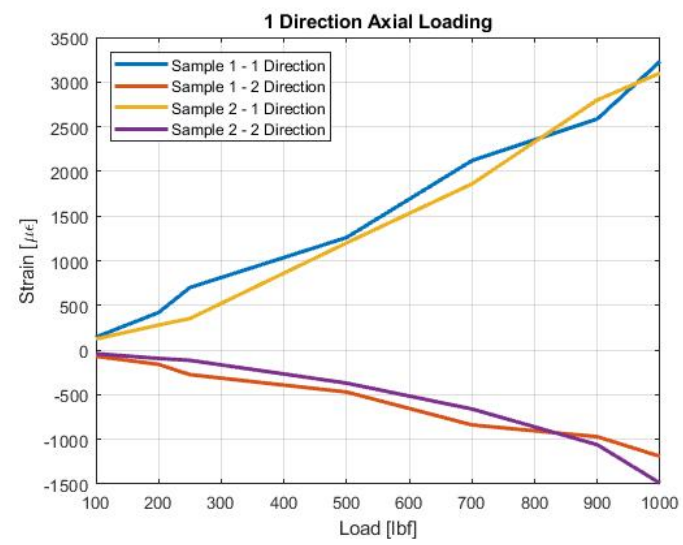

Figure 3.72: 1 direction compression results

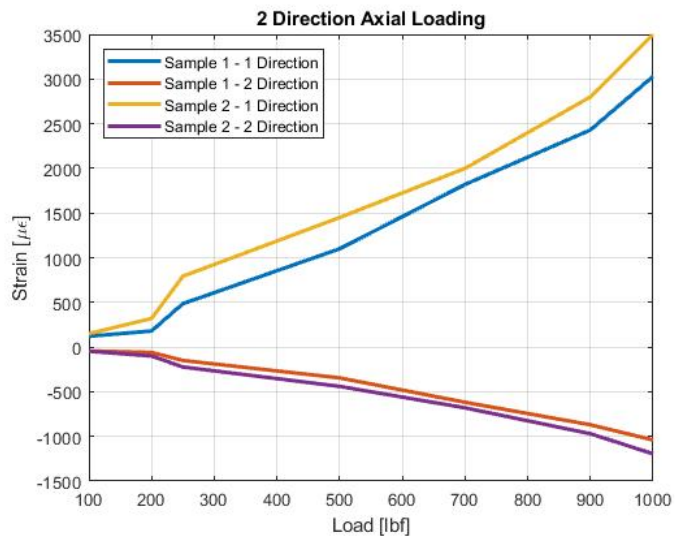

Figure 3.73: 2 direction compression results 


\section{Table 3.7: Experimentally obtained poisson's ratios

\begin{tabular}{c|c|c} 
& Chopped Fiber & Triaxial Weave \\
\hline$\nu_{12}$ & 0.156 & 0.342 \\
\hline$\nu_{21}$ & - & 0.330
\end{tabular}

As the chopped fiber material is assumed to act quasi-isotropically, it could be assumed that the $\nu_{21}$ would match that measured for $\nu_{12}$. However, due to a low sample size and the variability in samples this is a bold assertion to make without greater evidence. The triaxially woven material exhibited two poisson's ratios with a small relative error, confirming the quasi-isotropic nature of the material. The accuracy of the $\nu_{21}$ measured was tested using Equation 3.5.

$$
\frac{\nu_{21}}{E_{2}}=\frac{\nu_{12}}{E_{1}}
$$

The elastic modulus in the 1 and 2 directions were obtained from the previous experimental values provided in Table 3.6. This check showed that the measured $\nu_{21}$ showed a $9.77 \%$ difference relative to the theoretically expected value. This error is not unusual judging by the close proximity of data points and any variability in material behaviors induced from experiments or sample manufacturing.

\subsubsection{Failure Mode Analysis}

A variety of failure modes were observed between the different materials and orientations tested. Typical failure modes of composite specimen being tested in compression and tension include but are not limited to:

1. Fiber-matrix debonding

2. Filament pullout

3. Cracking 


\section{Delamination}

\section{Shear Failure}

Figure 3.74 exhibits the failed area of a chopped fiber tension sample 1 . The failure was so severe that when the specimen was removed from the test apparatus the failed section could not support the two segments and split completely. To characterize this as fiber pullout would be incorrect as the fibers are discontinuous and therefore would be expected to exhibit the jagged separation they do. The straightness of the break implies a brittle failure as would be expected since failure in tension would rely on the matrix strength.

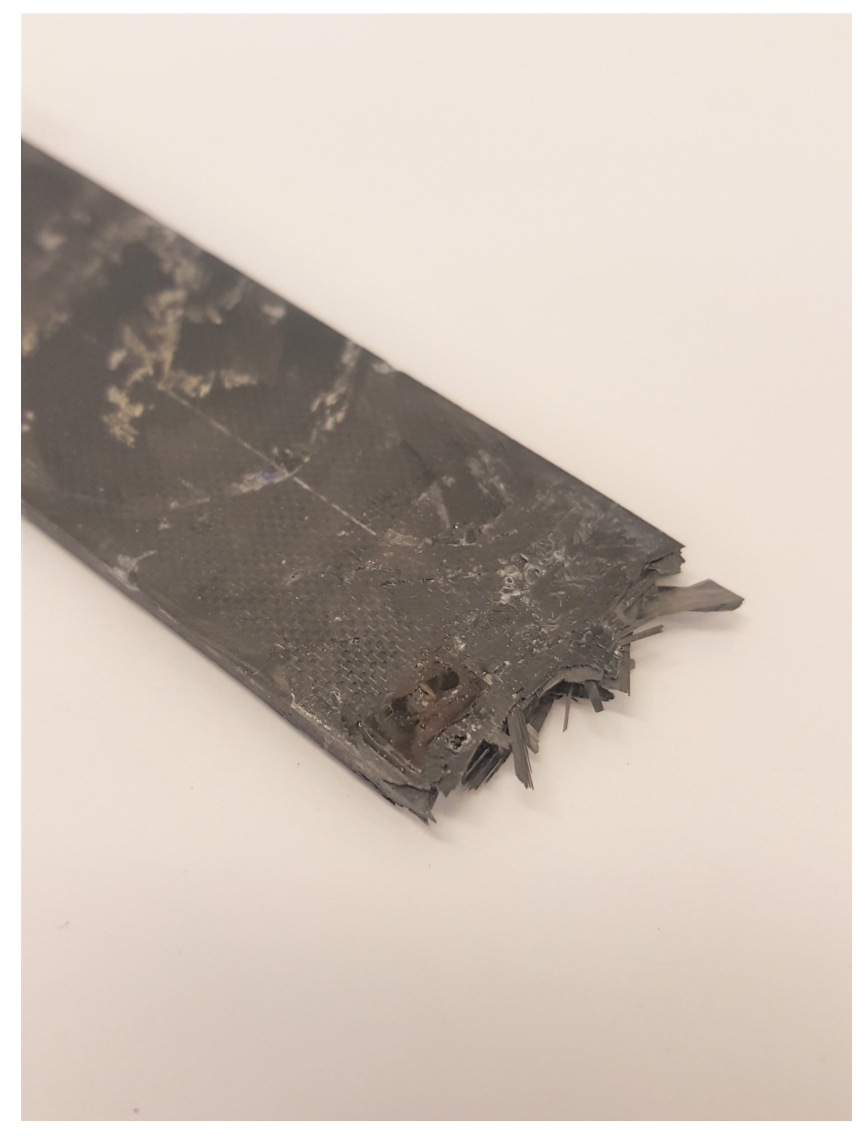

Figure 3.74: Chopped fiber tension failure

Figures 3.75 and 3.76 show the failure mode of the chopped fiber material in 
compression. The difference in failure propagation points to the variability from specimen to specimen. The cracking seen at different interfaces of the matrix to fiber interface shows that once again the material failed according to the matrix strength.

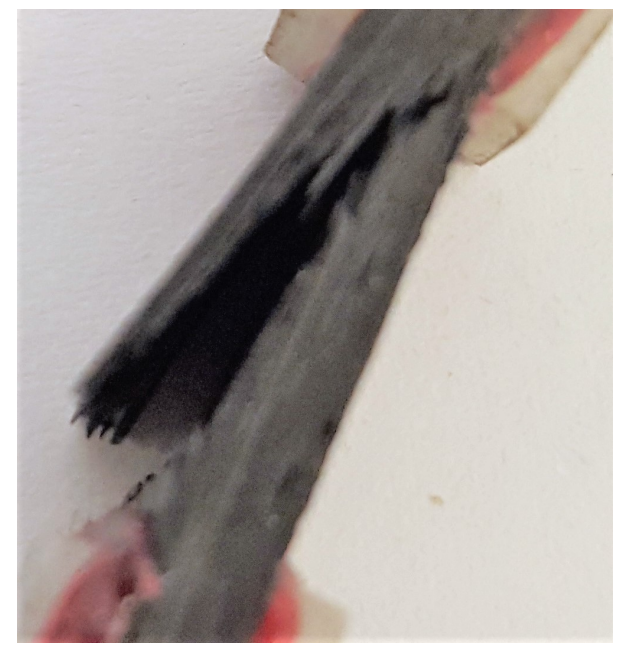

\section{Figure 3.75: Chopped fiber compression failure}
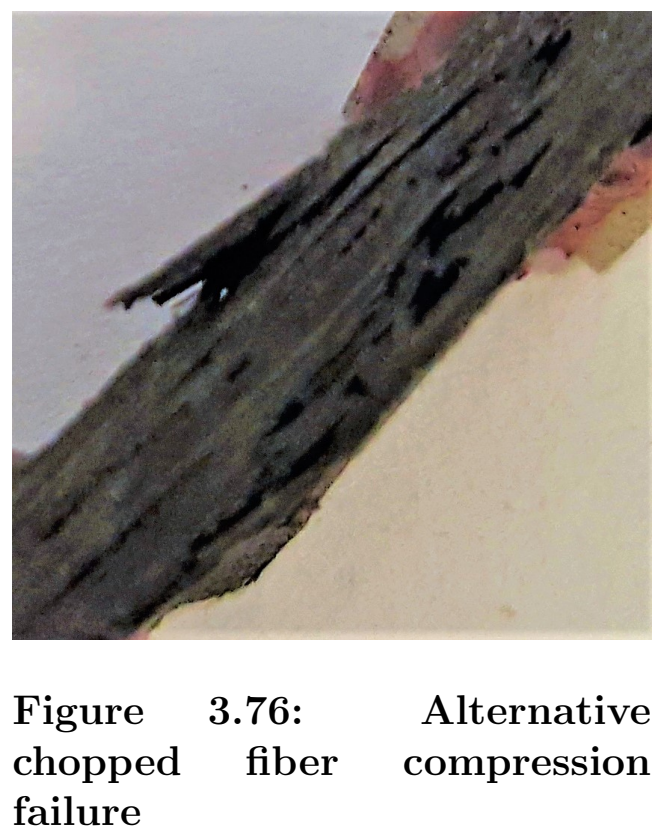

Figure 3.77 shows one of the typical failure modes of the woven material when loaded in tension with the material 1 direction in the loading axis. The material exhibited delamination and fiber pullout. Dependent on where in the original plate samples were cut from, $0^{\circ}$ fibers on the edges of specimen would fail and be forced to the edges of the specimen by the tension in the $\pm 60^{\circ}$ fibers. This is depicted clearly in the photograph below. 


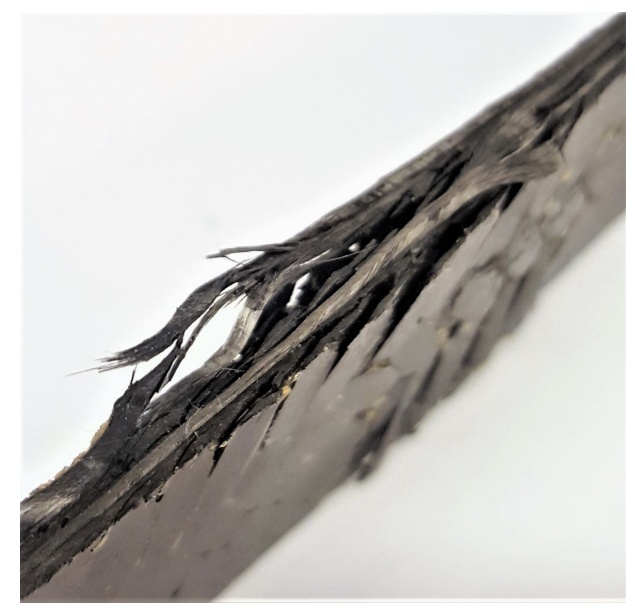

Figure 3.77: Woven 1 direction tension edge

Figures 3.78 and 3.79 exhibit another woven tensile specimens failure when oriented with the material 1 axis in the loading direction. This sample did not have a $0^{\circ}$ fiber running at its edges, so the failure differed from that experienced by the specimen in Figure 3.77. The two edges of this sample showed different lengths of failure, which could be a product of edge effects from cutting operations.

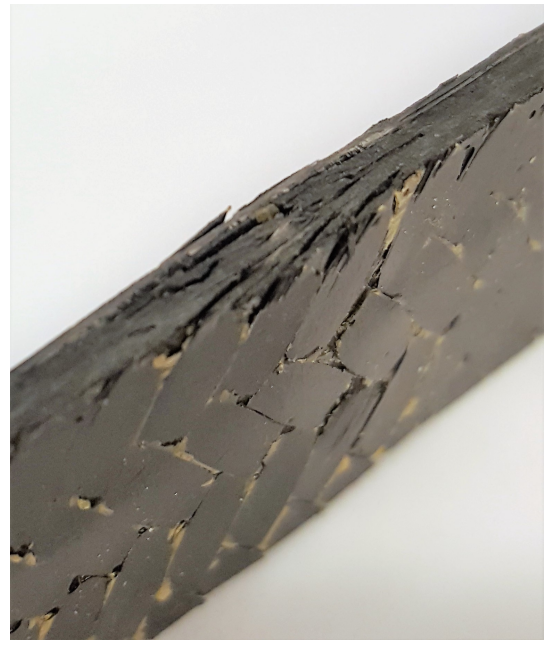

Figure 3.78: Woven 1 direction tension failure

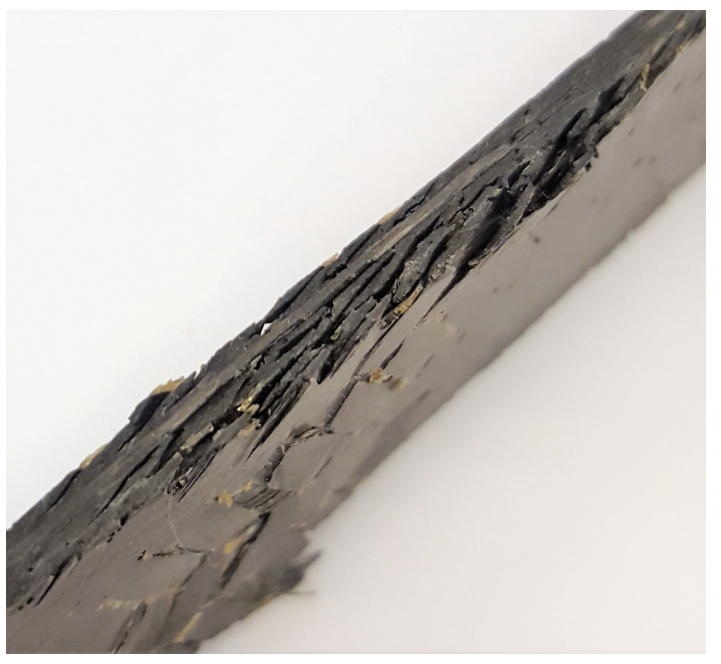

Figure 3.79: Woven 1 direction tension failure on opposite edge

Figure 3.80 shows a compressive sample of the woven 1 direction tests. The failure exhibited here is diagnosed as fracture and delamination between plies. 


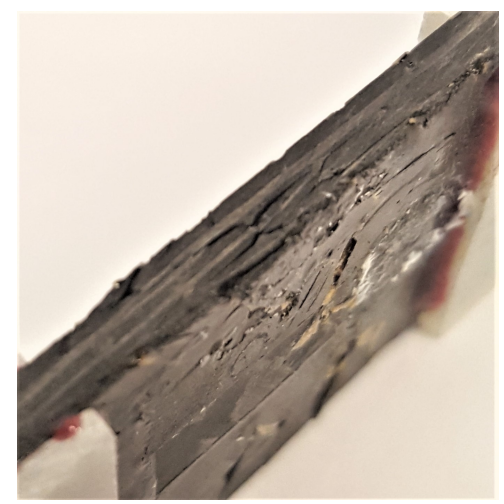

\section{Figure 3.80: Woven 1 direction compression failure}

Figures 3.81 and 3.82 exhibit the failure behavior of the woven material when loaded in tension with the 2 material axis in the pull direction. Based on the explosive behavior of all of the samples of this type this characterized the typical failure mode. Delamination and matrix failure occurred as a result of the high tension experienced by the $\pm 60^{\circ}$ fibers, now oriented at $\pm 30^{\circ}$ relative to the pulling force. This caused interply failure as the matrix failed, and eventually fiber failure at the ultimate load.

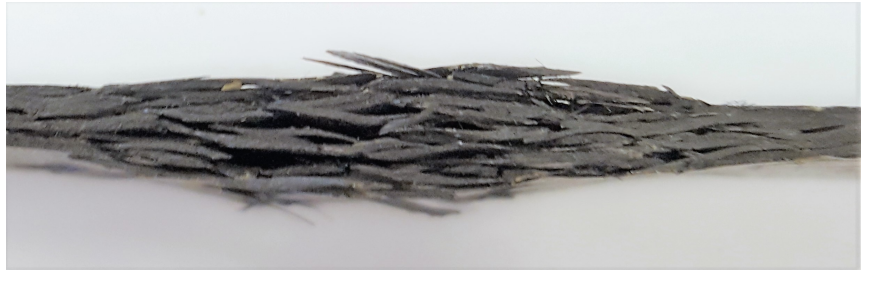

Figure 3.81: Woven 2 direction tension failure side view

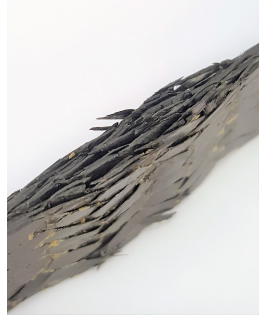

Figure 3.82: Woven 2 direction tension failure

Figure 3.83 shows a compressive specimen with the woven material 2 direction in the loading axis. Similarly to the tension failure, the $\pm 60^{\circ}$ fibers governed the delamination as they carried the compressive load. As microbuckling of fibers turned to debonding with the matrix, delamination occured between the plies and the fibers woven within a single ply. 


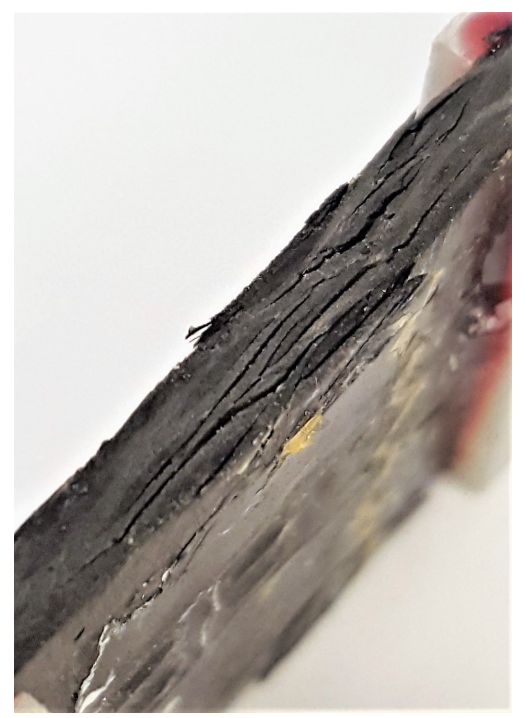

\section{Figure 3.83: Woven 2 direction compression failure}

\subsubsection{Error Analysis}

Errors in the data recorded could have stemmed from multiple points during sample manufacturing and preparation.

Manufacturing defects could have effected material performance during testing. This would include differences in void content between samples and slight misalignment of fibers between plies during plate layup. Edge effects of cutting samples could have induced microscopic defects unique to each sample and differences in stress concentrations along the gauge length. Additionally any change in orientation of the gripping tabs could have distributed the load differently between tests, causing divergent behaviors in the gauge area. Strain gauges applied were checked to be within $\pm 1^{\circ}$ of score mark alignment, but slight deviation was not uncommon. This coupled with differences in stress distribution could have contributed to discrepancies between data from samples in the same test group. Vertical alignment of samples when placed in machine vice grips was check to be within $\pm 1^{\circ}$ using the gauge pictured in Figure 3.84 . 


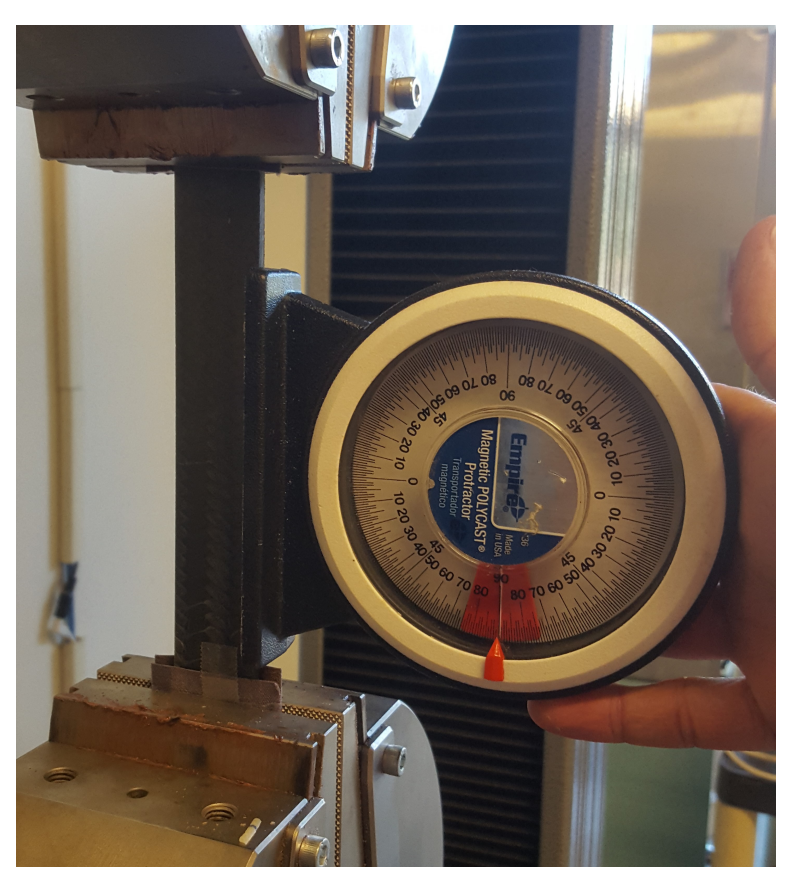

Figure 3.84: Gauge used for specimen vertical alignment

\subsubsection{Material Testing Results and Discussion}

The results from material behavior testing were used in the criteria of material selection for application to the machined into connecting rod geometry. The primary focus in selection were the compressive properties of the materials examined. The triaxially woven material proved to have a higher modulus when when loaded with the 2 direction oriented axially. Although this case exhibited a slightly lower ultimate strength than the alternate orientation, the standard deviation of tests was smaller. Small defects in manufacturing or test setup could have caused this discrepancy and therefore the higher elastic modulus was considered the better metric of performance. The chopped fiber compressive samples exhibited a high failure strength, but with an unacceptably high standard deviation. Additionally, the modulus data was voided by the errors in the Instron DAQ system. 


\subsection{Material Machinability}

One of the major criteria used in assessing materials for the connecting rod application was the ability to be machined. Evaluation included the resultant surface finish and ability to maintain the matrix to fiber interface without chipping or delaminating. In order to explore this, an arbitrary geometry was create in SolidWorks which captured contours mimicking dimensions and paths necessary to machine the connecting rod geometry. The area footprint of the test sample was based on the available 2 inch by 2 inch blocks which had been cut from chopped fiber and triaxially woven bricks during compression molding iterations. The CAD model for this geometry is displayed in Figure 3.85. The tool pathing was created using Mastercam, an associated plugin for SolidWorks.

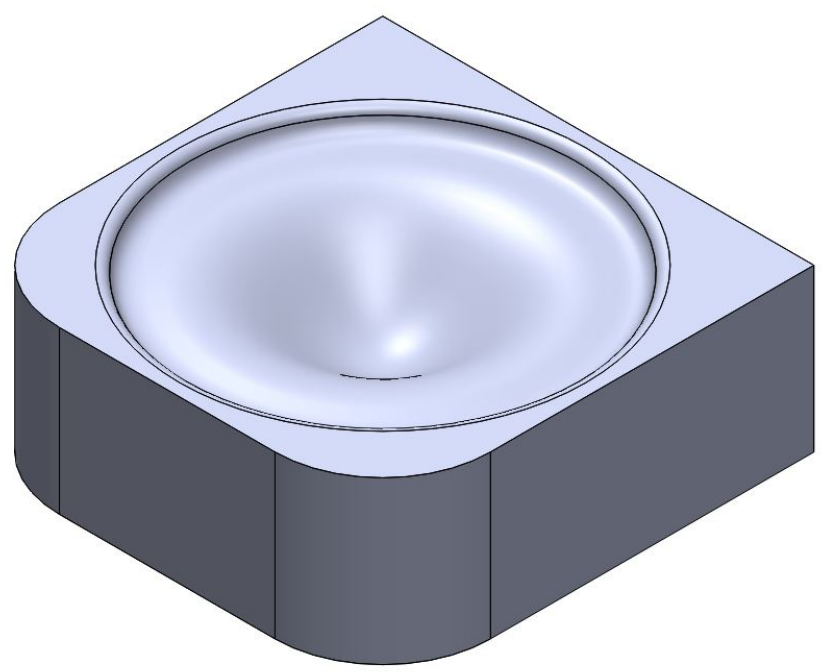

Figure 3.85: Arbitrary geometry for machining testing

\subsubsection{Tool Selection}

Tool selection is a critical decision in the machining of composite materials as found in the study by Machining of Composites (Teti, n.d.). Traditional tool designs for metal machining risk damaging composite layups as exemplified in Figure 3.86. Damages 
can include delamination which weakens overall laminate strength, and burring which disrupts fiber orientation while destroying the matrix to fiber interface. This can be mitigated by utilizing a compression spiral tool which both pulls and pushes material when at at certain depth to prevent delamination.

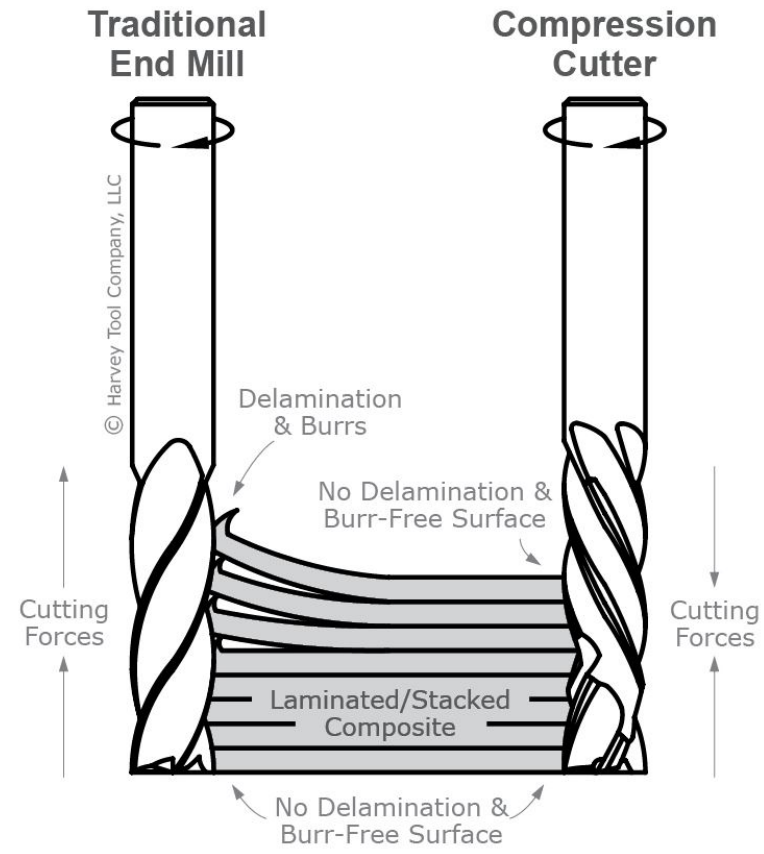

Figure 3.86: Schematic of tool differences (Harvey, n.d.-b)

Based on the intended geometry of the connecting rod, its dimensions, and the initial volume of material constituting a composite brick certain tool choices were narrowed down. To minimize cost of purchasing several tools, end mills which accomplished the many anticipated roles for the tool paths necessary to machine the final connecting rod were found. It was determined the largest compression spiral cutter diameter which could be utilized was $5 / 16$ ". This allowed for the same tool to be applied in maximum removal of material from the outer contours of the rod as well as in pocketing the web and boring the pin end holes. All roughing passes could be accomplished using a compression spiral cutter with this diameter. For finishing passes a ball end mill with a diameter of 0.118 inches was elected as this could ac- 
commodate all of the fillet radii on the connecting rod geometry. Although cost was a concern, getting tools with proper coatings or material composition ensured that the tools could withstand the volume of material they were intended to remove, and the wear induced by the composite without significant detriment to performance. Figures 3.87 and 3.88 show generalized dimensioned drawings of the two tools discussed. The corresponding dimensions for the tools selected from Harvey Tools are listed in Table 3.8 .
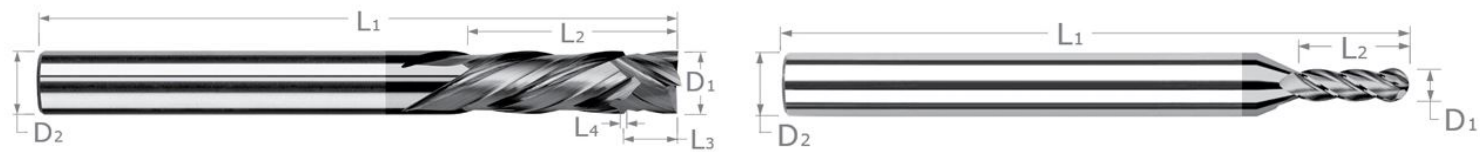

Figure 3.87: Compression spiral cut-Figure 3.88: Ball end mill schematic ter schematic (Harvey, n.d.-b) (Harvey, n.d.-a)

Table 3.8: Cutter specifications and dimensions in inches

\begin{tabular}{c|c|c|c|c|c|c|c} 
Cutter Type & Material & D1 & D2 & L1 & L2 & L3 & L4 \\
\hline \multirow{2}{*}{$\begin{array}{c}\text { Compression } \\
\text { Spiral }\end{array}$} & Carbide with & & & & & & \\
& amorphous & 0.3125 & 0.3125 & 2.5 & 1 & 0.3125 & 0.075 \\
diamond coat & & & & & & \\
\hline \multirow{2}{*}{ Ball End } & $\begin{array}{c}\text { CVD diamond } \\
\text { on solid carbide }\end{array}$ & 0.118 & 0.125 & 1.5 & 0.354 & - & -
\end{tabular}

The tools themselves are pictured below with Figure 3.89 being the compression spiral end mill, and Figure 3.90 the ball end mill. It should be noted that these images are prior to any cutting activities, showing the original state of tool condition. 


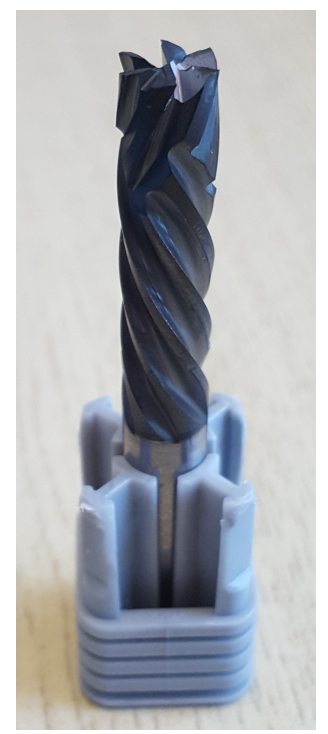

Figure 3.89: Compression spiral end mill

\subsubsection{Machining and Machinability Results}

Machinability tests were conducted in an enclosed Haas Mini-Mill within the Industrial Manufacturing Engineering Machine Shop at Cal Poly. The 2 inch by 2 inch brick samples from Figures 3.29 and 3.32 were each machined according to the proposed test geometry. Coolant was run as there were concerns about the safety of running for the first time without it. Initially it was though that speeds and feeds should be set to the manufacturer provided values, however the mill had a maximum speed lower than desired values. Instead tool speed was set to the machine maximum of 4000 RPM. The process of cutting the chopped fiber sample can be seen in Figure 3.91 . 


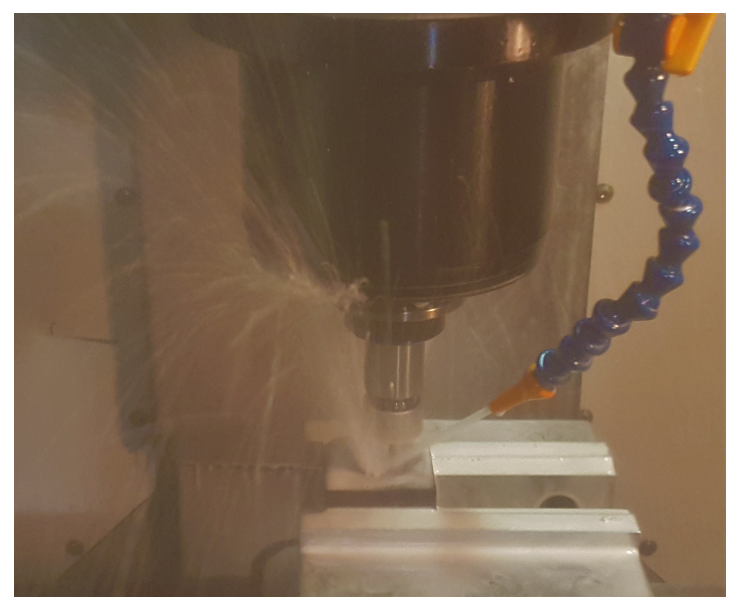

Figure 3.91: Haas Mini-Mill test operation

Although coolant was run as a safety precaution, it induced a significant issue for the operability of the mill's pump system for coolant filtering and recycling. The fine particulate created by machining the composite materials became integrated with the fluid and therefore entered the filtration system. Eventually the filter in the pump became so clogged that coolant could no longer recirculate. This required extensive cleaning of the entire machine after completing the experiment, as well as a full replacement of the cooling solution.

The completed chopped fiber sample is presented in Figure 3.92. It can be noticed that the surface has a prominent number of defects. Some of these are induced by the high void content of the sample. However, noticeable chipping was observed during the machining trial. This manifested in noticeably larger discontinuities in the surface of the machined sample, ultimately impacting the surface finishing of the component severely. 


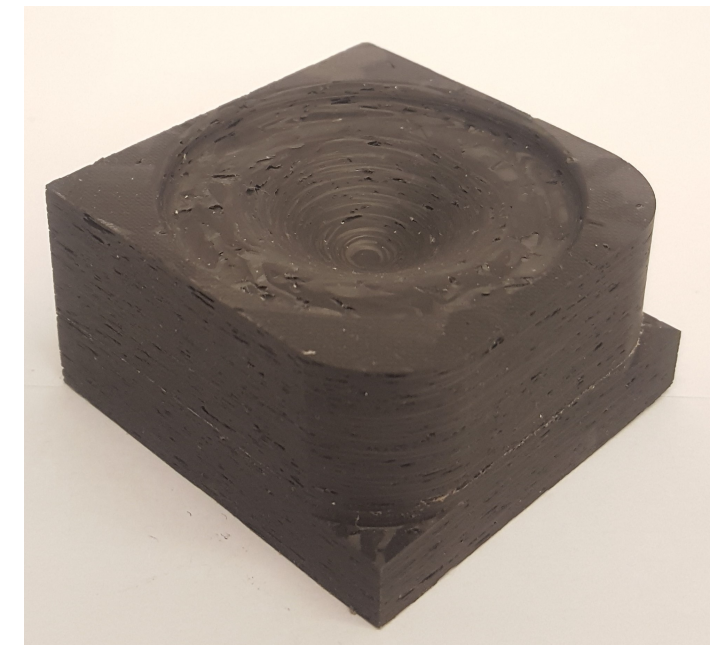

Figure 3.92: Machined chopped fiber brick sample

The machined triaxially woven sample is presented in Figure 3.93. This exhibited few surface defects compared to the chopped fiber test. The few voids present were a result of the edge curling visible from the side view provided in Figure 3.33. Otherwise the surface finish of the part was smooth and exceeded the expectation of the trial.

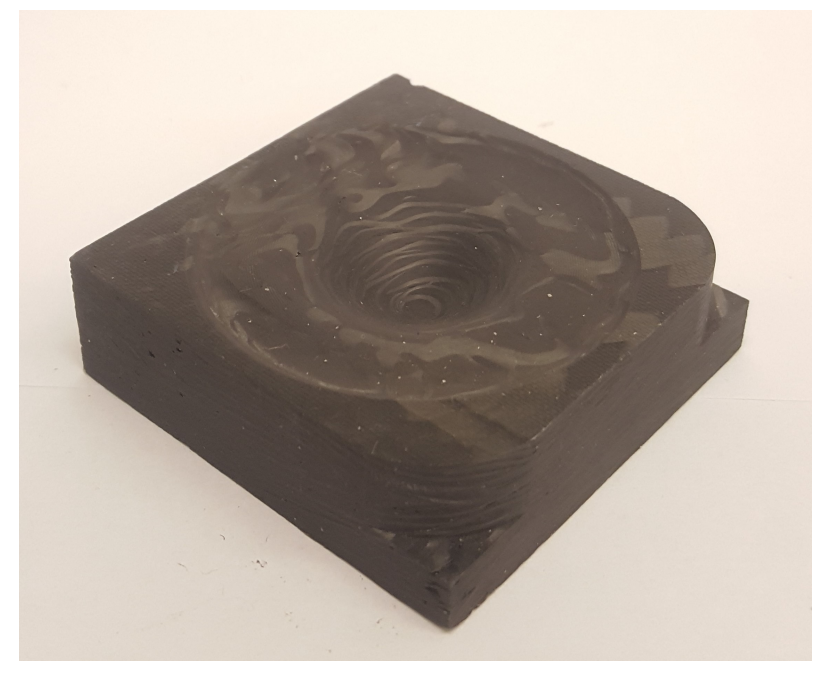

Figure 3.93: Machined triaxially woven brick sample 


\subsection{Material Selection Criteria and Decision}

Final material selection was based on consideration for a number of factors. Requirements and considerations taken into account during selection included:

1. Limited and containable resin loss during cure

2. Shape maintenance from initial layup through end of cure

3. Predictable cured thickness

4. Minimal void content

5. Best elastic modulus

6. Good machine finish with minimized tool induced defects

Although the HexPly ${ }^{\circledR}$ F-155 showed a good ability to maintain its expected cured thickness, the volume of resin loss was ultimately a concern. In the case of compression molding, minimizing resin loss is crucial to maximizing the mechanical performance of the fiber to matrix interface and ensure that the part can be freed from the mold. The cured thickness per ply, although not a constraint, was less desirable than the other materials as it would take a far higher volume of material to create the expected thickness of the final geometry than its competitors. For these reasons it was elected that the material not be pursued further than its initial cure test.

The chopped fiber composite showed varied acceptability within the requirements established above. As visible in iterations conducted, the final cured state of the layup was unpredictable. This is a result of the discontinuous nature of the fibers in the matrix. When the roll was initially removed from the freezer, the material was extremely rigid. However, as the temperature of the material went up the shape of the composite is subject to the flow of its matrix. This is especially pronounced 
during curing. Because the resin flows freely fibers follow the resin and the path of least resistance. This pointed to the necessity of utilizing a compression mold which would maintain its form around the material throughout the cure cycle. Although this produced frustration during early iterations, it showed good promise for allowing maximum material volume in a successful compression mold. The variability in result, especially with respect to void content proved problematic as this would vary the structural integrity of the material from cure to cure based on the pressure applied and distribution of material. Voids produced an inconsistent surface finish result when machined. Additionally, differences in void distribution was evident in the results of compression testing through the high standard deviation of ultimate strengths. As a result of its difficulty to work with, and inconsistency in test results the chopped fiber material was placed second to the triaxially woven composite.

The triaxial weave material performed excellently in preliminary tests. It showed a favorable ability to retain its resin after curing, and with ample pressure produce specimen with little void content. The quasi-isotropic behavior of the material confirmed through mechanical testing additionally added a favorable quality to the material specific for the connecting rod loading environment, along with the favorably high compressive elastic modulus and ultimate strengths. The machined sample produced superb results in surface finish and minimal chipping or defects. For these reasons the HX42 was elected the primary candidate of component development. 
Chapter 4

CONNECTING ROD NUMERICAL SIMULATION AND ANALYSIS

\subsection{Overview}

Numerical simulation was used to verify measurements taken experimentally on the steel connecting rod. FEA conducted in Abaqus was compared to both to theoretical calculation and experimental data to verify that load cases and boundary conditions were setup correctly. This also provided a foundation on which the connecting rod CAD could be verified the same as the steel component.

\subsection{CAD Model}

The CAD model of the steel connecting rod was obtained from the work conducted in Dynamic Analysis of Connecting Rods Using MSC ADAMS Modal Sythesis Method for Flexible Bodies (Bradaric, 2017). The model was created using a set of digital calipers and visual interpolation where necessary. The complete model of the rod can be seen in Figure 4.1.

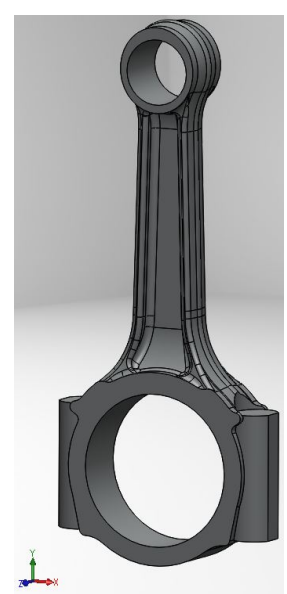

Figure 4.1: Connecting rod CAD 
Figure 4.2 asserts the naming convention used in reference to significant portions of the geometry being explored. Additionally, the coordinate system convention is asserted. The y-axis travels the axis of the component while the z-axis is the axis of rotation of the part. The $\mathrm{x}$-axis is oriented perpendicularly to the I-beam section.

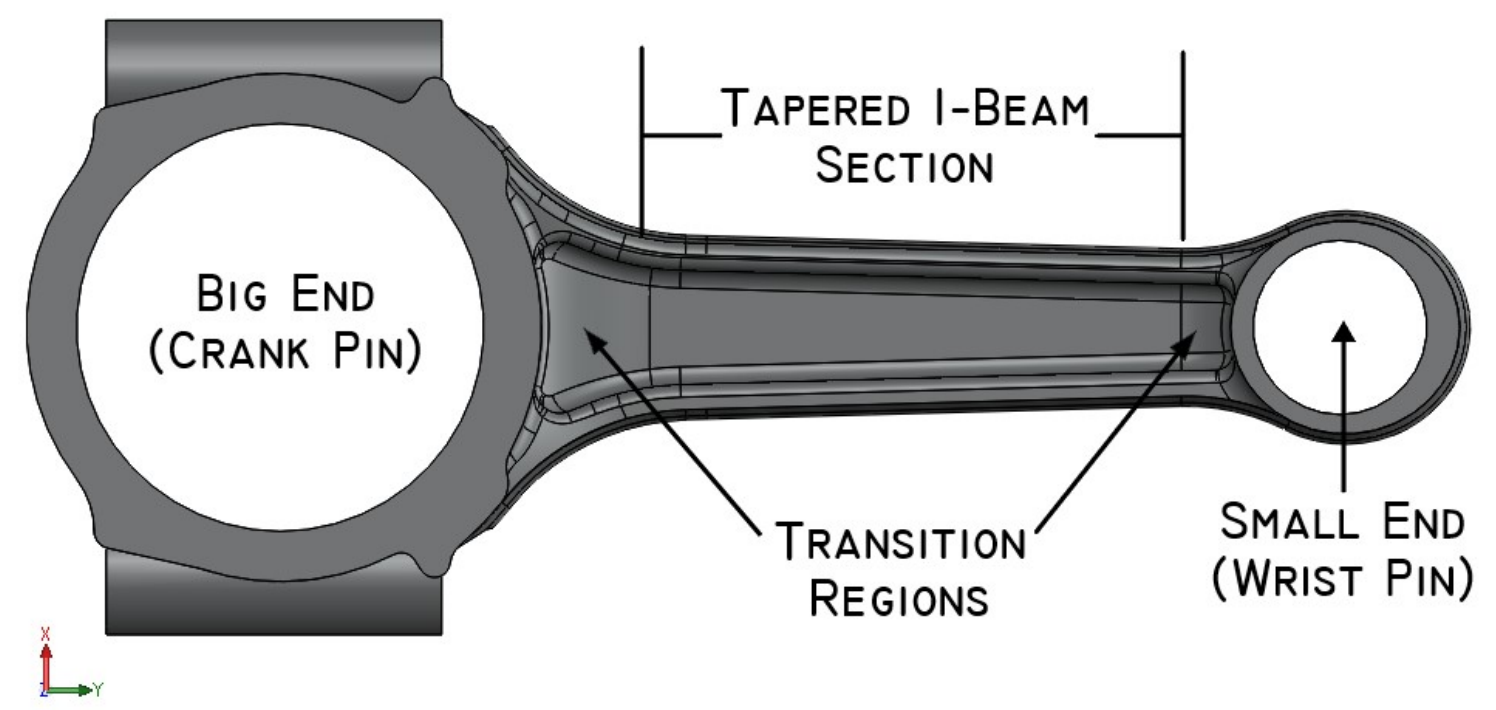

Figure 4.2: Definition of regions on rod

\subsection{Finite Element Analysis}

Finite element analysis (FEA) was conducted using Abaqus. Much of the guidance and reference for utilizing the program came from the Abaqus 6.10 User's Manual (Dassault, n.d.). The program was selected for its streamlined interface when conducting composite layup analysis. Therefore all analysis cases were setup in Abaqus to ensure consistency by using a single program.

\subsubsection{Steel Connecting Rod Numerical Analysis}

The connecting rod geometry was imported into Abaqus as a solid part file. Material properties capturing steel's assumed material behavior were applied to the entire 
specimen and are tabulated in Table 4.1.

Table 4.1: Material properties of steel applied in Abaqus

\begin{tabular}{c|c} 
Elastic Modulus & Poisson's Ratio \\
\hline $29 \mathrm{Msi}$ & 0.3
\end{tabular}

The model was then seeded and meshed. In choosing mesh controls solid, 3D stress elements modeled the physical situation best and would yield the least error. For this reason C3D10 (10-node quadratic tetrahedron) elements were applied in meshing. The final mesh on the part is pictured in Figure 4.3. Although small regions of the mesh did not exhibit the best geometric behavior, it was found the impact on results were near negligible. A mesh convergence study was conducted and is pictured in Figure 4.4.

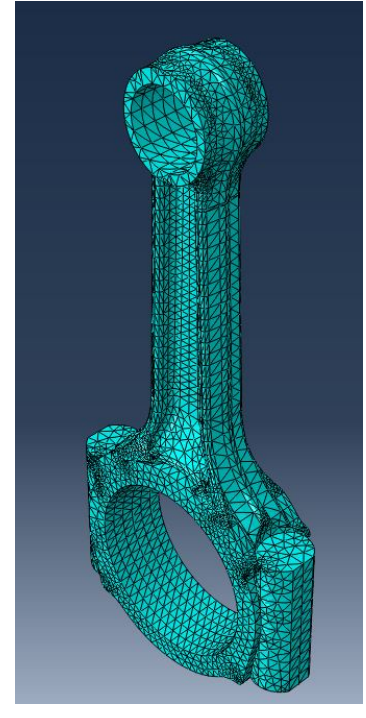

Figure 4.3: Mesh on geometry

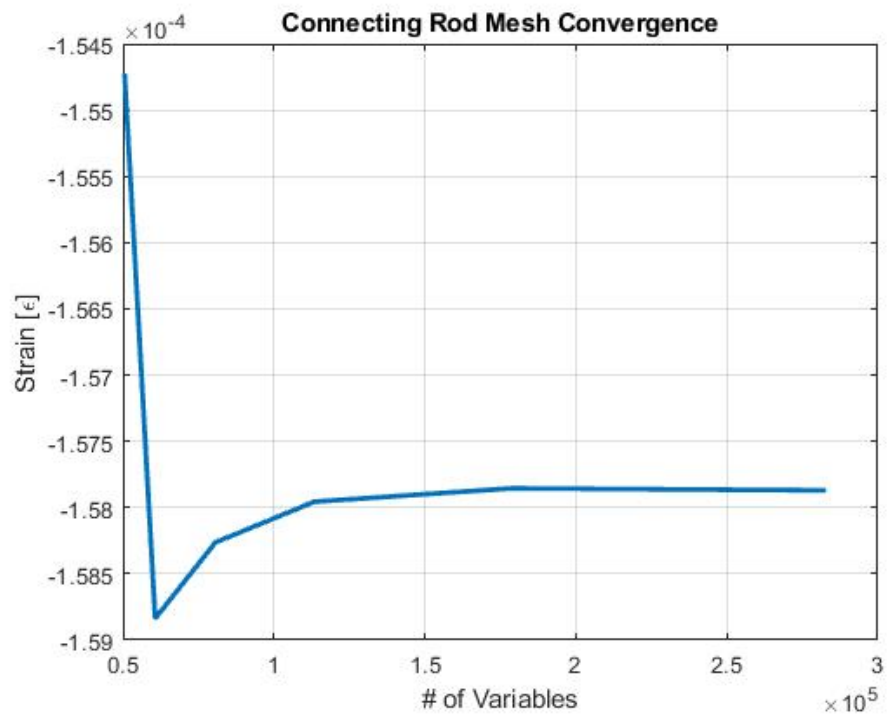

Figure 4.4: Mesh convergence study

The mesh convergence study showed that a global seed size of 0.15 was adequate to maximize the accuracy of results. This meant the model contained a total of 58523 nodes with 178695 total DOF.

After material properties and meshing were applied to the geometry, boundary 
conditions and constraints were applied to model the compression testing of the part in pure axial loading. The boundary conditions and constraints imposed are pictured in Figures 4.5 and 4.6 were as follows:

1. Small end center node zero displacement in $\mathrm{x}$ and $\mathrm{z}$ directions, and zero rotation about $\mathrm{x}$ or $\mathrm{y}$ axes

2. Big end center node zero displacement in $\mathrm{x}, \mathrm{y}$, and $\mathrm{z}$ directions, and zero rotation about about $\mathrm{x}$ or $\mathrm{y}$ axes

3. Bottom $120^{\circ}$ of surface of small end tied in all DOF to the center node of the diameter

4. Inner surface of crank end tied in all DOF to the center node of the diameter

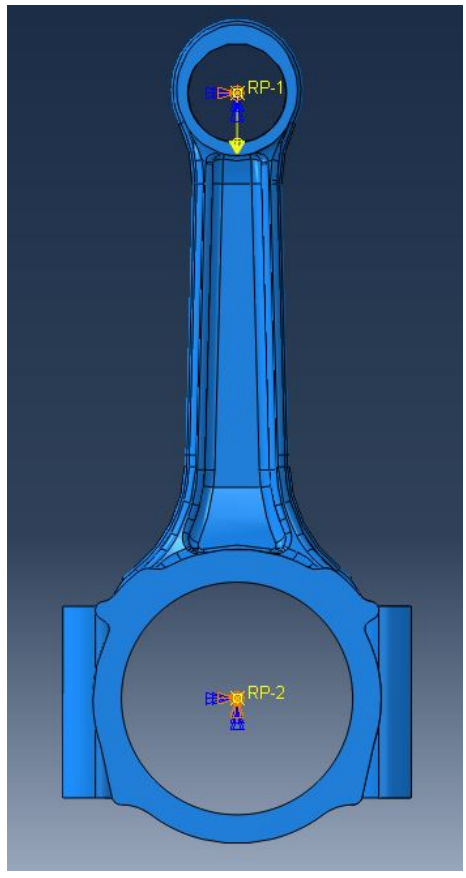

Figure 4.5: Boundary conditions imposed on geometry

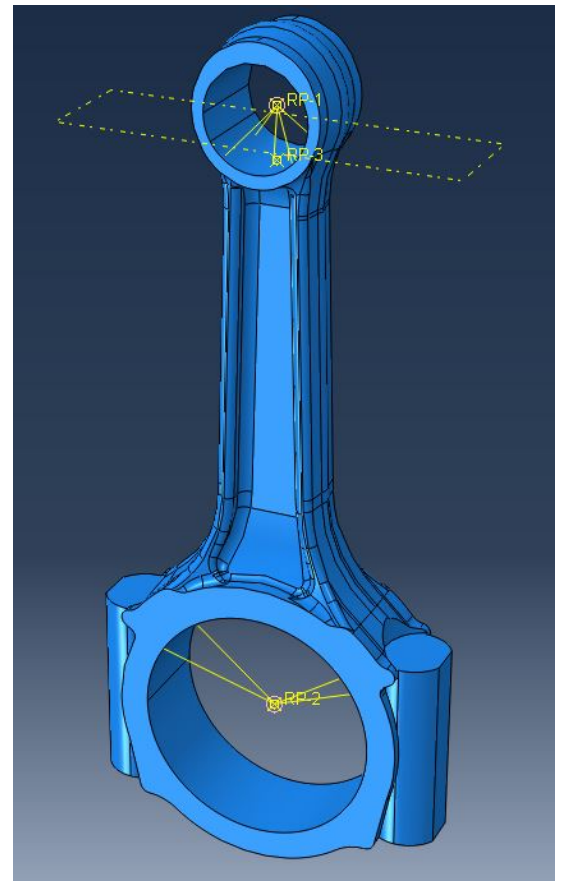

Figure 4.6: Coupling constraints imposed

The coupling constraints placed from the inner surfaces of the small and big ends modeled the contact with fixtures to be used in testing. The boundary condition 
placed at the big end ensured the end was fully constrained in translation and only allowed to rotate about what would be the crank pin axis. The small end boundary condition allowed for translation in the direction of loading and rotation about what would be the piston pin axis. These conditions not only captured the testing conditions being used, but realistic end loads of a connecting rod in an engine.

Next, a concentrated load (shown in Figure 4.5) was applied at the center node of the small end which was tied to the lower $120^{\circ}$ of the diameter surface as was done in Shenoy (Shenoy and Fatemi, 2006). This modeled the piston pressure applied across that surface in a purely axially manner. A $1000 \mathrm{lbf}$ load in the negative yaxis was applied for simulation as this was achievable and safe in the experimental environment.

The region of interest was located at 2.5" down from the center node of the pin end. This was asserted by the location of the strain gauge on the physical steel rod which would be tested and measured for axial strain. The results for axial strain of the whole geometry and the location of interest are shown in Figures 4.7 and 4.8 respectively. The probed strain value at the location of interest was $-158.65 \mu \epsilon$.
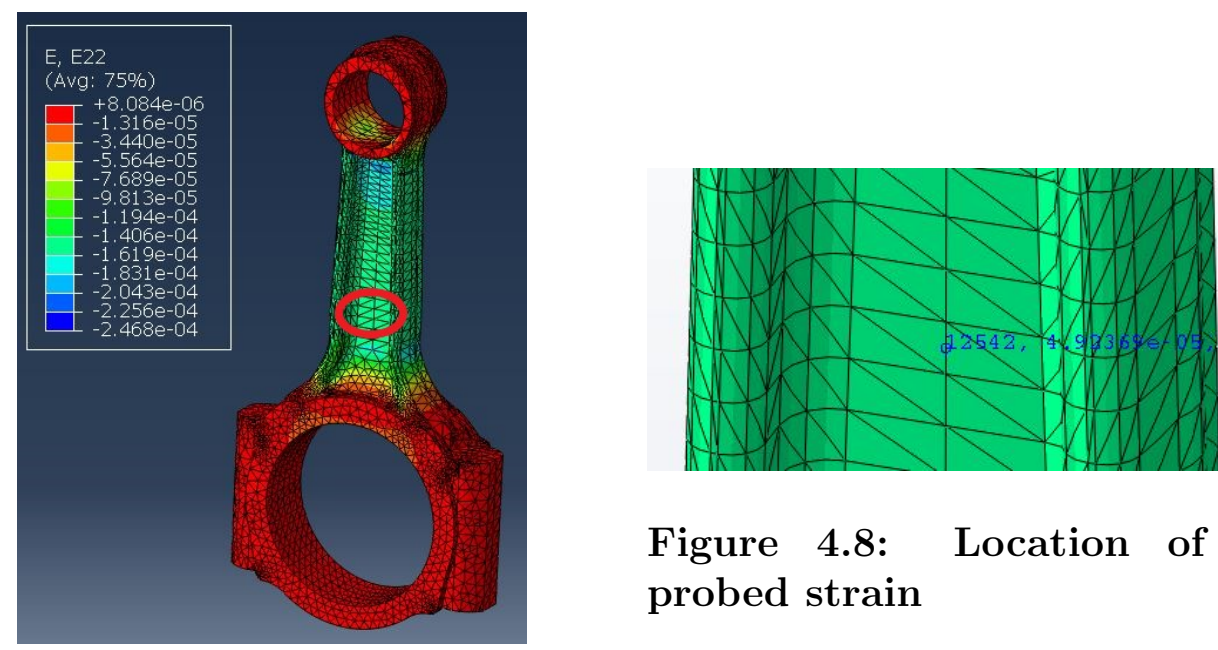

0.000158652

Figure 4.8: Location of interest probed strain

Figure 4.7: Axial strain results 


\subsubsection{Steel Connecting Rod Testing for Verification}

Experimental testing was conducted on the steel connecting rod to validate that the FEA has been set up with the correct conditions and verify the accuracy of the CAD model. Testing fixtures were obtained from the work conducted in Bradaric's work (Bradaric, 2017) and are pictured in Figures 4.9 and 4.10.

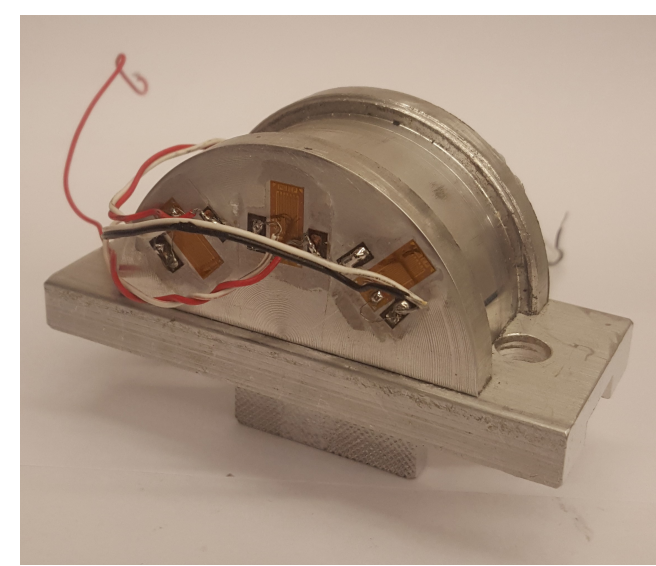

Figure 4.9: Crank end fixture

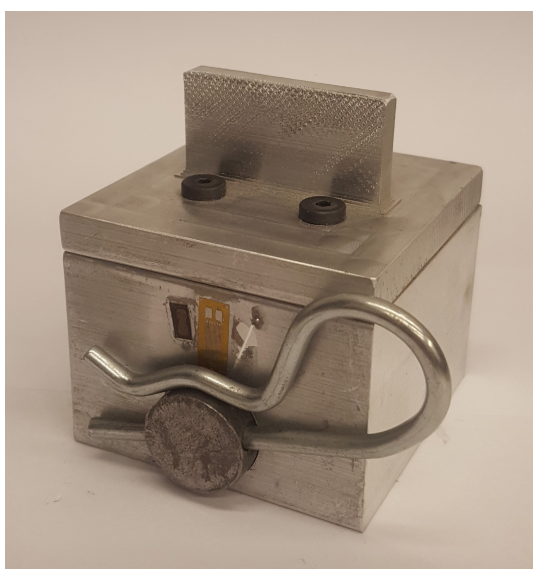

Figure 4.10: Piston end fixture

The connecting round mounted on the fixtures and placed in the vice grips of the Instron is pictured in Figure 4.11. The data was collected from the same type strain gauge which had been used in material testing, and located on the inside web of the I-beam section 2.5" down from the center of the small end inner diameter. A wheatstone bridge was used in the quarter bridge configuration to read the data as this experiment occurred during the troubleshooting period of the Instron's DAQ system inaccuracies. The strain data for both sides of the web is exhibited in Figure 4.12 . 


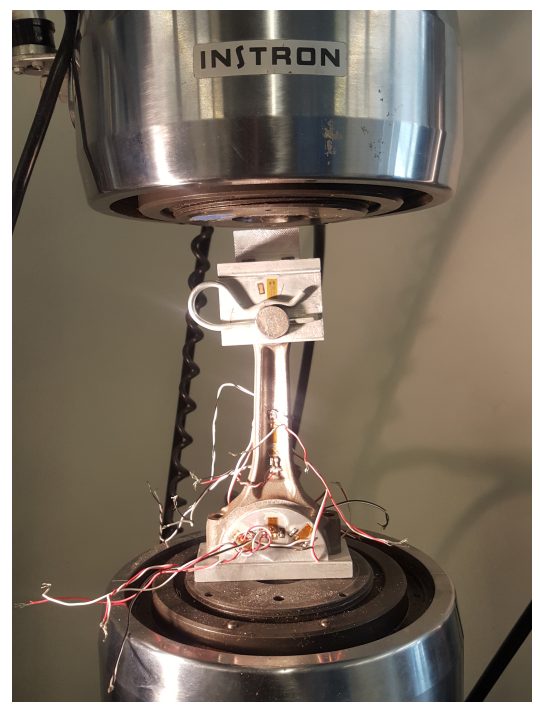

Figure 4.11: Boundary conditions imposed on geometry

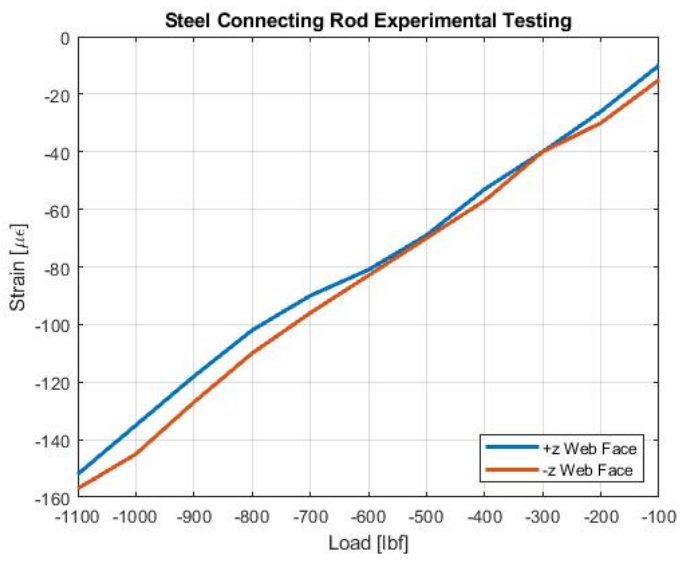

Figure 4.12: Coupling constraints imposed

The theoretically calculated strain expected at the location of interested utilized Equation 3.2 in conjunction with Equation 4.1.

$$
\epsilon=\frac{\sigma}{E}
$$

Where $E$ is the same elastic modulus assumed for the FEA material. Stress was calculated using the $1000 \mathrm{lbf}$ compressive force and an area of $0.222 \mathrm{in}^{2}$ (obtained from the location of interest cross section using Solidworks). A comparison of the results between FEA, experimental testing, and theoretical calculation is shown in Table 6.1. 


\begin{tabular}{c|c|c|c}
\multicolumn{2}{c|}{ Table 4.2: Steel connecting rod strain comparison } \\
& Abaqus & Experimental & Theory \\
\hline $\begin{array}{c}\text { Strain }[\mu \epsilon] \\
\text { \% Difference from }\end{array}$ & -158.65 & -145 & -155.33 \\
Theory & 2.14 & 6.65 & - \\
\hline \% Difference from & 9.41 & - & - \\
Experimental & & &
\end{tabular}

The results of this comparison are highly encouraging. Both the Abaqus and experimental results show well under $7 \%$ error when compared to the expected theoretical value. This asserts a few known truths. As the modeled geometry shows a low difference with theory, the load case was set up correctly within the simulation. The experimental strain most likely deviates from theory due to small inconsistencies in the manufactured part, misalignment in the strain gauge, or load transfer issues from the test fixtures. Therefore a comparison of the Abaqus results to the experimental data is necessary. This shows a difference still under 10\%, but higher than the comparisons made with theory. This could be due to any discrepancies or error buildup in the modeled geometry versus the true geometry, or the aforementioned contributions from manufacturing and testing errors. Differences in the manufactured component from the assumed isotropic material properties and symmetric geometry of the specimen would result in a different transfer of the load down the axis of the component. This coupled with interpolation conducted on hard to model sections of the connection rod (such as transitions of the I-beam) would propagate error further and cause the discrepancy seen in the Abaqus results. 
Chapter 5

CONNECTING ROD MANUFACTURE AND TEST

\subsection{Overview}

A total of four woven bricks and one composite brick were manufactured using the asserted compression molding process to be machined into the final connecting rod geometry. The dimensions of the bricks after curing are all available in Appendix B. A few minor geometric accommodations were made in the originally modeled geometry to significantly reduce machining time and simplify regions which could not be machined with a 3-axis mill. A soft jaw was machined, and tool paths created for composite rod machining. After machining, the composite rods were cleaned and instrumented with strain gauges for experimental testing.

\subsubsection{Geometric Accommodations}

To accommodate limited machine access time and machine constraints certain adjustments had to be made to the originally modeled CAD geometry of the connecting rod. The hours of access to campus facilities were limited on a daily basis due to safety regulations and operating hours, therefore the times for cut operations had to be reduced to fit within these constraints. A primary driver of long machine times was the rounded outside faces of the tapered I-beam section. To drive down the cut time on these portions of the I-beam the round was flattened as exemplified by the diagram in Figure 5.1. The red vertical lines imply where the new geometry of the I section ends, and any geometry outside of these extents is removed. Fillets were maintained to transition to the new flat faces to mitigate stress concentrations experienced in any cross-sectional area along the axis of the part. 


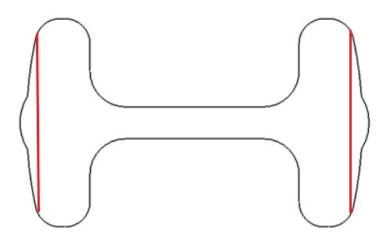

\section{Figure 5.1: Flange modifications}

In addition to the revision made to the I-beam, a simplification of geometry at the crank end mount points needed to be made. As Figure 5.2a exhibits, the original geometry created negative draft angles which would not be feasible to machine with a 3 -axis mill. As the primary region of interest was location on the inside web of I-beam it was asserted that this geometry could be simplified by simply cutting through it and relieving stress concentrations with a fillet along the right angle of the cut. This revision is visible in Figure 5.2b.

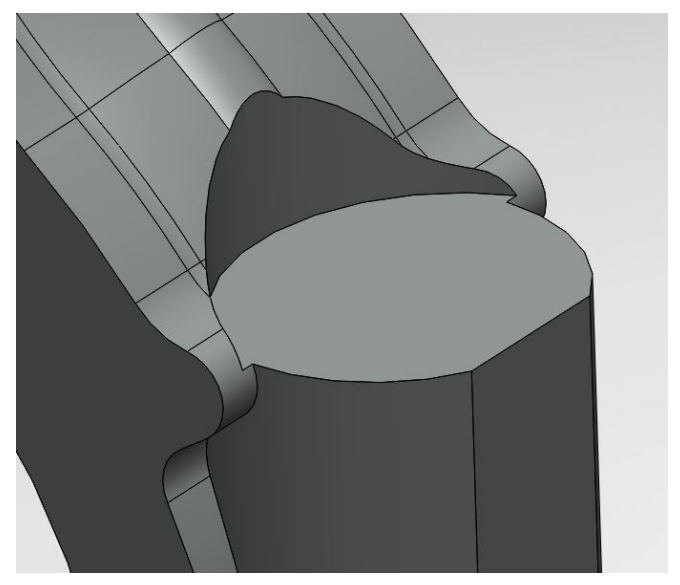

(a) Original mount point

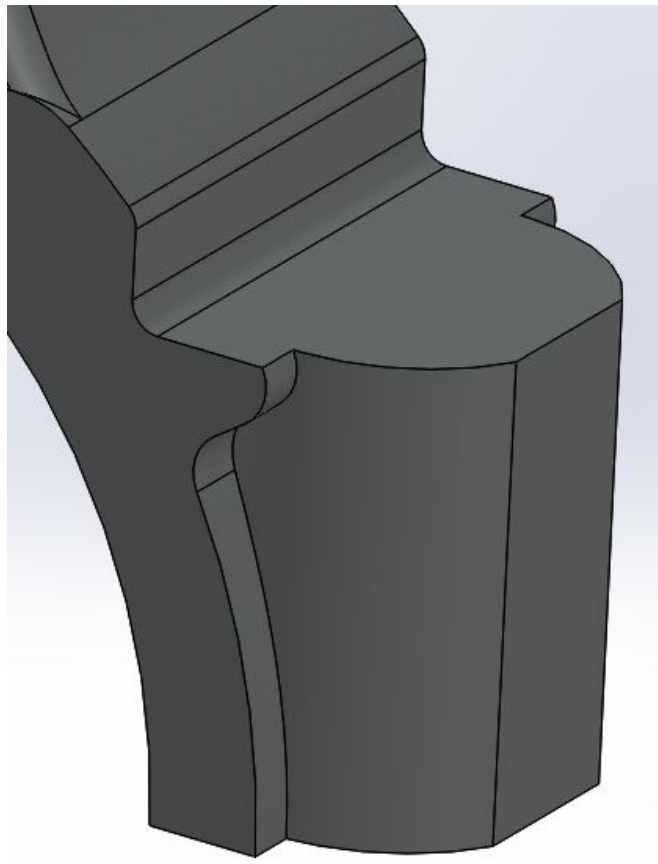

(b) Modified geometry

Figure 5.2: Modified bolt mount area

A comparison of the original and modified geometries is shown below with Figure 
5.3a being the initially provided CAD, and Figure 5.3b the revised connecting rod for composite manufacturing and testing. Note that the rod cap (lower half of the big end) has been cut away to accommodate the text fixture provided.

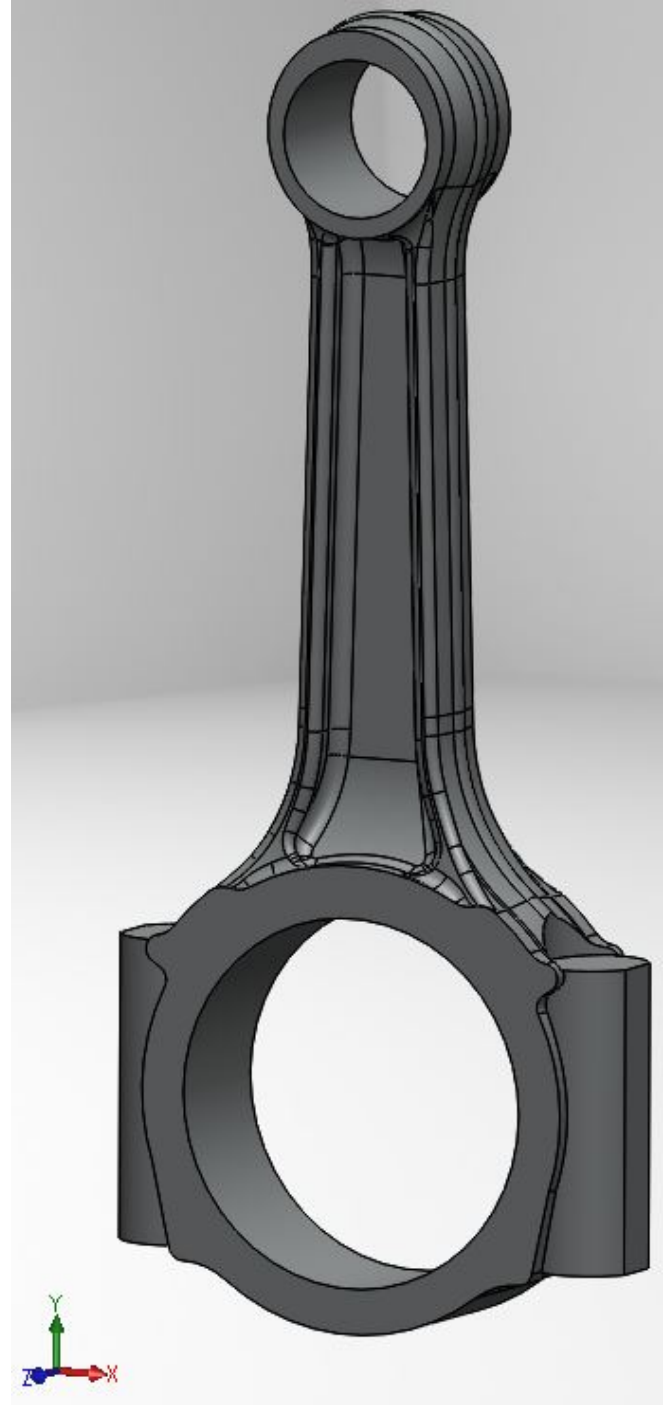

(a) Original CAD

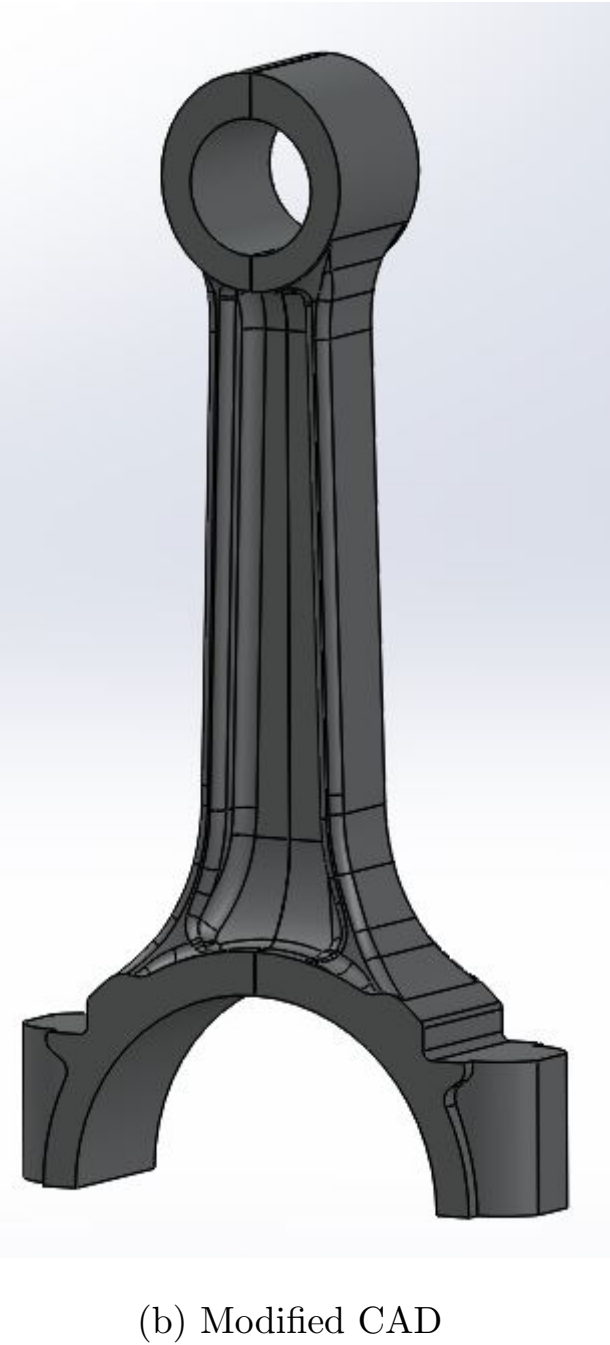

(b) Modified CAD

Figure 5.3: CAD geometry comparison

\subsubsection{Speeds and Feeds}

Manufacturers typically provide machining values as a recommendation for speeds and feeds. This ensures that the matrix to fiber interface is maintained and a good surface 
finish is achieved after machining. Tencate provides a Tooling Prepreg Processing Guide (Tencate, 2018) which recommends speeds and feeds based on a 0.5 ball end, 2-Flute cutter. A spindle speed of 6112 RPM is suggested, while stated feed rates are set to 50 inches per minute for pocketing and 25 inches per minute for 3D contouring. These values were used as the baseline for asserting speed and feed rates for machining the composite connecting rod.

Due to machine limitations the recommended speed could not be met; instead the machine maximum of 4000 RPM was applied. To mimic the recommended parameters for the pocketing operations the compression spiral cutter was run at 52" per minute as the diameter was large enough to keep the tool stiff and handle the rate. The ball end mill was set to 18 " per minute as a high feed rate would produce a load which could risk breaking the tool. Because the chopped fiber material had no recommendation for speed or feed, the values from the HX42 settings were maintained.

\subsubsection{Toolpath}

Tool pathing was created using HSMWorks CAM software. The elected pathing was not optimized as this study was not focused on machine efficiency or mass production of the connecting rods. The only constraint placed on cutting operations was imposed by facility operating hours.

\subsubsection{Cutting Operation 1}

Cutting operation 1 (OP1) tool paths were split into two routines which encompassed roughing and finishing passes. The roughing pass utilized the compression spiral cutter for pocketing and major material removal, while the finishing pass used the ball end mill. The roughing and finishing passes are exhibited in Figures 5.4 and 5.5 respectively. Blue path lines represent cutting motions, green are lead in, and 
yellow are rapid non-cutting paths to expedite translation across the part. The home location for OP1 was set for the top left corner of the composite block. The expected end product of the OP1 passes is provided in Figure 5.6.

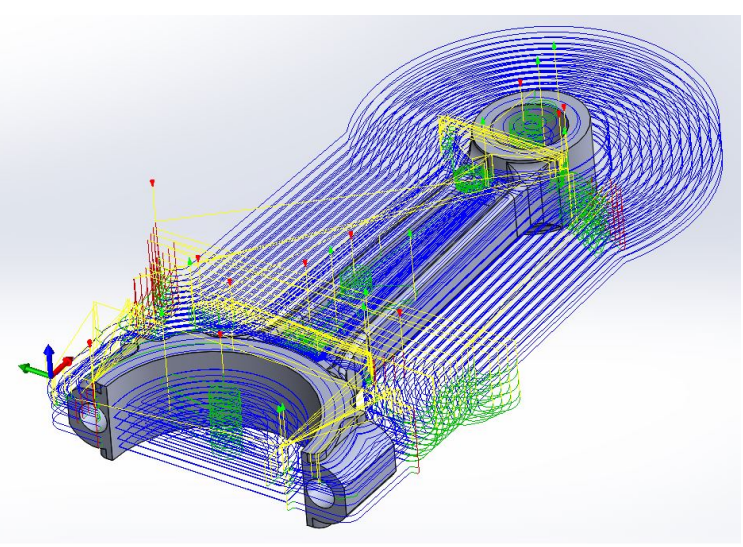

Figure 5.4: OP1 roughing path

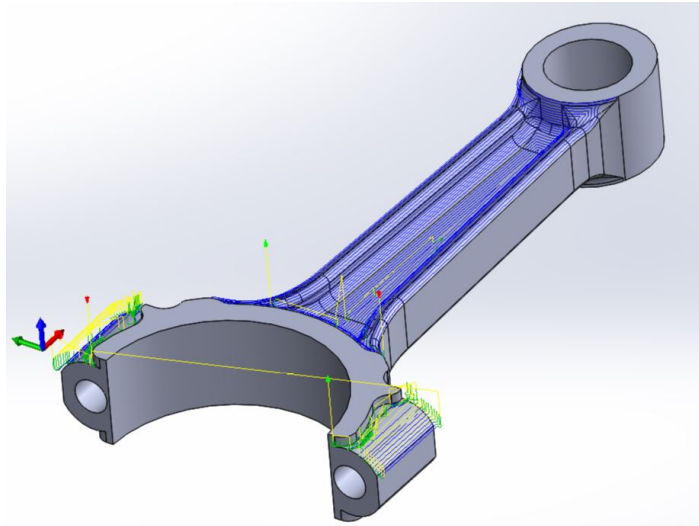

Figure 5.5: OP1 finishing path

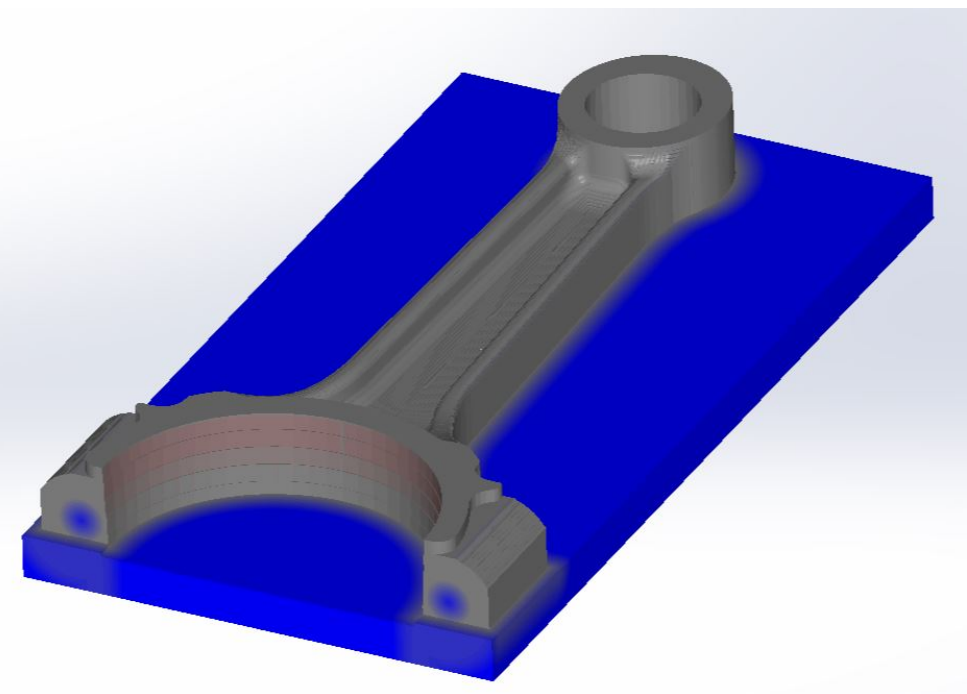

Figure 5.6: Expected geometry after OP1

\subsubsection{Cutting Operation 2}

Cutting operation 2 (OP2) mirrored the cuts and contouring made in OP1 with some minor changes. The working part would be flipped and placed in an aluminum soft 
jaw, so a new home location had to be established to ensure the part geometry was set correctly relative to the OP1 geometry previously cut. The new home location was set to the upper left corner of soft jaw. The roughing and finishing passes of OP2 are depicted in Figures 5.7 and 5.8. The color conventions for paths generated in HSM are consistent with those described for OP1.

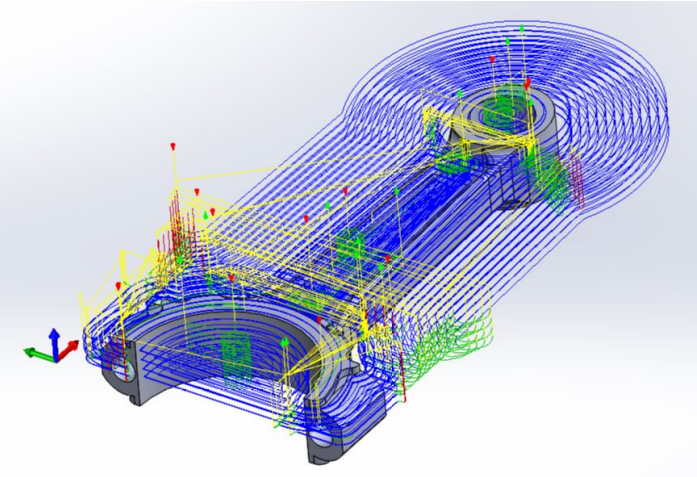

Figure 5.7: OP2 roughing path

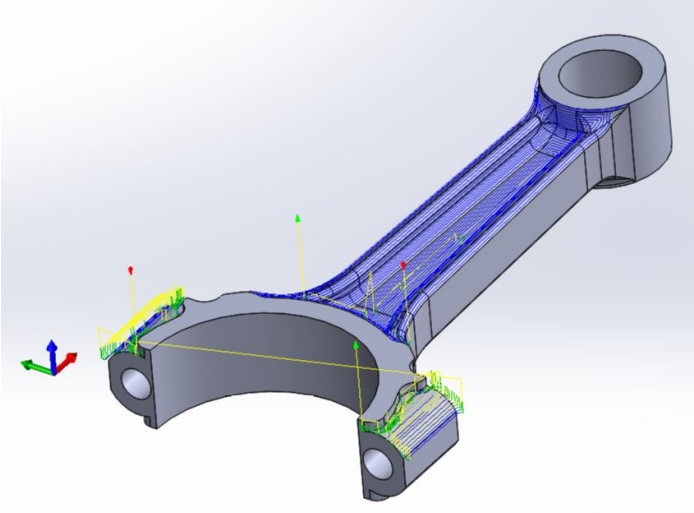

Figure 5.8: OP2 finishing path

\subsection{CNC Machining}

CNC machining included the aluminum soft jaw and a total of five composite connecting rods. The soft jaw geometry was derived from the negative of the connecting rod CAD, but neglected 3D pocketing or fillets of the I-beam geometry as these were unnecessary for providing ample side force to the composite OP1 geometry. The aluminum used was series 6061 which had vice grip bolt holes located on the two segments from a previous soft jaw design. This meant the only required cuts on the aluminum sections were facing operations to remove the prior geometry, and the OP1 rough negative pocketing. The completed aluminum soft jaw is shown in Figure 5.9. The parts were machined in the Cal Poly IME Haas Mini-mill. 


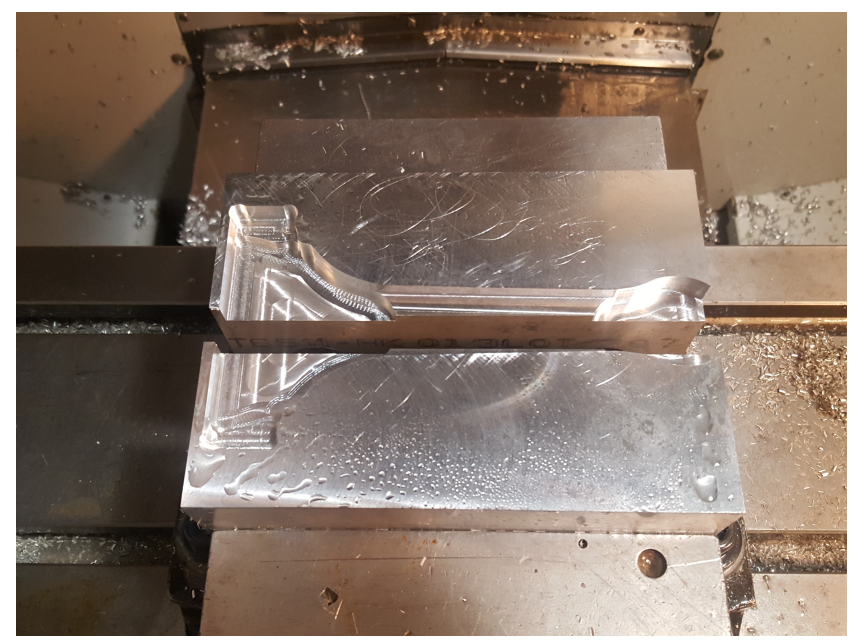

Figure 5.9: Aluminum soft jaw used to hold composite component for OP2

Because of limits with access to the Haas Mini-mill used for soft jaw machining it was decided to schedule composite cutting operations for the Haas TM-1 located in the Cal Poly Aero Hangar Machine Shop. This machine had heritage cutting carbon fiber parts so the process was pre-approved and made setup easy. The mill is pictured in Figure 5.10 below.

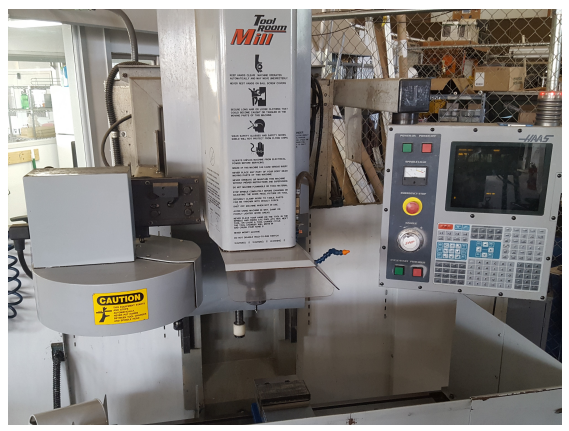

\section{Figure 5.10: Aero Hangar TM-1 Haas mill}

Personal protective equipment was acquired to ensure that a safe working environment was maintained. This gear included a dust mask, safety goggles, and gloves for part handling. As coolant had proved to be a significant source of difficulty in cleanup with the machinability tests conducted, a vacuum equipped with a HEPA filter was used to keep composite waste manageable. This proved to be an easy method for 
particulate control, while cooling (when necessary) was provided by spraying water from a squirt bottle onto the cutter. Occasionally the compression spiral cutter would begin to heat machined sections to the point where they smoked, at which point the program was paused to allow the material to cool, and the tool was sprayed with water.

Once the vice had been squared into the mill, a composite brick could be inserted into the grips and the home location set as established by the paths generated in HSM. Figure 5.11 shows the composite product after rough cuts were made, while Figure 5.12 exhibits the result after finishing passes marking the end of OP1.

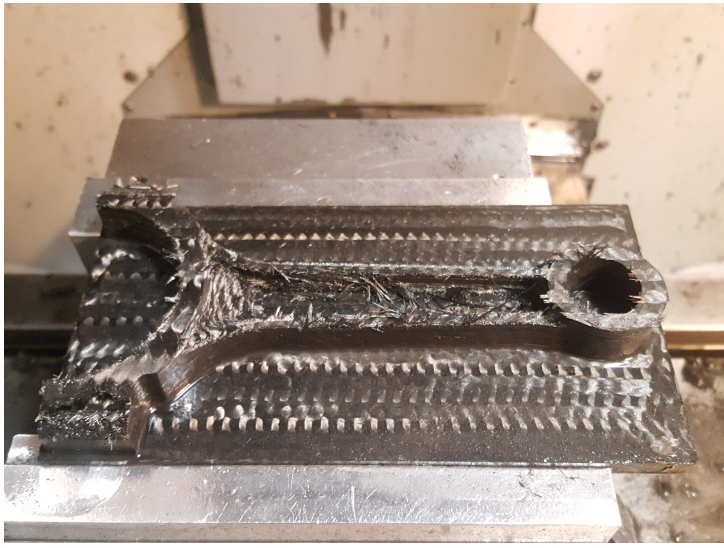

Figure 5.11: Completed OP1 roughing

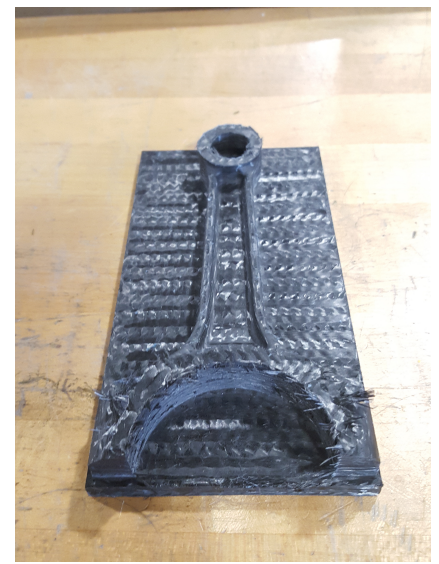

Figure 5.12: Completed OP1

At the completion of OP1 the composite part was removed from the vice and the soft jaw was bolted into place. The part could then be secured into the soft jaw. The home location was reset to the upper left corner of the aluminum jaw. The composite component approximately halfway through the roughing cuts of OP2 can be seen in Figure 5.13. 


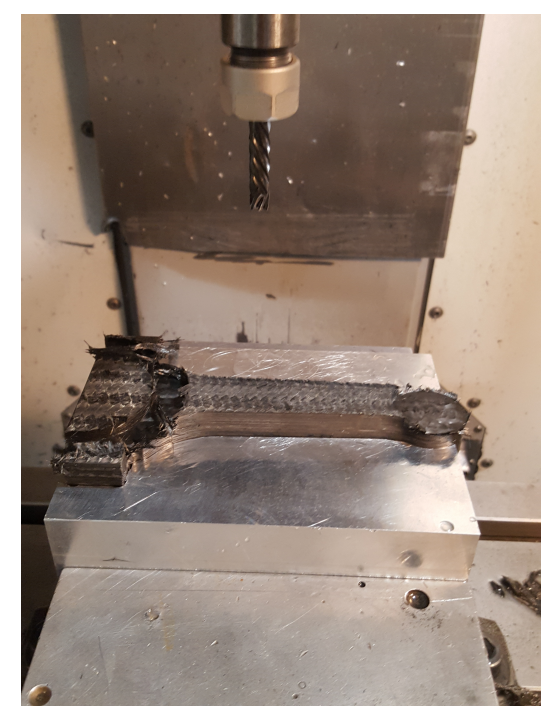

Figure 5.13: OP2 roughing

The first connecting rod which was machined to this point revealed a significant oversight in the original home location setting within the tool path generation. The depth at which the home had been set had not compensated for the height difference created by the negative impression of the soft jaw. Assuming a part depth equal to that of the OP1 roughing cuts resulted in cutting through the composite part as seen in Figure 5.14. Fortunately, the composite layup on which this occurred was the "weaker" orientation in compression of the woven bricks manufactured, and therefore was accepted as a failed test of the tool paths. This ensured that any mishaps in the program could be removed before machining the connecting rods critical to experimentation. 


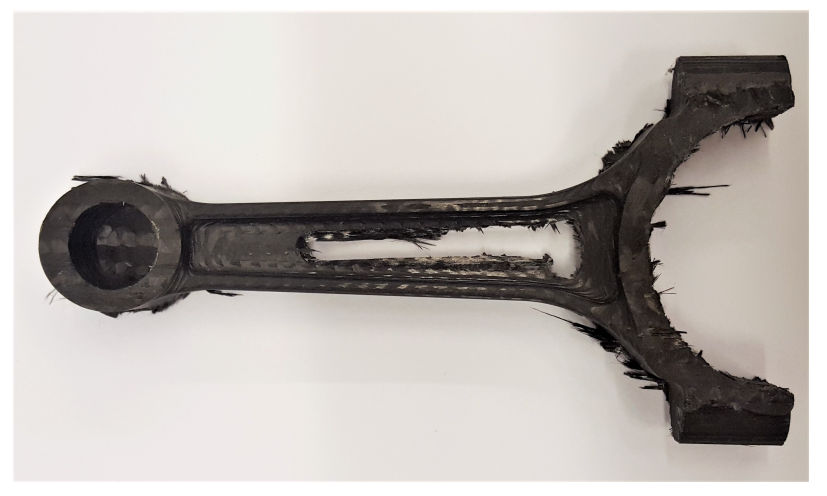

Figure 5.14: Failed machining attempt

After the error in home location was revised the remaining composite bricks were machined to the correct geometry. As exhibited by Figure 5.15 the finish achieved when machining was completed was imperfect. Fiber fraying at the edges of the part required some post processing. It was found these frayed edges were easy to remove with light sanding using 220 grit sandpaper. The remaining surfaces of the part were sanded with 320 grit sandpaper to remove any small steps and seams generated by tool passes, and ensure a continuous and smooth surface finish. The inside diameters of both the big and small ends of the connecting rods were sanded more aggressively to guarantee that contact surfaces would be flush with test fixtures.

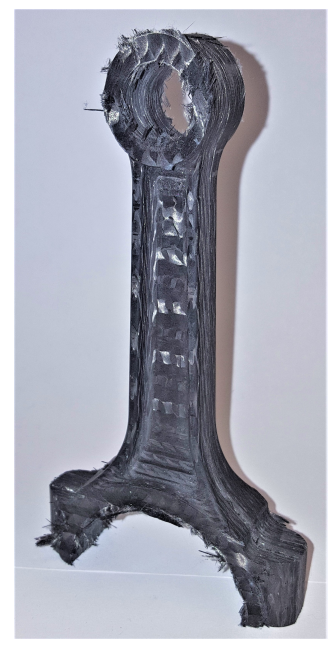

Figure 5.15: Machined connecting rod prior to cleanup 
Figures 5.16 and 5.17 exhibit finished examples of a woven fiber connecting rod and chopped fiber connecting rod respectively. The chopped fiber connecting rod surface finish was still subject to some small voiding, although less than the machinability test which had been run. However, the woven fiber still showed less voiding and a better final surface finish, reinforcing the decision made to focus on the HX42 in testing.

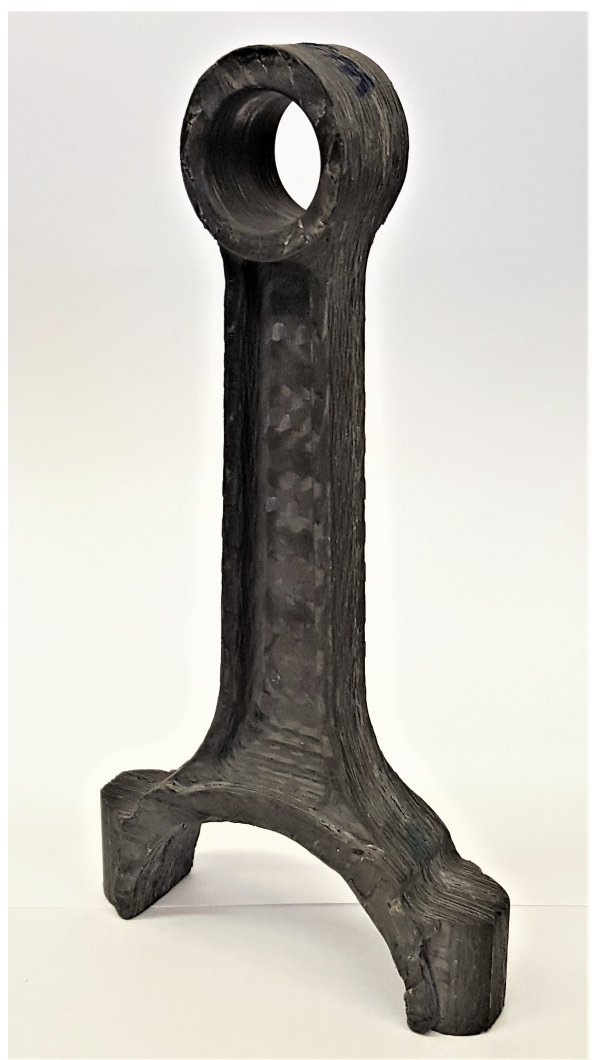

Figure 5.16: Cleaned woven rod

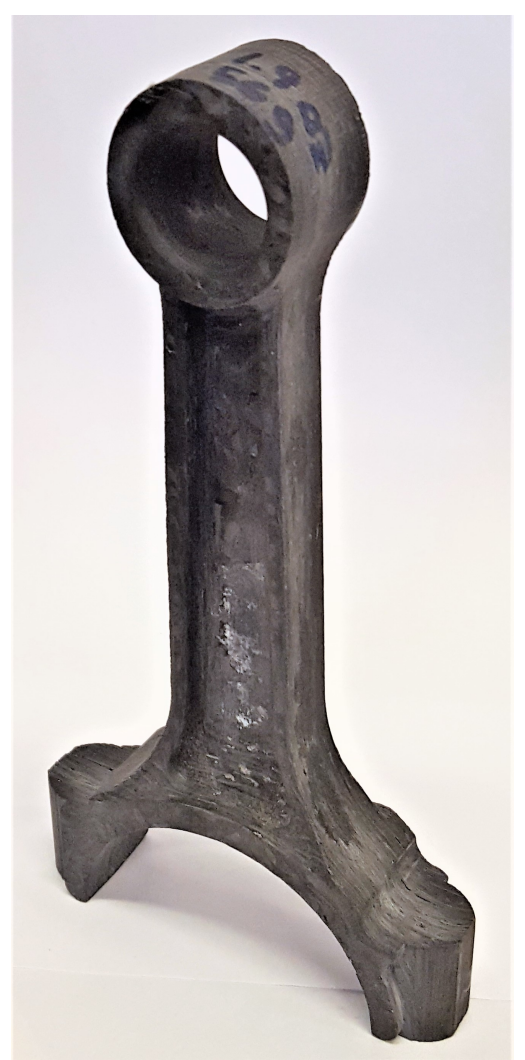
Figure 5.17: Cleaned chopped fiber
rod

\subsection{Experimental Testing and Results}

Prior to instrumenting the composite rods for testing, each rod was weighed on a digital scale to gather data for strength to weight calculation. The weights of the rods are presented in Table 5.1. 


\section{Table 5.1: Weight of experimental connecting rods in pounds}

\begin{tabular}{c|c|c|c|c} 
Steel Rod & Woven 1 & Woven 2 & Woven 3 & Chopped Fiber \\
\hline 0.7938 & 0.1438 & 0.1375 & 0.1375 & 0.1188
\end{tabular}

After weights of each rod were recorded, strain gauges were installed on each specimen. The gauges and the procedure used to apply them match that which was described in Section 3.4.1 for the material property characterization samples. The location of the gauge was set based on the location of interest asserted 2.5" below the center of the inner diameter of the small end inside the I-beam web. An example of an installed gauge on a composite rod is shown in Figure 5.18.

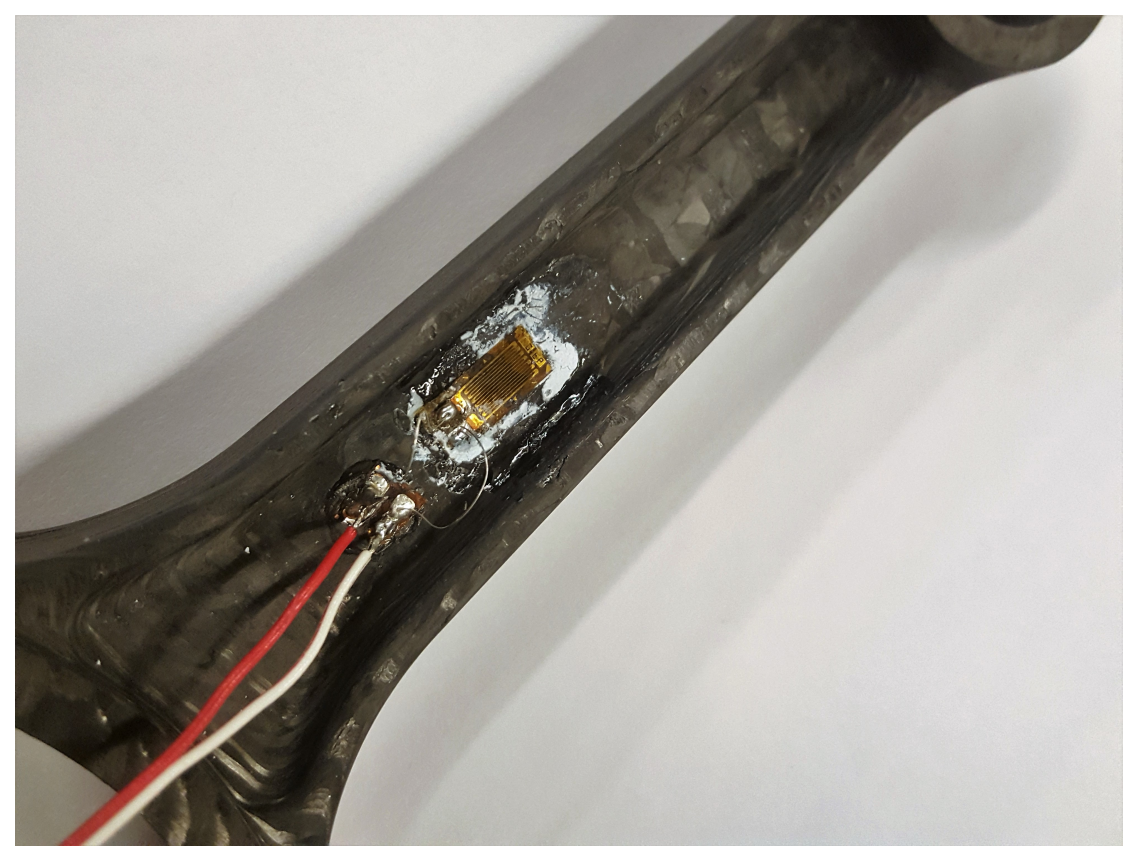

Figure 5.18: Strain gauge located on connecting rod

Each rod was tested using the same fixtures used for steel connecting rod testing. An example of a composite rod mounted on the fixtures and placed in the grips of the Instron 1331 machine can be seen in Figure 5.19. 


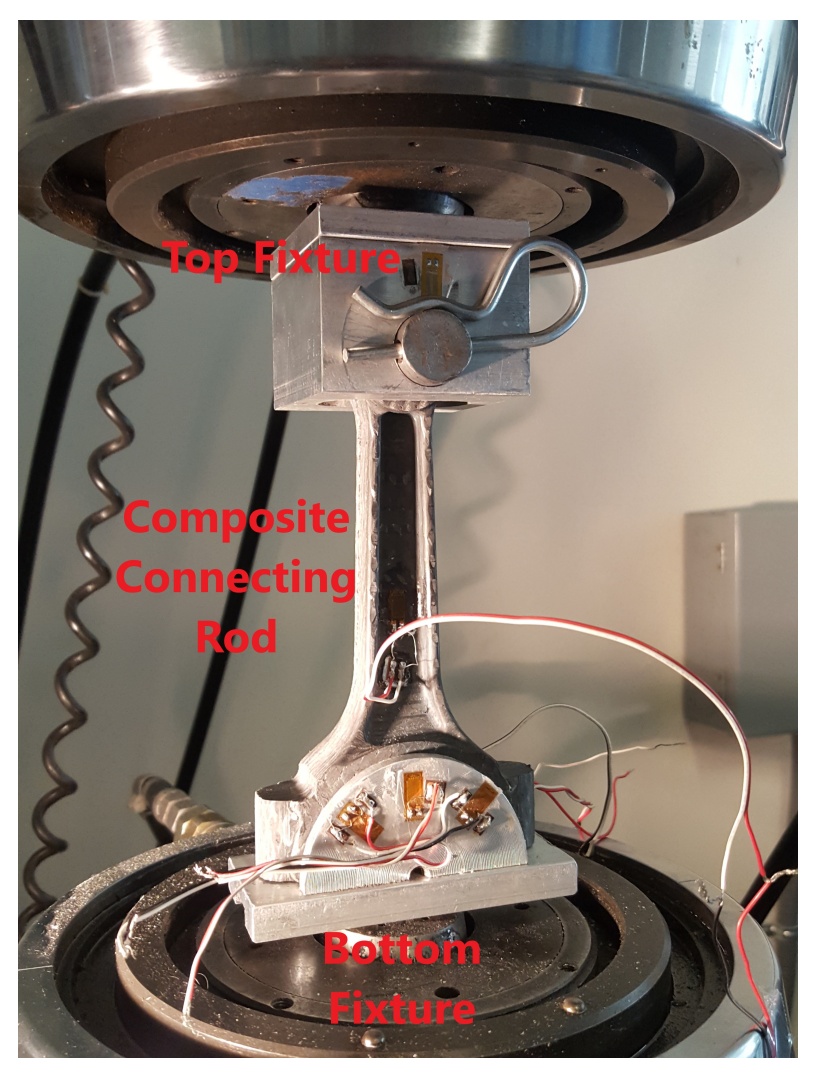

\section{Figure 5.19: Composite connecting rod experimental setup}

Prior to running destructive testing on the parts, each part was tested up to approximately $800 \mathrm{lbf}$ to ensure linearity in data and consistency between test samples. Compression was run at a rate of $0.0005 \mathrm{in} / \mathrm{min}$. Each composite connecting rod was run at minimum four times. The data for the pre-failure check conducted is available in Figure 5.20. Note that while woven rods 1 and 3 shows excellent consistency in results between each other, rod 2 exhibits a lower slope. To troubleshoot this the strain gauge was reapplied in the event it had not been located correctly the first time. However, the results remained inconsistent pointing to an issue within that specimen potentially arising from manufacturing defects. The overall expected results remained true with the woven composite outperforming the chopped fiber composite. 


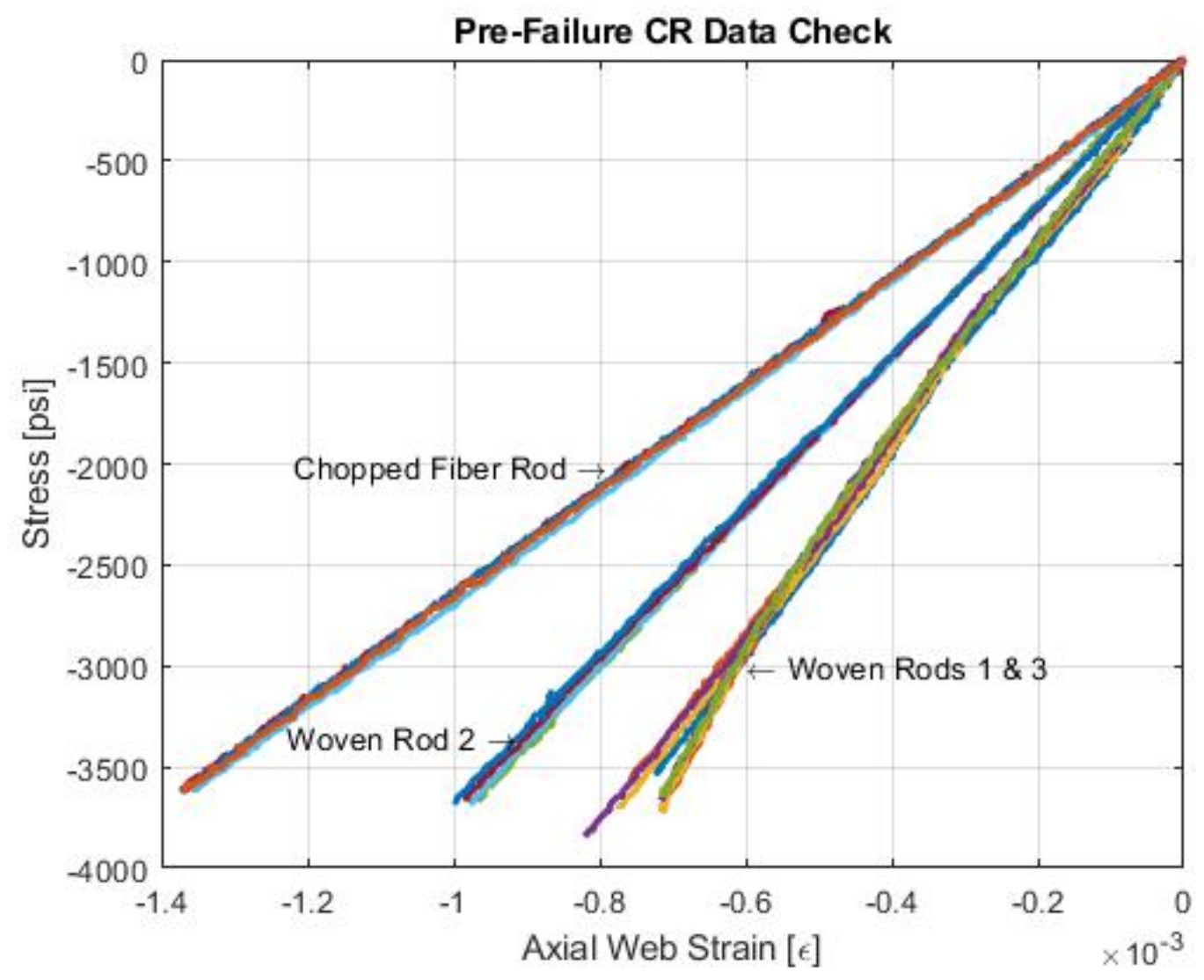

Figure 5.20: Data check conducted on all rods

After the rods were checked in the preliminary test case woven rod 3 was selected to be tested destructively as it showed a consistent elastic behavior with woven rod 1, but a lower weight. The chopped fiber rod was also tested to failure. The data recorded from destructive testing is seen in Figure 5.21 


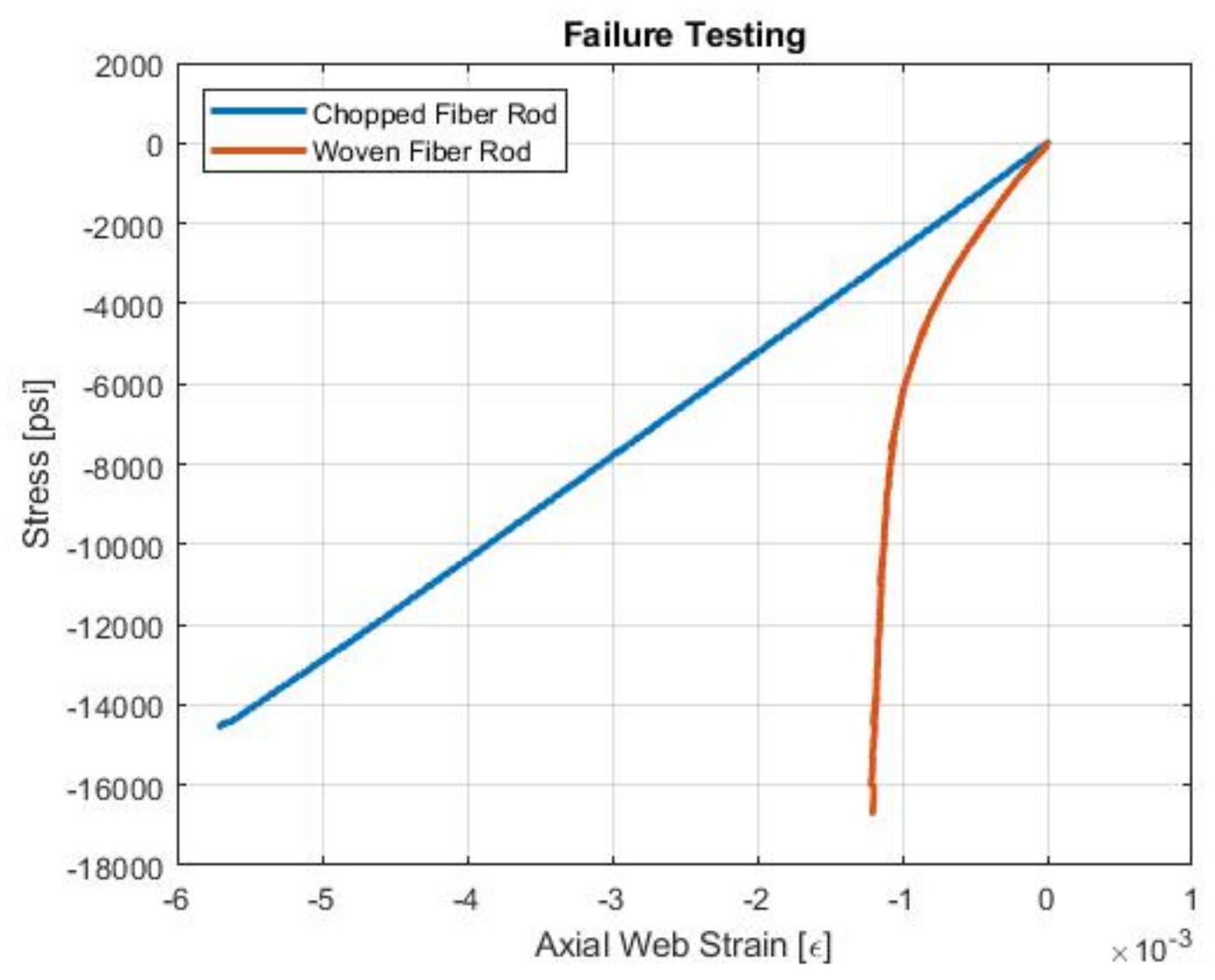

Figure 5.21: Failure test data

The data taken from destructive testing confirmed the expected results, with some deviation in the behavior of the reaction of the woven fiber to higher loading. The ultimate compressive loads of the woven and chopped fiber rods were about 3700 lbf and 3235 lbf respectively. This aligns with the trend seen in the failure loads experienced in material property testing. The chopped fiber rod exhibited clean linear behavior, while the woven rod deviated significantly from its originally linear behavior. Although a linear trend would have been preferable, the test was continued out of fears of having induced micro-fractures. Therefore the test was allowed to run to failure. This increase could be explained by gradual compaction of the matrix which would result in a stiffness increase as load increased, or a settling into the test fixture resulting in a true recording of the materials behavior. This would result in 
the gradual "knee" where the original linear region transitions into a higher slope. The secondary linear region dominates the majority of high loading past $1000 \mathrm{lbf}$ until the ultimate failure of the specimen.

The failure modes of each of the rods differed slightly based on the material constituting the specimen, but the regions of failure remained consistent. These failures were the same as the common failure modes observed from material characterization testing. The chopped fiber connecting rod failure is depicted in Figure 5.22.

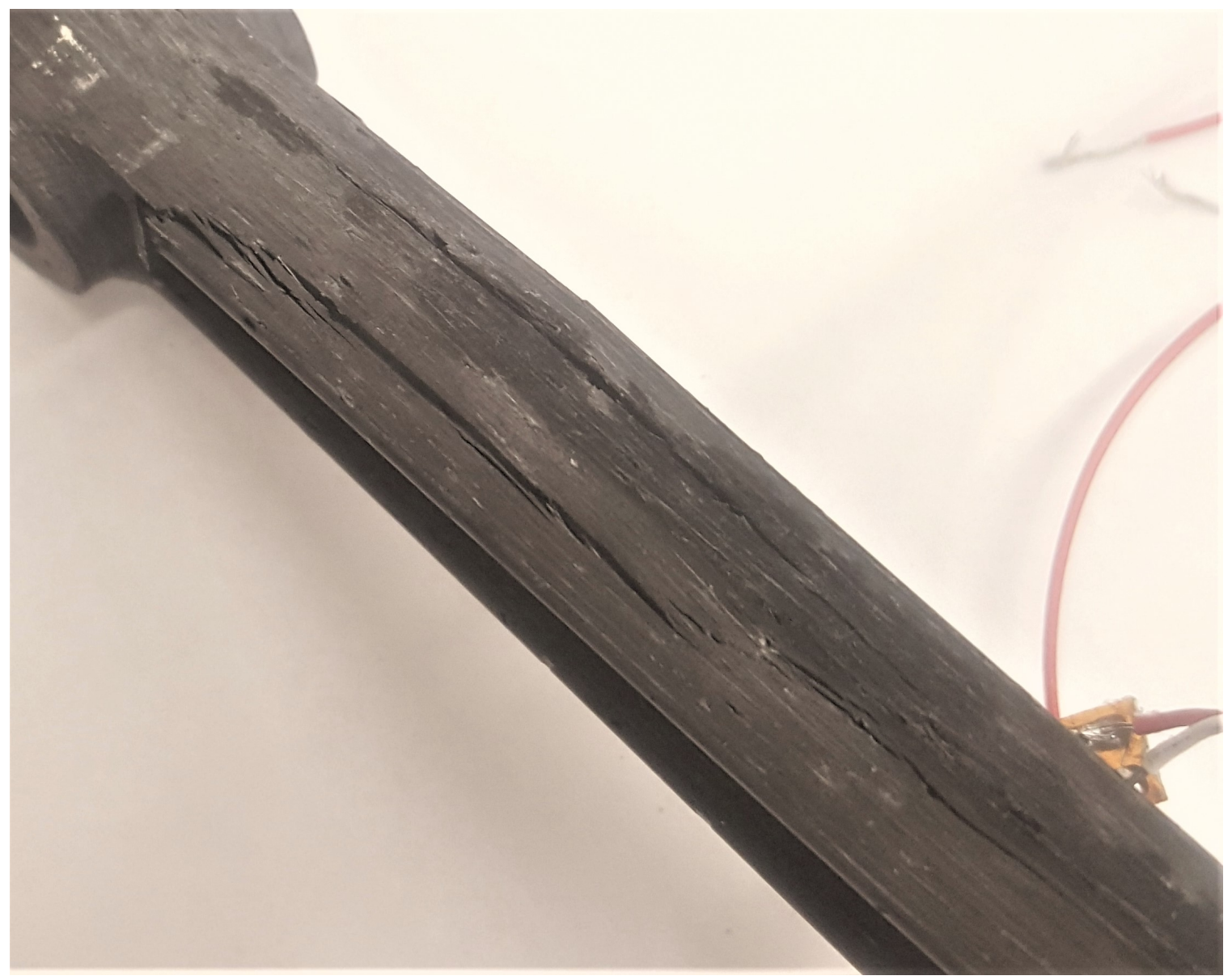

Figure 5.22: Flange failure of chopped fiber connecting rod

As presented in the image above the chopped fiber only failed on a single side of the I-beam geometry. This could imply bending or buckling in the specimen, or more likely manufacturing or layup differences in the failed flange from the opposite face. 
Delamination occurred between the flange layers and the primary web. Fractures formed which travel the axis of the part exhibiting that the stress was being carried primarily along the inside fillet of the I-beam.

The failure of the woven connecting rod tested is shown in Figures 5.23 and 5.24. Unlike its chopped fiber counterpart the failure region was far more localized. Failures exhibited in Figure 5.23 show delamination not limited to only the separation of the flange plies from the primary web. This supports the theory that manufacturing defects most likely dominated the failure mode of the chopped fiber rod. Fracture occurred in a "V" shape proving that the load was distributed through the cross section rather than being concentrated in the axial direction along the flanges. The opposite flange face shown in Figure 5.24 exhibits delamination more similar to that of the chopped fiber rod. The assymmetry of the failure mode could imply bending in the specimen again, or any unique discontinuities imposed by differences in fiber orientation from the resultant machined geometry.

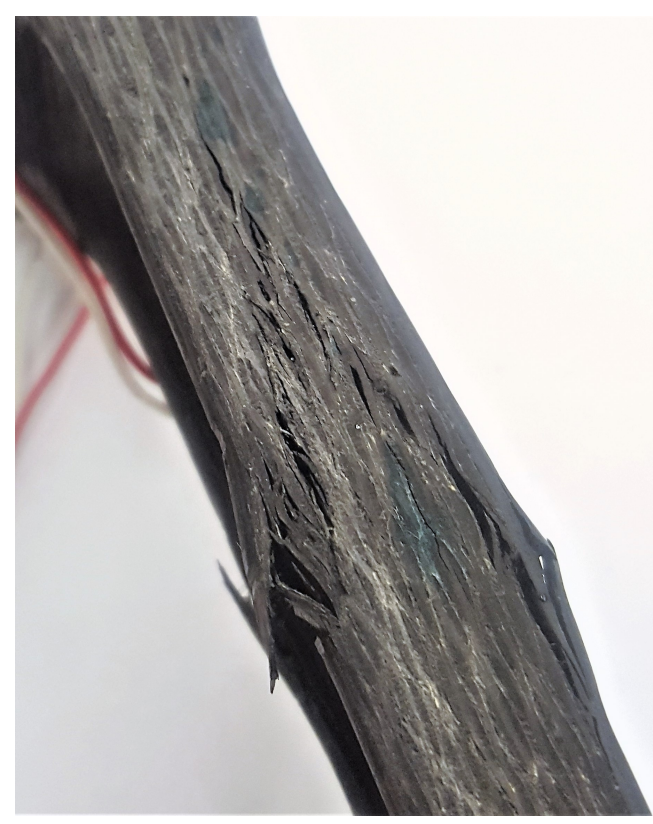

Figure 5.23: Woven rod flange failure

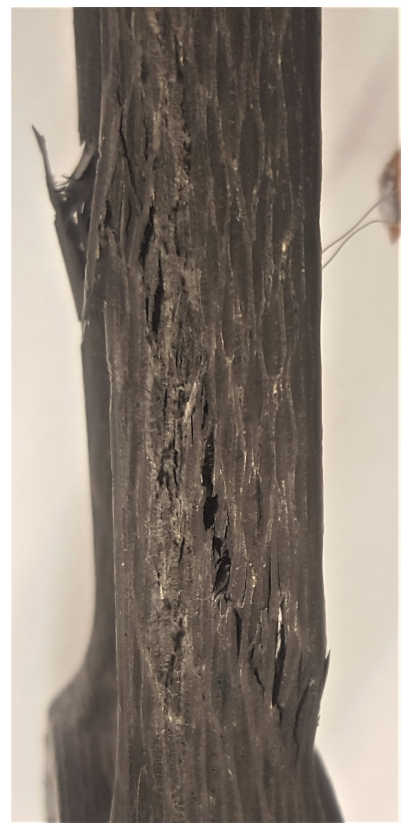

Figure 5.24: Woven rod opposite flange 
Chapter 6

\section{RESULTS AND DISCUSSION}

The primary objective of testing the composite connecting rods was to evaluate the strength to weight ratio compared with that achieved by a steel component. The composite rods exhibited a total weight of 15\%-17\% compared to the steel alternative. Table 6.1 provides the calculated strength to weight ratios of the tested rods and the steel counterpart. The table provides the calculated strength to weight ratio

of each rod using a design load of $4900 \mathrm{lbf}$ as referenced from Shenoy (Shenoy and Fatemi, 2006). However, it is important to note that the design load is higher than the ultimate strengths recorded from both material characterization and destructive testing.

\begin{tabular}{|c|c|c|}
\hline Woven Rod & Chopped Fiber Rod & Steel Rod \\
\hline 35636.36 & 41263.16 & 6173.23 \\
\hline
\end{tabular}

As this metric is reliant on a theoretical design value, it favors the lightest component (the chopped fiber rod). However, it is important to recognize that the chopped fiber rod in experimental testing exhibited a lower ultimate strength than the woven fiber rod, with only a $13 \%$ difference in weight between the two components. Although the chopped fiber rod exhibits the best theoretical strength to weight ratio, the difficulties associated with working with the material make it a less reliable solution in the context of this study.

The woven composite rod offers a significant source of weight reduction when compared to the traditional steel component. The ultimate strength recorded from destructive testing is approximately $29 \%$ less than the required theoretical design 
load, although this load creates a large factor of safety on the component. Even when the ultimate strengths of the composite rods are applied in strength to weight ratio and compared with the metal component ratio using the steel's ultimate strength (approximately 80,000 psi), the composite rods show a significant advantage. These metrics are presented in Table 6.2.

Table 6.2: Failure load strength to weight ratios of rods
\begin{tabular}{c|c|c} 
Woven Rod & Chopped Fiber Rod & Steel Rod \\
\hline 26909.10 & 27242.11 & 22374.80
\end{tabular}

Once again the difference in weight of the composite components drive their respective scores, but both outdo the steel connecting rod. One interesting evaluation to consider in the difference of the material's modulus exhibited in the connecting rod geometry. Figure 6.1 exhibits the failure data of the composite rods tested, as well as the extrapolated slope from steel connecting rod experimental data. 


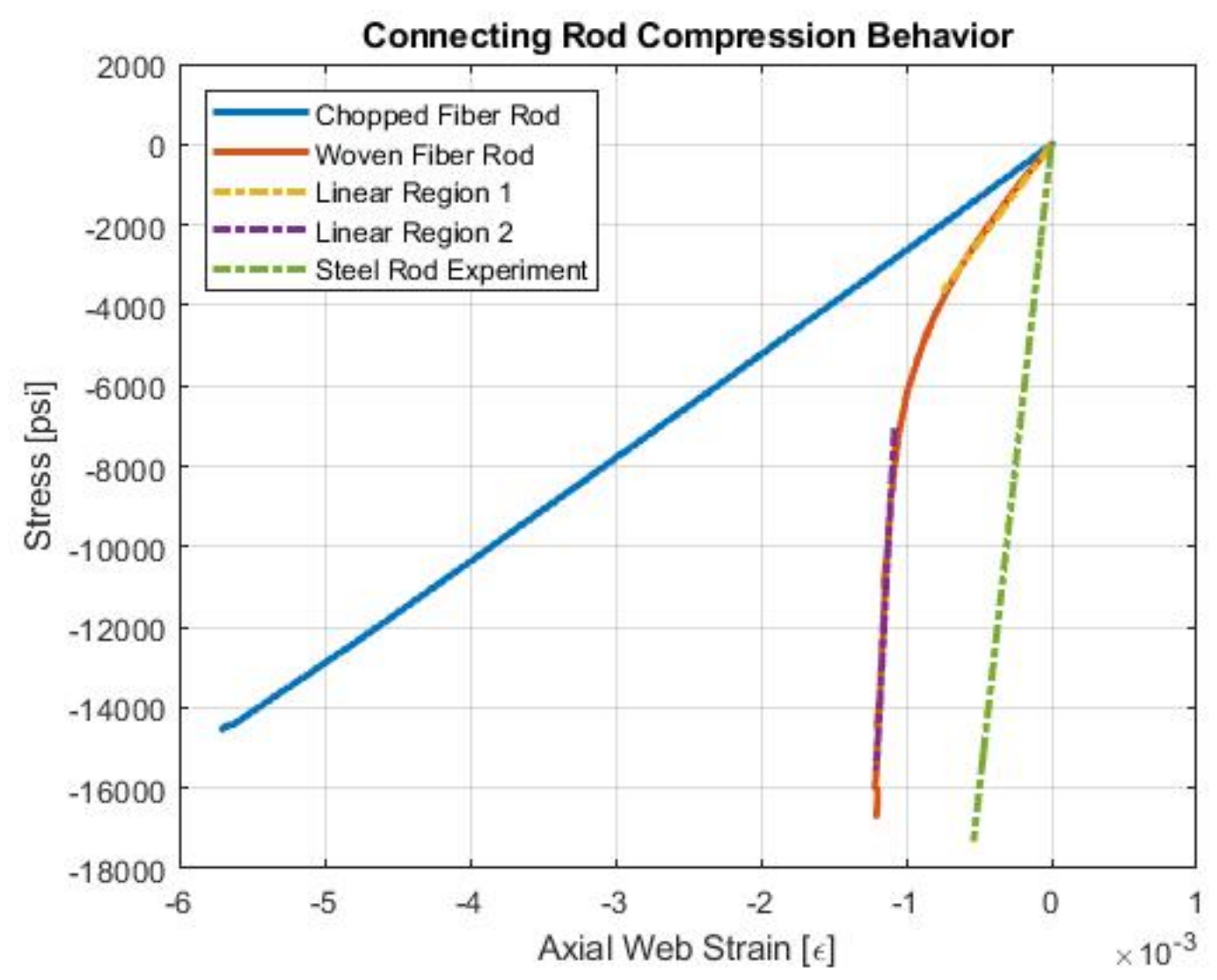

Figure 6.1: Comparison of linear regions of connecting rods tested

Most notable is the significant increase in stiffness of the woven material visible in "Linear Region 2". The steel rod exhibited an average elastic modulus of 32.28 Msi. This could explain the deviation from theory when examining experimental results found with the steel component as the assumed modulus was 29 Msi. The woven rod exhibited an initial elastic behavior of $4.88 \mathrm{Msi}$, which deviated from the experimental results obtained in ASTM testing. This was most likely due to the increased pressure applied by the compression mold process versus the hot press method used for specimen manufacturing. However, after the trend bends it straightens again and the woven rod's elastic behavior jumps an order of magnitude to $68.1 \mathrm{Msi}$. This could be representative of either hardening in the material as it undergoes compression, or implies additional available strength from an increased compaction of material during 
cure. The chopped fiber exhibited a modulus of 2.65 Msi which compared to 2.58 in Table 3.6 points to original data being correct. However, with the differences in void content (there being far less in the connecting rod), this simply confirms that the data from material testing was void. The chopped fiber still exhibited less value than the woven material, most likely as a result of inadequate pressure to the material during curing therefore not maximizing the material's strength or stiffness potential. 
Chapter 7

UNIDIRECTIONAL COMPOSITE I-BEAM STUDY

\subsection{Overview}

Modeling the machined composite geometry in Abaqus produced a number of errors relative to the experimental data recorded. Instead, composite FEA was explored for a study on an I-beam geometry composed of a UD material. Composite FEA methods were verified using a problem with a known solution, then applied to the simplified I-beam with layups capable of meeting the design load of a typical connecting rod.

\subsection{Composite FEA Test Case}

In order to ensure that the composite layup tool within Abaqus was being utilized properly a verification problem with a known solution was tested. The case is an adaptation of problem 6.10 from Analysis and Performance of Fiber Composites (Agarwal et al., 2018). The problem statement used is provided as follows:

A balanced cross-ply laminate possessing midplane symmetry is made up of laminae having the following properties:

$$
\begin{array}{cc}
E_{1}=15 G P a & G_{12}=3 G P a \\
E_{2}=6 G P a & \nu_{12}=0.5
\end{array}
$$

The laminate is subjected to a normal axial stress of $15 \mathrm{MPa}$. Calculate the normal stresses in the $0^{\circ}$ and $90^{\circ}$ plies.

Based on the methods in the book, the problems expectation was that classical lamination theory (CLT) would be applied. In order to capture this expectation a tensile test coupon was modeled as a shell in Abaqus according to the ASTM-3039 
specifications for tensile testing of a composite (ASTM, 2016a). This would allow for an element centered on the gauge length to act as the theoretical plate element which the problem would solve for in theory. The expected results based on Matlab calculation using CLT are tabulated in Table 7.1.

\begin{tabular}{|c|c|c|}
\hline & $0^{\circ} \mathrm{Ply}$ & $90^{\circ} \mathrm{Ply}$ \\
\hline$\sigma_{11}$ & $22 \mathrm{MPa}$ & $8 \mathrm{MPa}$ \\
\hline$\sigma_{22}$ & $2 \mathrm{MPa}$ & $-2 \mathrm{MPa}$ \\
\hline
\end{tabular}

After the geometry was modeled the edges were seed to a global seed size of 0.1. This allowed for three elements to span the width of the specimen and a center element to be used for data retrieval. The meshed shell plane is shown in Figure 7.1. Because of the simplicity of the problem and resolution needed for understanding if the set up had been executed properly, a mesh convergence study was considered unnecessary.

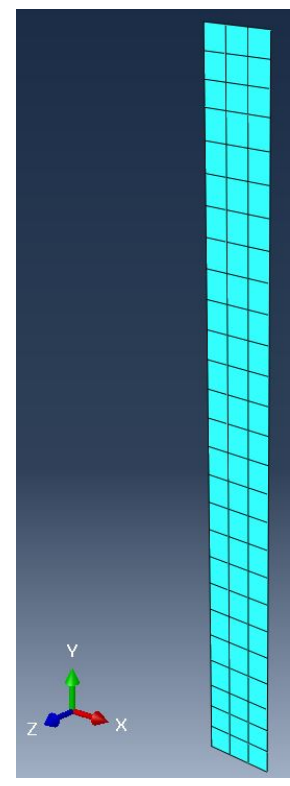

Figure 7.1: Sample problem mesh

Boundary conditions applied modeled what the physical situation would entail 
should a coupon be tested in a tensile tester. Each of the ends of the specimen were partitioned equally to simulate tabbing areas. The bottom tab was constrained to be fully encastre, meaning all DOF were maintained as zero displacement and rotation. The upper tab was constrained such that it could only translate in the axial direction. A line load of $15 \mathrm{MPa}$ per unit length (the same as the unit width of the part) was applied at the upper edge of the shell. These conditions can all be seen in Figure 7.2.

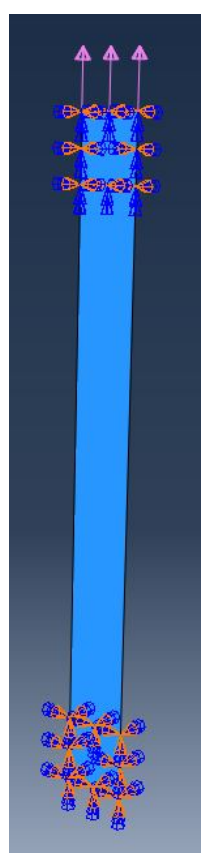

\section{Figure 7.2: Boundary conditions and load applied}

Material properties were input for a single lamina as provided by the problem. $G_{13}$ and $G_{23}$ were both assumed to be $1 \mathrm{GPa}$ as there was not enough information to calculate them. The laminate schedule of

$$
[0 / 90]_{s}
$$

was then applied to the composite layup manager, which allowed for the region, material thickness, and rotation angle to be set for each ply. The ply thickness was modeled as 0.25 as this is just a relative value and acts as a ratio of ply thicknesses to each other. The coordinate system of the layup was defined using a discrete coordinate 
definition. The normal of the layup, defining the rotation axis for ply orientation, was set to perpendicular to the specimen area. The primary axis was set to one of the vertical edges of the specimen and in the same direction as the global positive y-axis. The resulting ply stack plot from the symmetric layup generated is available in Figure 7.3.

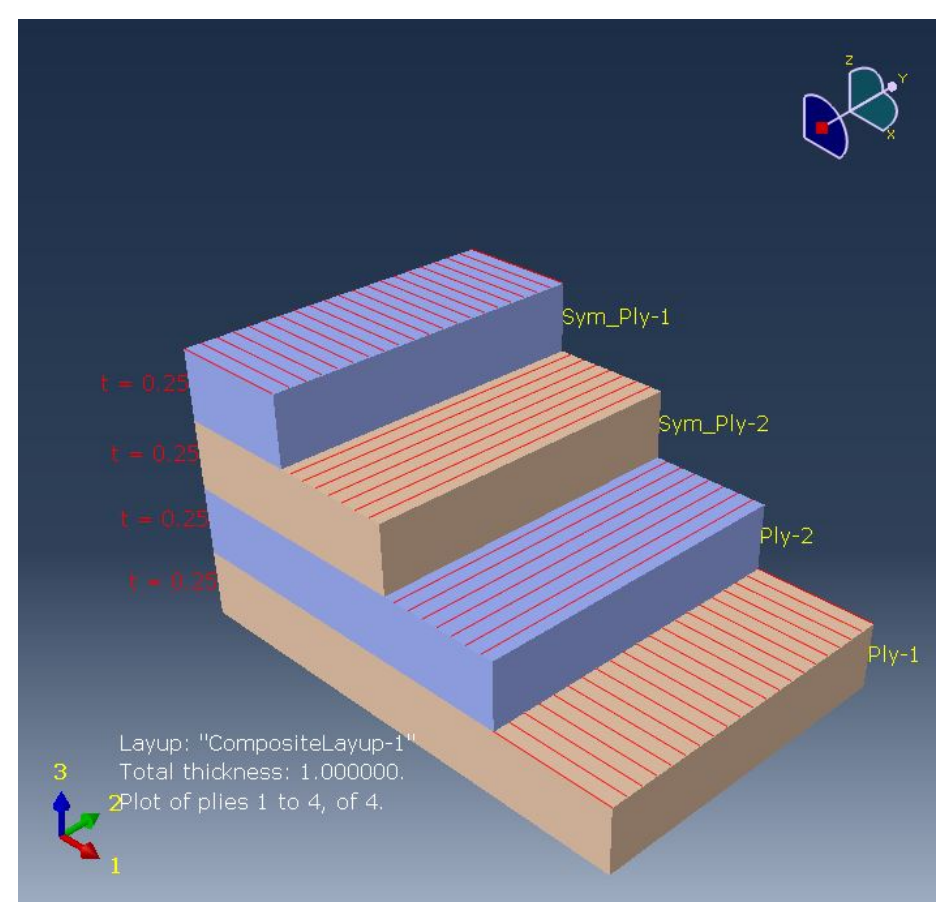

Figure 7.3: Ply stack plot of laminate

The solutions from the center element of the test sample are provided graphically in Figure 7.4. This plot shows the stress state through the thickness of the symmetric test specimen. S11 is the normal stress in the 1 direction, or loading direction, and S22 is the normal stress in the 2, or transverse direction. 


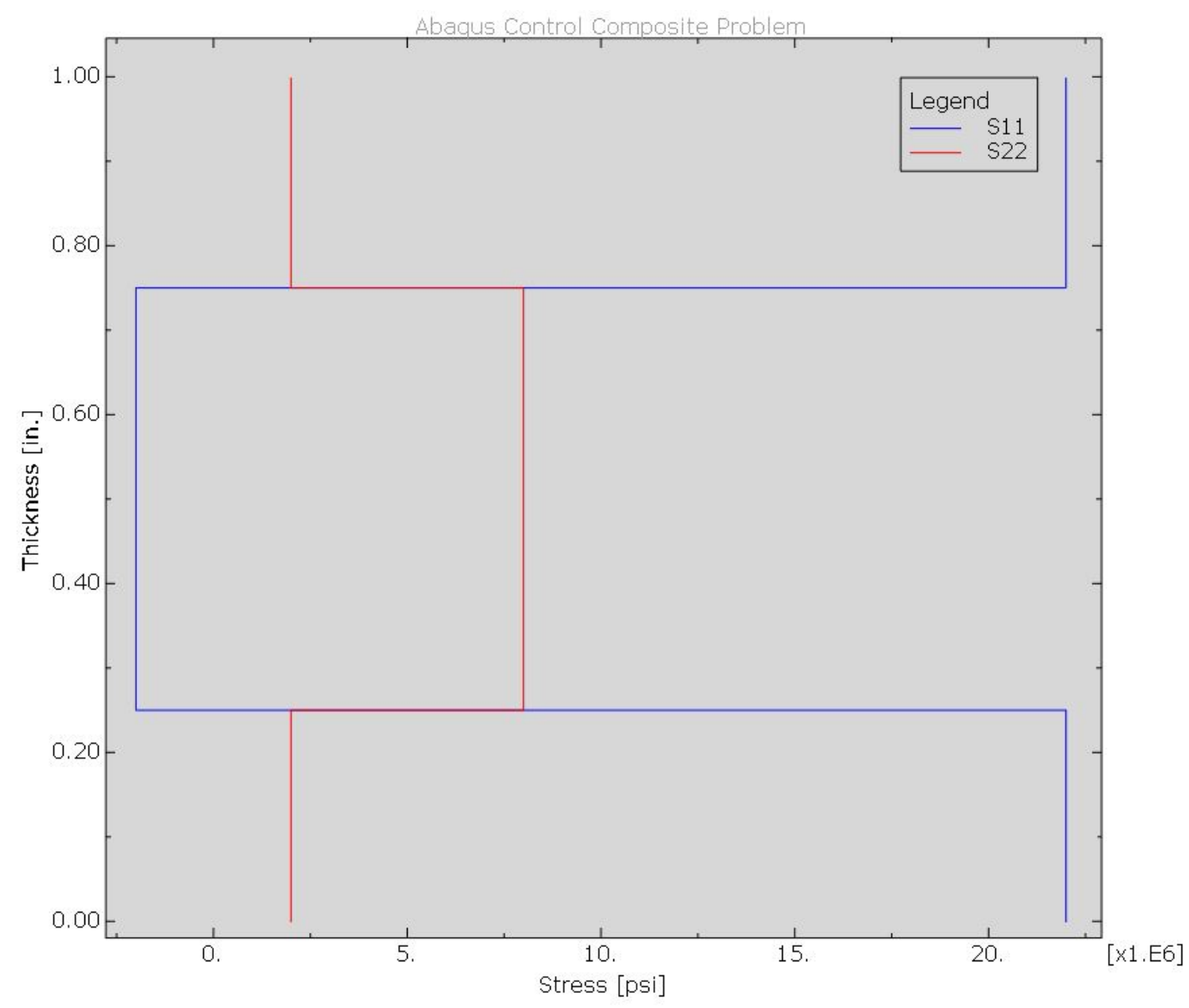

Figure 7.4: Normal stresses through laminate thickness of 4 ply simulated specimen

The simulation showed a $0 \%$ error from the Matlab results obtained, affirming that the case had been setup correctly. This provided confidence in ability to use the composite layup manager in Abaqus and run the UD I-beam geometry.

\subsection{Unidirectional Composite I-beam}

In the interest of approaching a theoretical design problem a unidirectional composite I-beam was proposed to quantify the feasibility of designing for the typical design load case of a steel connecting rod. The requirement of the design load used was derived from the maximum gas pressure of 37.3 bar provided in Shenoy et. al (Shenoy and 
Fatemi, 2006) which provides a force resulting in significant over design of the part. The objective of the study was to select a UD composite material and formulate layups for the web and flange areas separately, then evaluate the weight savings from the resultant design. The orientation of fibers was selected to allow for the compression load to be carried without reaching the ultimate stress of the composite as provided by the manufacturer, while still including plies which would handle bending loads which were not modeled. Because the taper of the steel connecting rod I-beam is so gradual, as shown in Figure 7.5, the geometry was simplified to represent a straightened geometry.

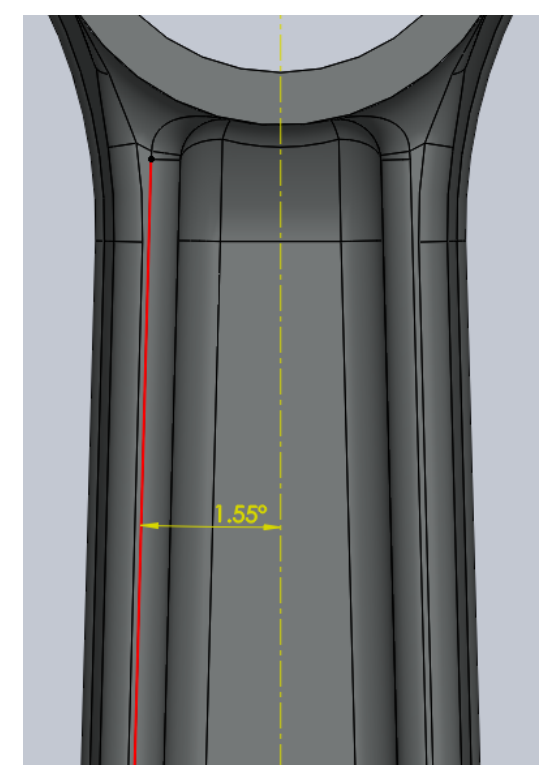

\section{Figure 7.5: Actual taper angle of I-beam geometry}

The material selected for this simulation was a Toray 2510 P707AG-15 Unidirectional carbon fiber-epoxy prepreg system (Toray, n.d.). This material had prior heritage being used in the labs on campus and therefore provided a familiar profile to work from. The "I" geometry was derived from the extents of the cross section from the location of interest being used on the steel connecting rod in experimental testing. From this thickness values of the laminates for the web and flanges were 
derived from an expected cured ply thickness of 0.006 inches. The dimensions of the resulting cross section are provided in Figure 7.6, with dimensions in red being those driven by ply thickness. Based on the desired thicknesses the web region required 16 ply while the flanges would each have 24 ply. The $0^{\circ}$ direction was established as the y-axis running the axial length of the geometry.

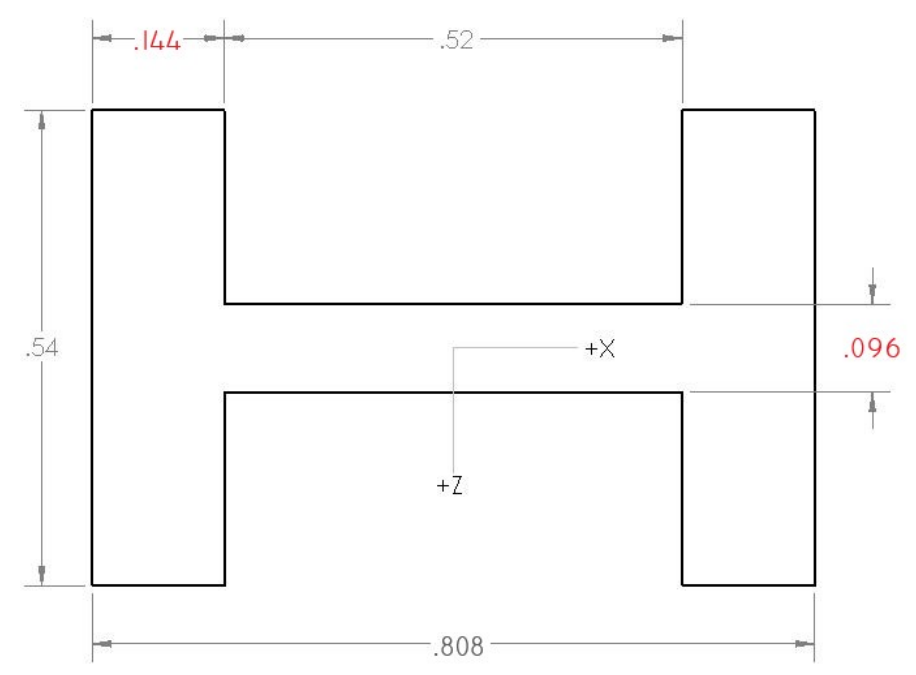

Figure 7.6: Simplified "I" geometry applied in Abaqus

The cross section was drawn in Abaqus using lines which could be extruded into shell planes. An extrusion length of 2.5 inches was used. The shells were then assigned thicknesses individually, as well as offsets to ensure the modeled thickness and direction was properly captured. The shell geometry is exhibited in Figure 7.7, while the same model with the thicknesses rendered to verify offset direction is shown in Figure 7.8. 


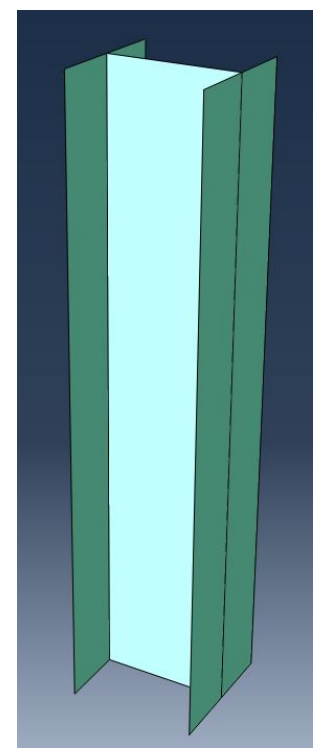

Figure 7.7: Shell I-beam

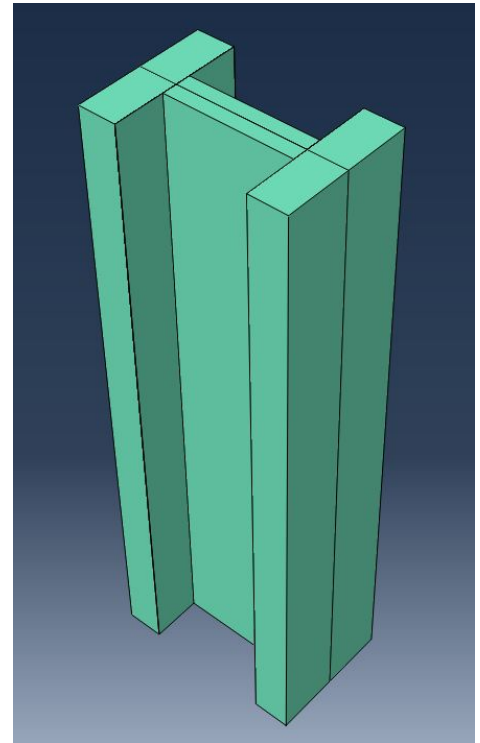

Figure 7.8: Shell geometry with thickness rendered

The model was then constrained based on the constraints of compression testing, with the bottom end of the extrusion being fully constrained in all DOF. A line load of $-3045 \mathrm{lbf} /$ in was applied at the upper surface of the geometry to capture the expected distributed load derived from a total design force of 4872 lbf. The conditions applied are visible in Figure 7.9.

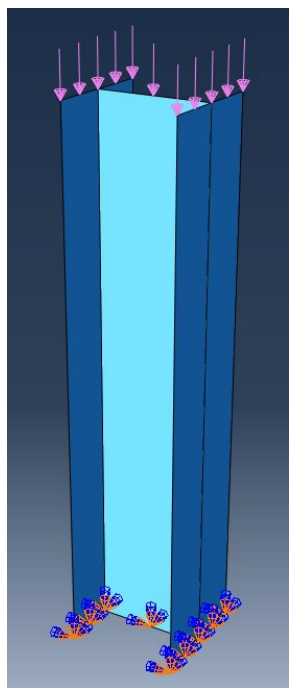

Figure 7.9: Load and boundary conditions on I-beam 
After the physical scenario was properly modeled, a composite material was established with the material properties listed in Table 7.2. These were obtained from the material data sheet which provided compressive moduli for both the $0^{\circ}$ and $90^{\circ}$ orientations, as well as poisson's ratio and in-plane shear modulus. The out of plane shear moduli were assumed to be generalized epoxy values and were obtained from Table 3.4 in Mechanics of Composite Materials (Kaw, 2006).

Table 7.2: Material properties applied to UD composite

\begin{tabular}{c|c|c|c|c|c}
$\mathbf{E}_{1}$ & $\mathbf{E}_{2}$ & $\nu_{12}$ & $\mathbf{G}_{12}$ & $\mathbf{G}_{13}$ & $\mathbf{G}_{23}$ \\
\hline 16.3 Msi & $1.23 \mathrm{Msi}$ & 0.31 & $0.61 \mathrm{Msi}$ & $0.1897 \mathrm{Msi}$ & $0.1897 \mathrm{Msi}$
\end{tabular}

Laminates with all $0^{\circ}$ plies were modeled for all sections of the geometry. This served as a mechanism by which the part could be meshed and a mesh convergence study be conducted. S8R5 elements were applied to the model as shell elements are required when evaluating thin composite laminates for accurate results and model compatibility. Ultimately a seed size of 0.025 was elected as increasing the number of nodes further had sever impacts on computation time (approximately a $400 \%$ increase) with negligible change to results. The meshed geometry and convergence study are shown in Figures 7.10 and 7.11 respectively.

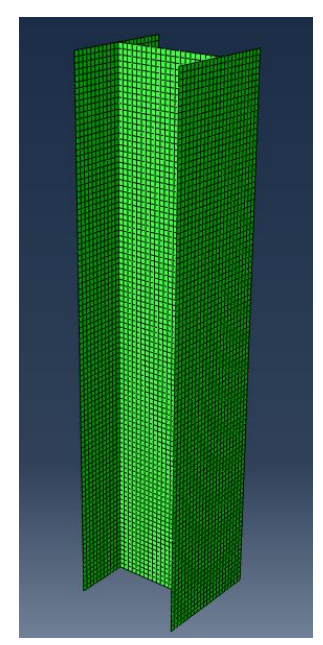

Figure 7.10: Meshed shell I-beam

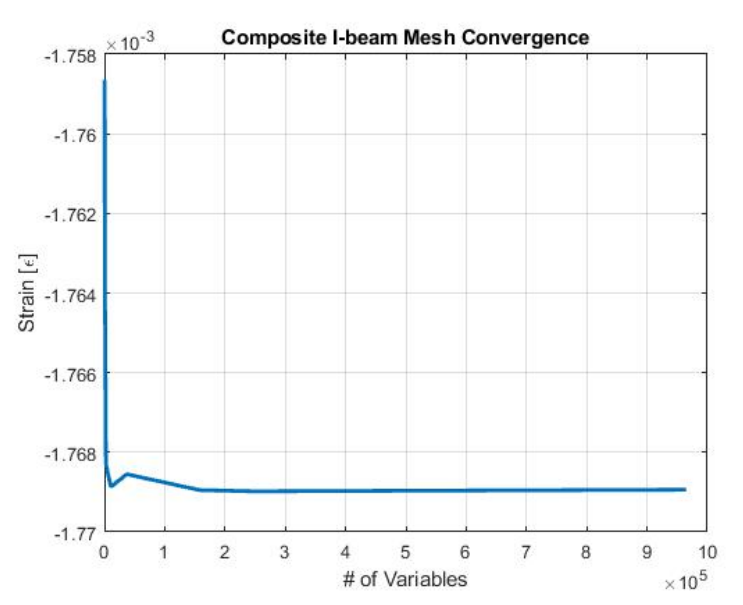

Figure 7.11: I-beam mesh convergence study 
Using the established material profile the composite layup manager was used to conduct iterations of laminate schedules for each section of the geometry. It was asserted that the layup schedule should remain symmetric as deviation from this would induce curvature into the flat plates should the concept ever be manufactured. Layup schedules were experimented with until results showed that both the web and flange areas experienced stresses under the quoted compressive strengths of the material. This meant that the dominant orientation required was $0^{\circ}$, but plies of $\pm 15^{\circ}, \pm 30^{\circ}$, and $\pm 60^{\circ}$ were included to account for bending and non-axial load cases. When the stresses measured at the center nodes of each face each came within the required envelope the laminate designs were considered successful. The final layup schedule of the web laminate was:

$$
[0 / 30 /-30 / 0 / 0 / 0 / 0 / 0]_{s}
$$

The final layup schedule of the flange laminates was:

$$
[15 /-15 / 0 / 60 /-60 / 0 / 0 / 0 / 0 / 0 / 0 / 0]_{s}
$$

The ply stack plots for the web and flange are shown in Figures 7.12 and 7.13 with the material coordinate system established in the bottom left hand corner.

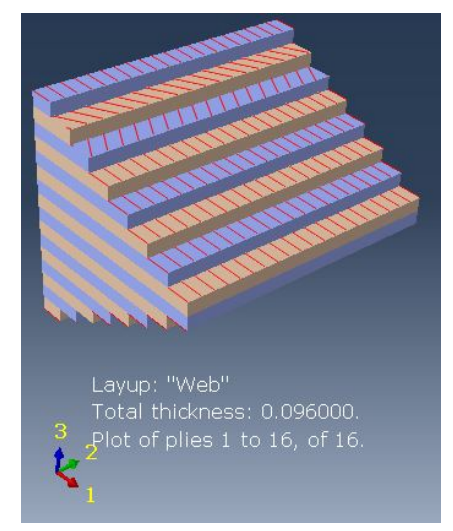

Figure 7.12: Web laminate ply stack plot

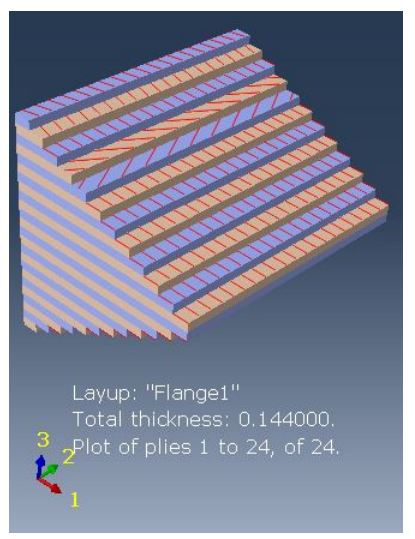

Figure 7.13: Flange laminate ply stack plot 
The results of the simulation run are shown as stress contour plots for the outermost $0^{\circ}$ ply of each laminate. Figure 7.14 shows the stress contour in the y-axis, or axial direction of the I-beam of the stress acting in the aforementioned plies reported in the global coordinate system.

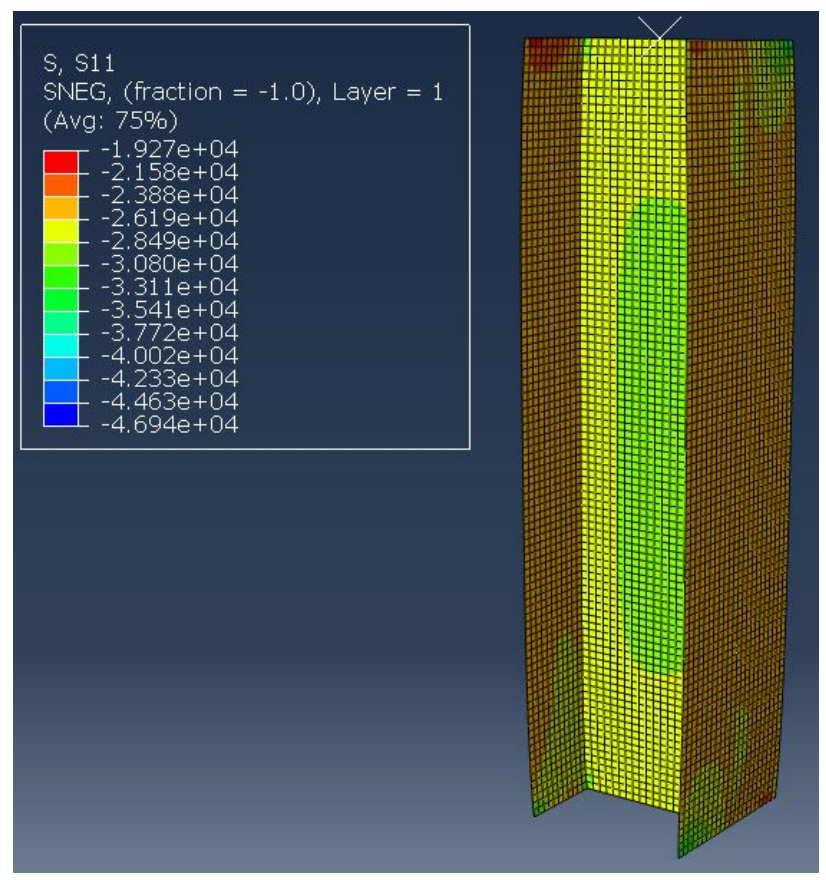

Figure 7.14: Axial stress results in $0^{\circ}$ ply of laminates

To evaluate the feasibility of each laminate iteration conducted, the stresses through the thickness of the web and flanges were plotted. If values exceeded the ultimate strengths of the material in compression provided by Toray a new layup schedule was examined. The final stress profiles for the web and flange are shown in Figures 7.15 and 7.16 respectively. S11 is the normal stress in the 1 direction, or loading direction, and S22 is the normal stress in the 2, or transverse direction. S12 is the shear stress in the laminate coordinate system. The maximum compressive stress in the any direction did not exceed the worst case failure strength of $28.8 \mathrm{ksi}$ quoted by Toray, showing that the layup schedule was successful. 


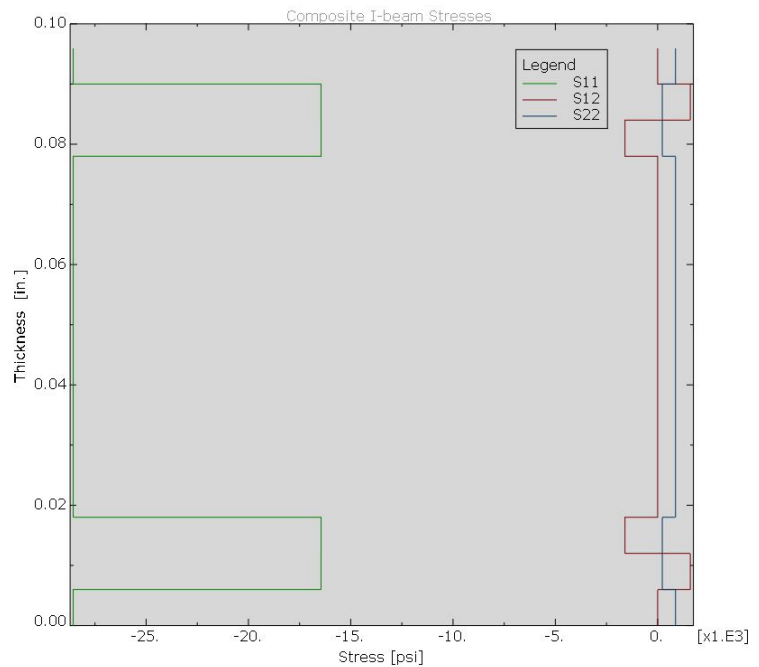

Figure 7.15: I-beam web stresses

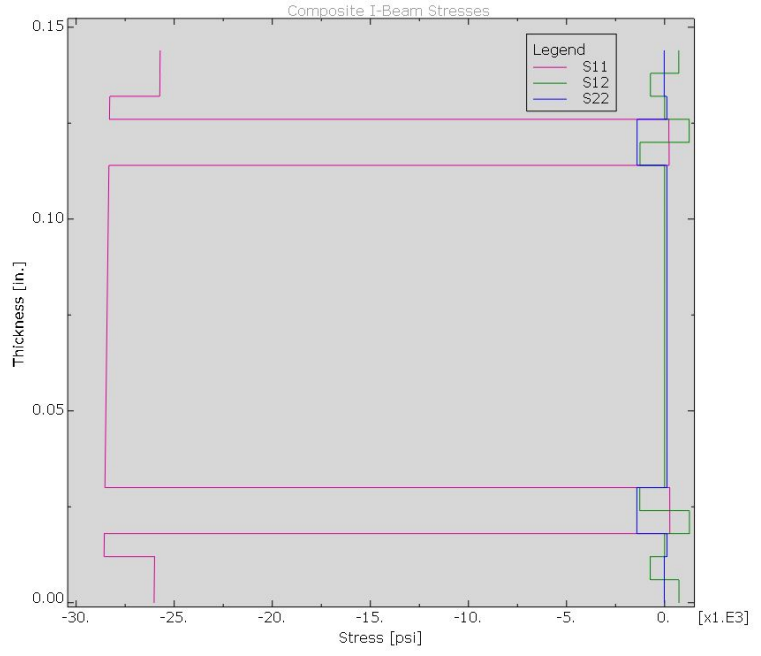

Figure 7.16: I-beam flange stresses

From this a weight per unit length was calculated for steel and the UD composite assuming the same cross-sectional area to prove the savings of the material alternative. These values are shown in Table 7.3. It is apparent that the composite offers a favorable solution with nearly a $90 \%$ reduction in weight.

Table 7.3: Weight per unit length material comparison

\begin{tabular}{c|c} 
Steel & Toray UD CFRP \\
\hline $0.0586 \mathrm{lb} / \mathrm{in}$ & $0.0074 \mathrm{lb} / \mathrm{in}$
\end{tabular}


Chapter 8

CONCLUSION

Creating a process for the manufacture of a composite connecting rod produced a multitude of learning situations. Working with multiple materials provided insight into the variability between different types of weaves and resin systems, and methodologies to try to get the best result from layups. Compression molding proved difficult based on the facilities and equipment available. Finding machinery which could provide the recommended pressure requirements for curing could have impacted decisions made and results significantly.

Material testing specifically called attention to good experimental practices. Checking machine calibration prior to destructive testing would have reduced time for the re-manufacture of test specimen. Confirming the integrity of test apparatuses and DAQ systems is a crucial step before collecting any viable data.

The manufacture of the composite rods using machining for 3D contours was proven a viable concept. The woven rod with the material 2 direction in the axis of loading exhibited a modulus of 68.1 Msi, well above that measured from experimental tests of the steel component and showing a clear advantage in stiffness. The composite rods similarly showed improvement over the steel alternative with weights of $15 \%$ $17 \%$ compared to that of the original component. Although failure strengths maxed out at $3700 \mathrm{lbf}$ (a 29\% decrease from the established design load), improvements in process could produce higher strength components capable of reaching similar loads expected of the steel rod.

Lessons learned from this study provide excellent paths forward for future work. Perfecting working with the chopped fiber resin system could provide results which 
meet or surpass the performance of the triaxially woven material. Additionally, reworking the connecting rod geometry to maximize lamina interactions could take more advantage of composite properties. Because this study looked to compare weight with a constant geometry the I-beam cross section was maintained, but in future work creating a solid section as seen with other studies could significantly improve the stiffness of the structure and laminate bonding with very little impact to overall component weight. Examining the interaction of inertial and tension loads on a composite alternative would strengthen the argument for feasibility. With some consideration for a new geometry and high quality manufacturing methods the concept of a composite connecting rod could be proven viable in application. 


\section{BIBLIOGRAPHY}

3D composites. (2019). Wikimedia Foundation. Retrieved from https://en.wikipedia. org/wiki/3D_composites

3M. (2009). 3m scotch-weld structural adhesive film af 163-2. Retrieved from https: //www.3m.com/3M/en_US/company-us/all-3m-products/ /3M-Scotch-WeldStructural-Adhesive-Film-AF-163-2/?N=5002385\%203292667667\&rt=rud

Adams, M. (2013). Measuring the mechanical properties of a newly developed discontinuous carbon fiber and epoxy composite. CA.

Afzal, A. \& Fatemi, A. [Ali]. (2003). A comparative study of fatigue behavior and life predictions of forged steel and pm connecting rods.

Agarwal, B. D., Broutman, L. J., \& Chandrashekhara, K. (2018). Analysis and performance of fiber composites. J. Wiley.

ASTM. (2016a). Astm d3039/d3039m 17 standard test method for tensile properties of polymer matrix composite materials. PA.

ASTM. (2016b). Astm d3410/d3410m 16 standard test method for compressive properties of polymer matrix composite materials with unsupported gage section by shear loading. PA.

Bhavi, I. \& Kurbet, S. (n.d.). Finite element analysis of a diesel engine connecting rod for shape optimization. India.

Bradaric, G. (2017). Dynamic analysis of connecting rods using msc adams modal synthesis method for flexible bodies.

Christensen, C. (2018). Naimo composites developing ls carbon fiber connecting rods. Retrieved from https://www.lsxmag.com/tech-stories/engine/naimo-compositesdeveloping-ls-carbon-fiber-connecting-rods/

Dassault. (n.d.). Abaqus users manual. 
Dhananjayan, V. K. (2013). Design and analysis of a compression molded carbon composite wheel center (Doctoral dissertation).

Feraboli, P., Gasco, F., Maier, S., Kwan, R., Masini, A., DeOto, L., \& Reggiani, M. (n.d.). Lamborghini "forged composite" technology for the suspension arms of the sesto elemento.

Ford Vulcan engine. (2019). Wikimedia Foundation. Retrieved from https://en. wikipedia.org/wiki/Ford_Vulcan_engine

Harvey. (n.d.-a). Diamond end mills for non-ferrous materials - cvd diamond - ball. Retrieved from http://www.harveytool.com/prod/Diamond-End-Mills-forNon-Ferrous- Materials / Material-Specific-End- Mills / Browse- Our-Products_ 247 / Diamond - End - Mills - for - Non - Ferrous - Materials --- CVD - Diamond --Ball_192.aspx

Harvey. (n.d.-b). End mills for composites - compression cutter. Retrieved from http : / / www . harveytool . com / prod / End - Mills - for - Composites / Material Specific-End-Mills / Browse- Our-Products_248 / End- Mills-for-Composites--Compression-Cutter_187.aspx

Hexcel. (2016). Hexply f-155 product data sheet. Retrieved from https://www . heatcon . com/wp-content/ uploads / 2017 / 09 / HCS2403-015_Hexcel- F155- 71TDS_Prepreg.pdf

Instructables. (2017). Steps to analyzing a material's properties from its stress/strain curve. Instructables. Retrieved from https://www.instructables.com/id/Stepsto-Analyzing-a-Materials-Properties-from-its/

Joshi, P. \& UmairZaki, M. (n.d.). Fem analysis of connecting rod of different materials using ansys.

Kaw, A. K. (2006). Mechanics of composite materials. Taylor Francis.

Khan, A. H. \& Dolas, D. R. (2017). Design, modeling and static structural analysis of connecting rod. India. 
Milberg, E. (2017). Engines with carbon fiber could be next step for lamborghini. Retrieved from http://compositesmanufacturingmagazine.com/2016/07/enginescarbon-fiber-next-step-lamborghini/

Norton, R. L. (1999). Design of machinery: An introduction to synthesis and analysis of mechanisms and machines. McGraw-Hill.

Olsson, J. (2008). Process study on compression moulding of smc using factorial design.

Ozsoy, N., Ozsoy, M., \& Mimaroglu, A. (2016). Mechanical properties of chopped carbon fiber reinforced epoxy composites. Acta Physica Polonica A, 130(1), 297fffdfffdfffd299. doi:10.12693/aphyspola.130.297

Prakash, S., Prabhahar, M., Jeshuran, S. J., \& Manish, K. S. (2017). Analysis of weight reduction in connecting rod by using different materials in ansys.

Repgen, B. (1998). Optimized connecting rods to enable higher engine performance and cost reduction.

Rockwest. (2019). Prepreg - carbon fiber - 42. Retrieved from https://www.rockwestcomposites. com/14062-d

Schulman, A. (n.d.-a). Amc 8500 vinyl ester matrix.

Schulman, A. (n.d.-b). Quantum amc 8593, 126-76-118.

Shenoy, P. S. \& Fatemi, A. [A.]. (2006). Dynamic analysis of loads and stresses in connecting rods. Ohio.

Sydanna, T. R. \& Kumar, B. S. (n.d.). Design and analysis of composite connecting rod.

Tencate. (n.d.). Tencate ambertool hx42 tooling prepreg.

Tencate. (2018). Ambertool tooling pre-preg processing guide.

Teti, R. (n.d.). Machining of composite materials. Italy.

Toray. (n.d.). 2510 prepreg system - toraycma.com. Retrieved from https://www. toraycma.com/files/library/166e096be76c7eb7.pdf 
Trunzo, M. E. (2012). Integration of carbon fiber composite materials into air-cooled reciprocating piston engines for uav applications. UNITED STATES NAVAL ACADEMY.

Vishay. (n.d.). Strain gage installations with m-bond 200 adhesive. 


\section{APPENDICES}

Appendix A

\section{ALUMINUM MOLD DIMENSIONS}




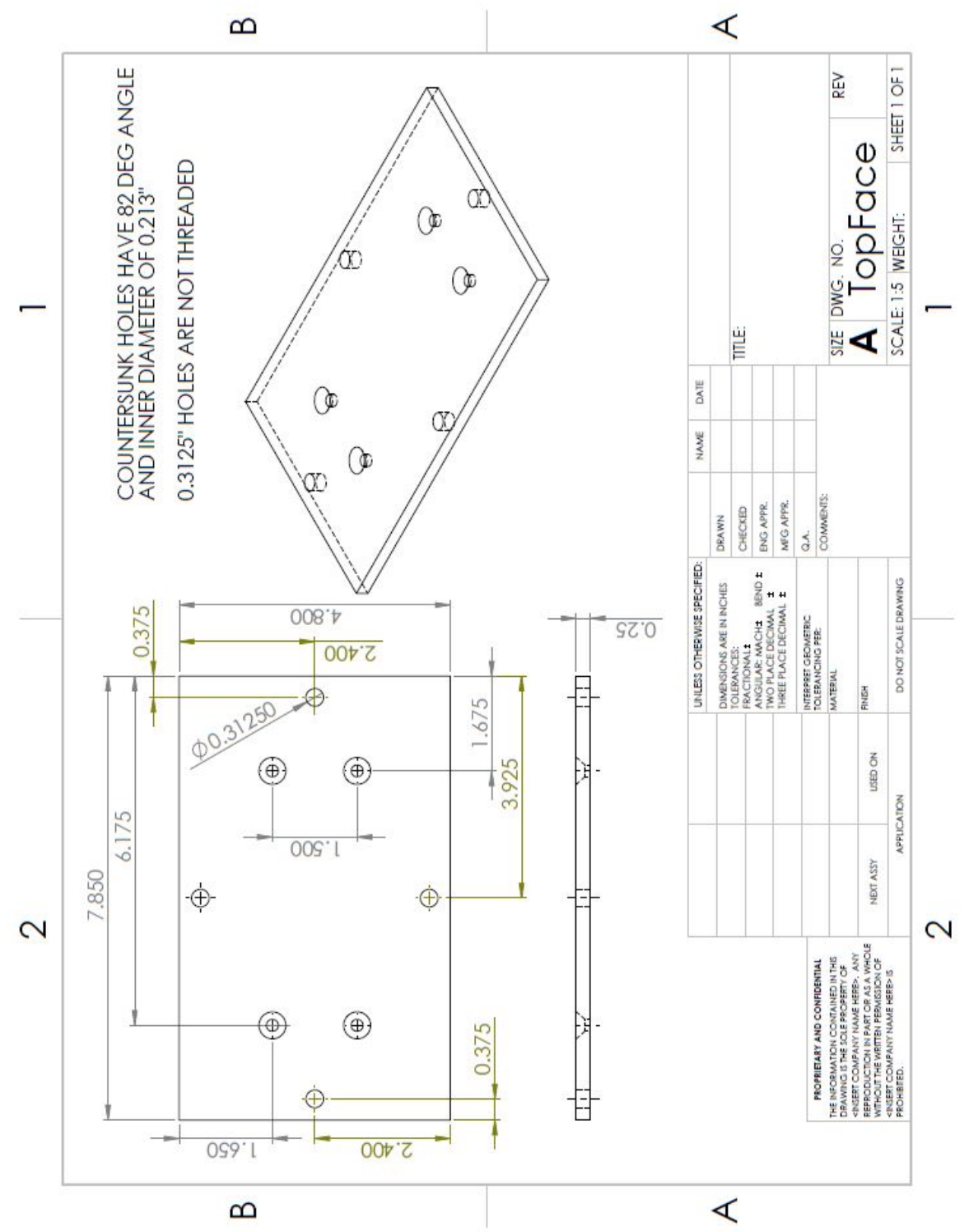

Figure A.1: Top plate dimensions 


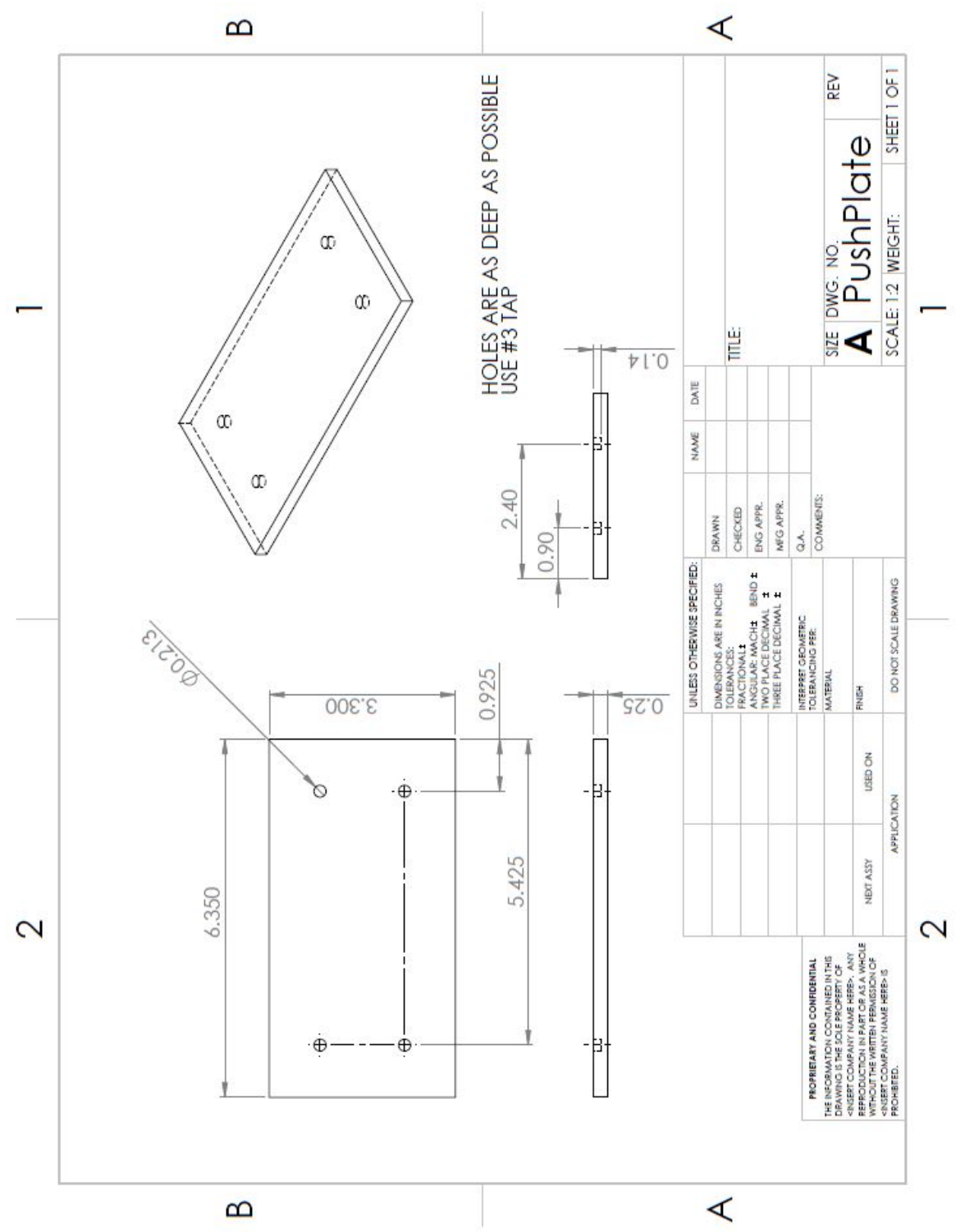

Figure A.2: Push plate dimensions 


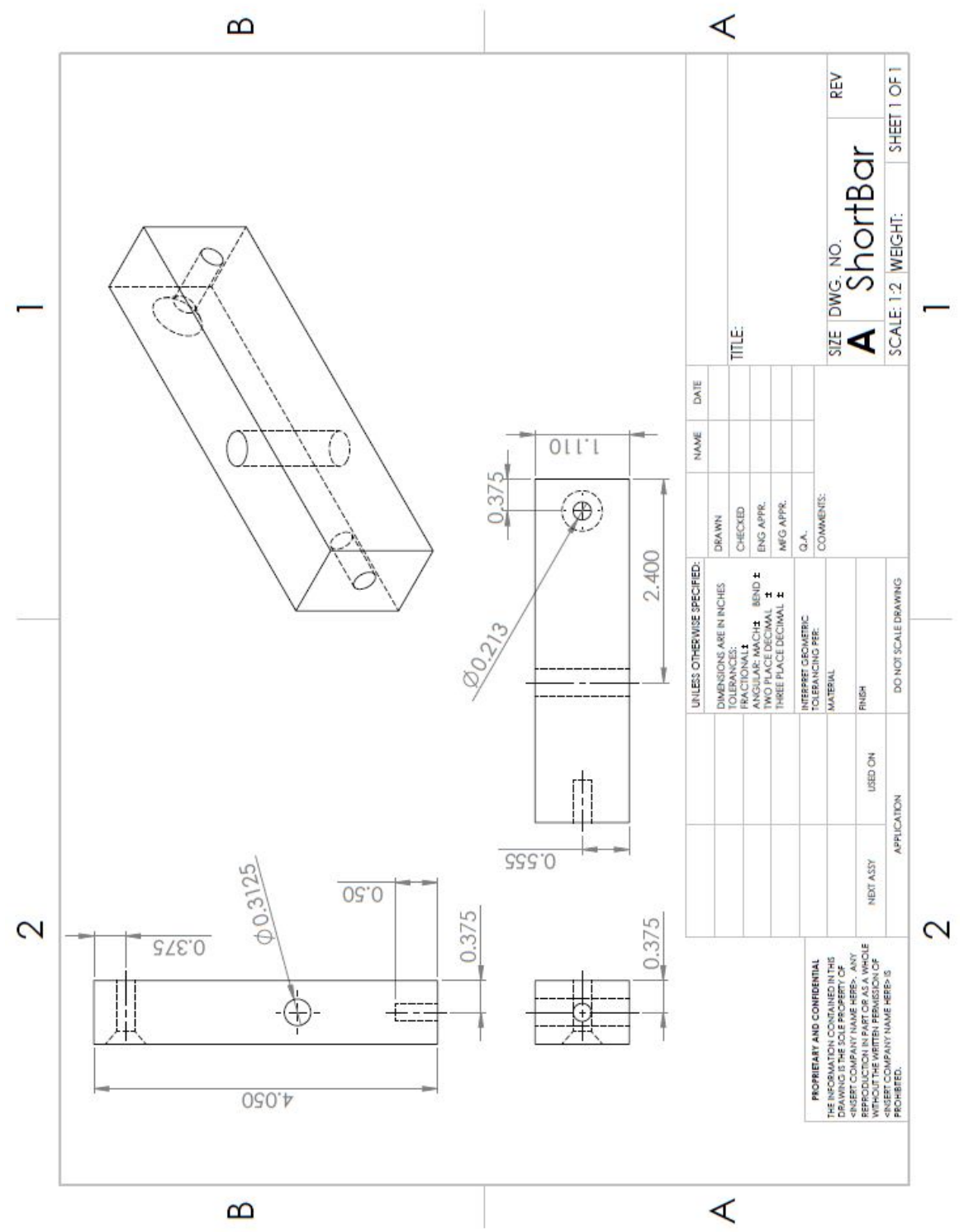

Figure A.3: Short bar dimensions 


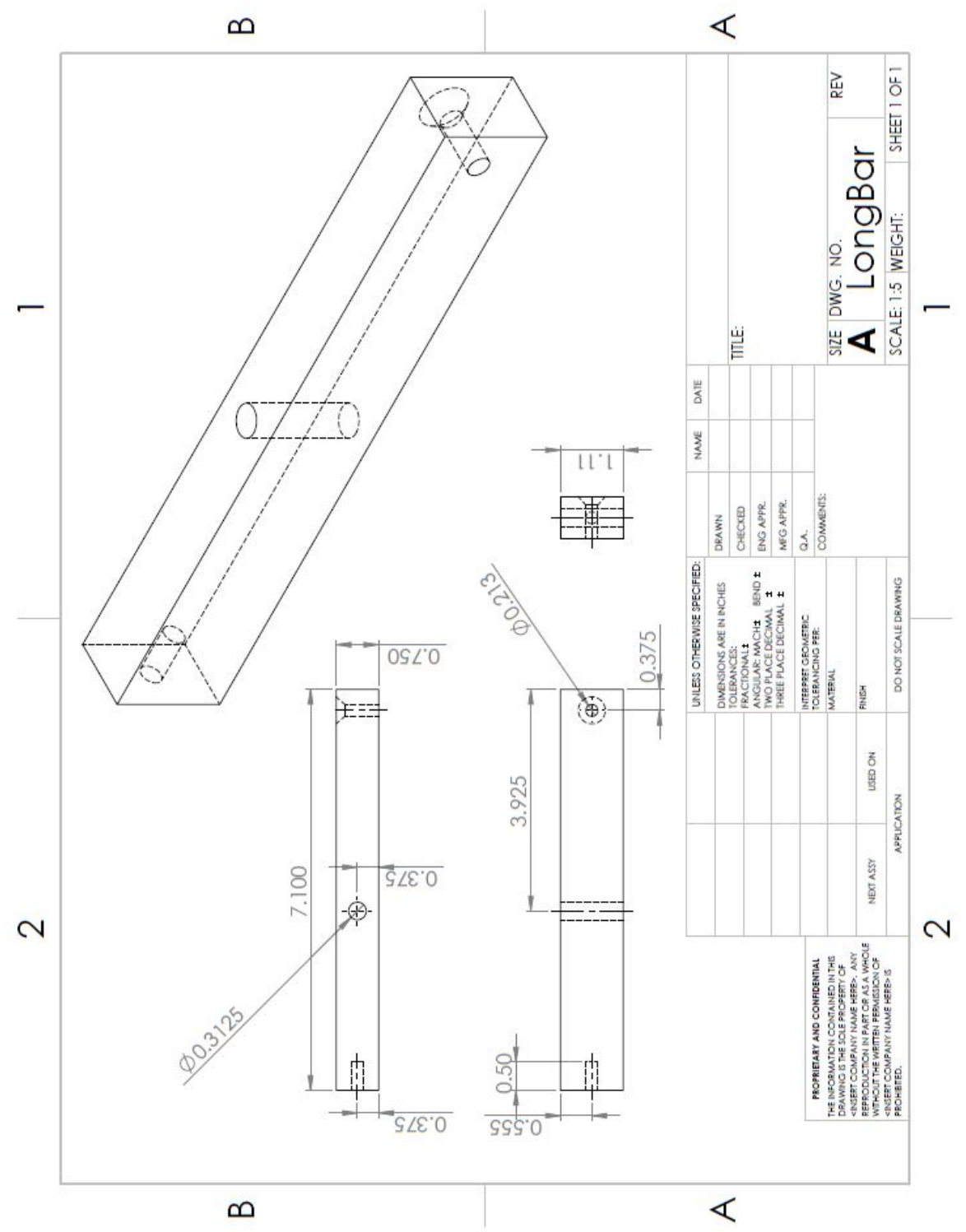

Figure A.4: Long bar dimensions 


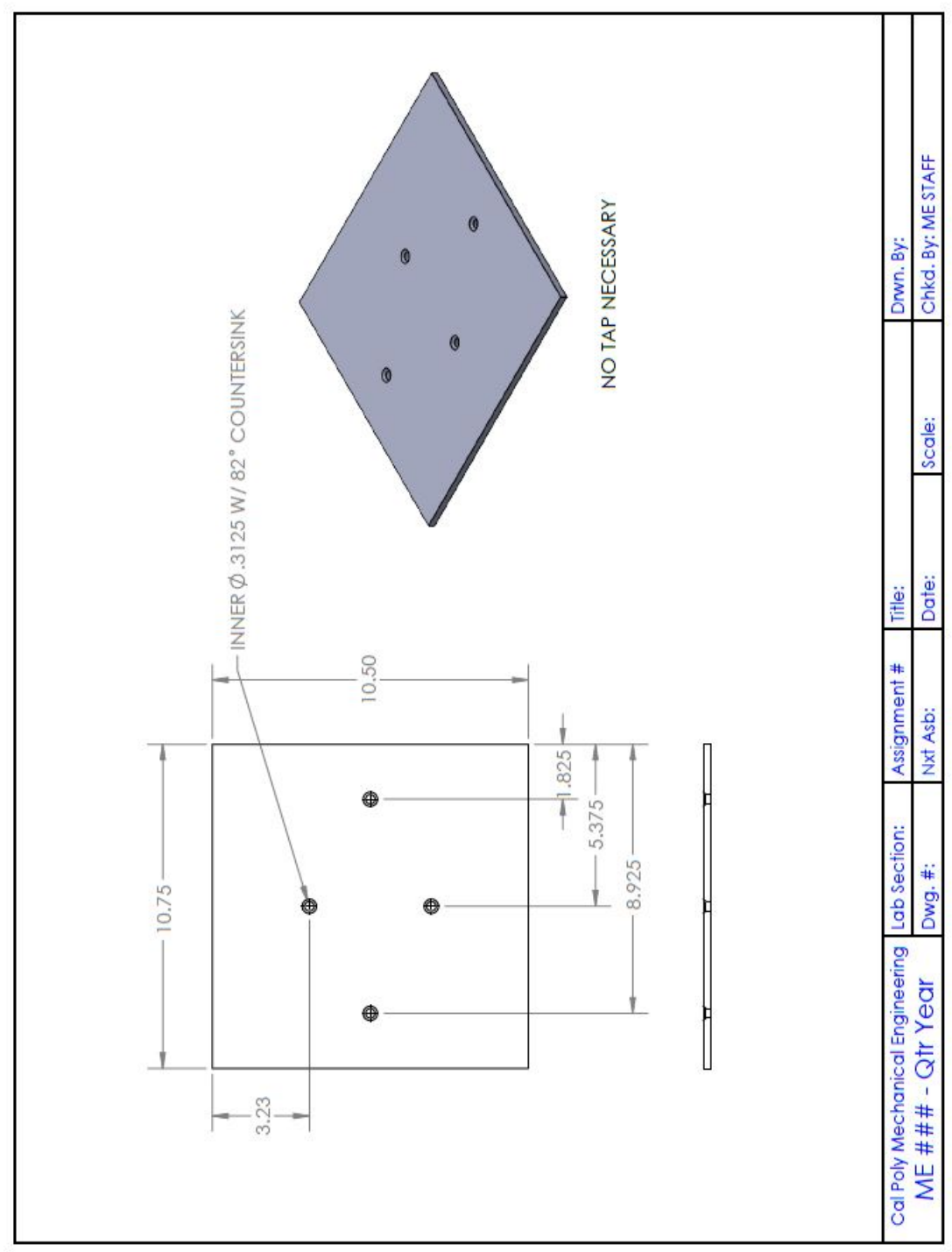

Figure A.5: Bottom plate dimensions 
Appendix B

BRICK DIMENSION MEASUREMENTS

Table B.1: Measurements at varied locations on all bricks

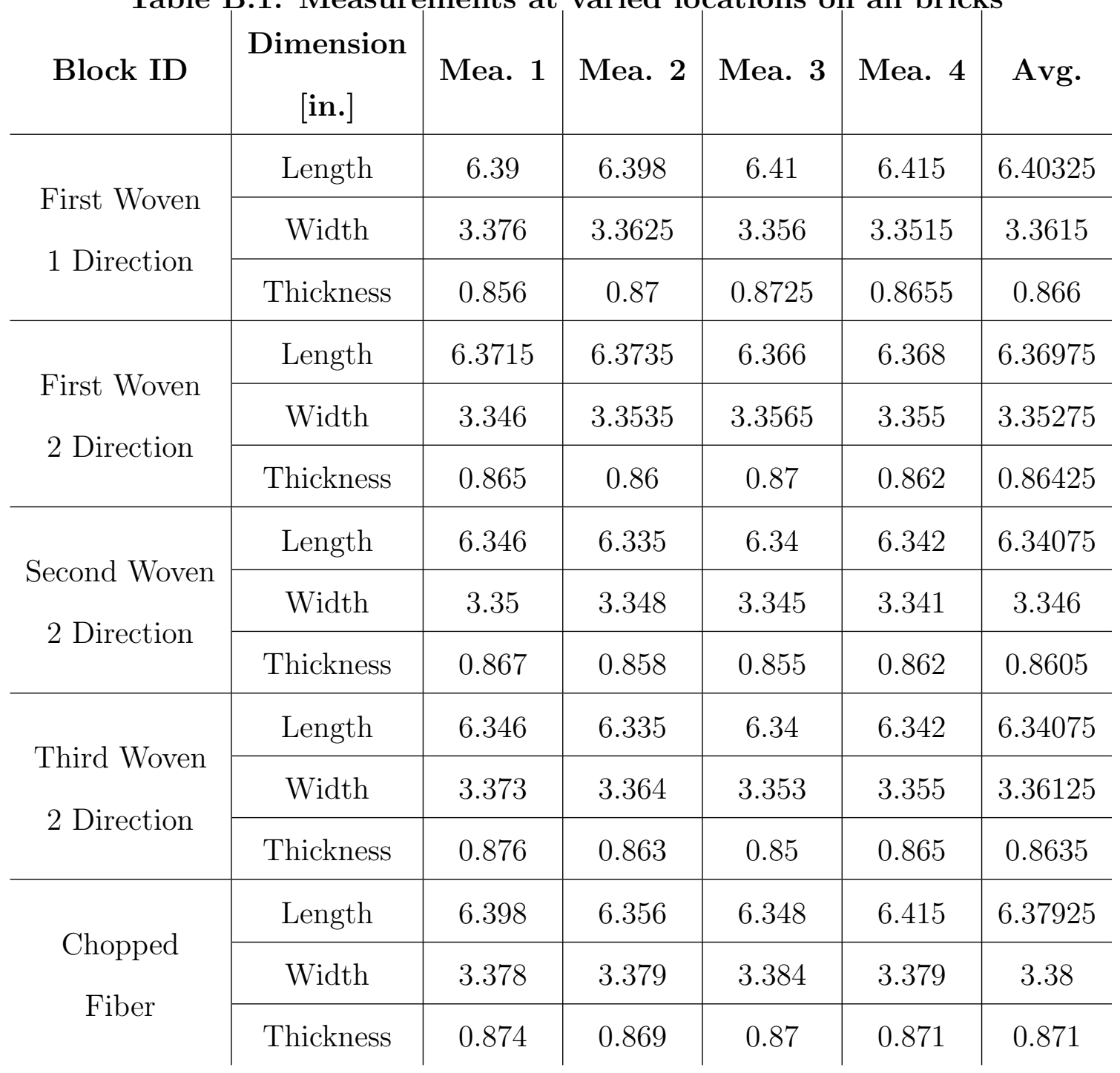


Appendix C

ACTUAL TEST SPECIMEN DIMENSIONAL MEASUREMENTS

Table C.1: Woven 1 direction tension sample dimensions

\begin{tabular}{|c|c|c|c|c|c|c|c|}
\hline Sample \# & Dimension & Mea. 1 & Mea. 2 & Mea. 3 & Mea. 4 & Measure Avg & Calculated Area [in^2] \\
\hline \multirow{3}{*}{1} & Length [in.] & 8.6875 & 8.688 & 8.6875 & 8.68745 & 8.6876125 & \multirow{3}{*}{0.1054929688} \\
\hline & Width [in.] & 0.9915 & 0.985 & 0.997 & 0.998 & 0.992875 & \\
\hline & Thickness [in.] & 0.1065 & 0.1085 & 0.104 & 0.106 & 0.10625 & \\
\hline \multirow{3}{*}{2} & Length [in.] & 8.625 & 8.624 & 8.627 & 8.625 & 8.62525 & \multirow{3}{*}{0.1136671875} \\
\hline & Width [in.] & 1.023 & 1.028 & 1.029 & 1.03 & 1.0275 & \\
\hline & Thickness [in.] & 0.113 & 0.1135 & 0.107 & 0.109 & 0.110625 & \\
\hline \multirow{3}{*}{3} & Length [in.] & 8.55 & 8.56 & 8.54 & 8.555 & 8.55125 & \multirow{3}{*}{0.1044599063} \\
\hline & Width [in.] & 0.9445 & 0.95 & 0.9665 & 0.968 & 0.95725 & \\
\hline & Thickness [in.] & 0.109 & 0.109 & 0.1095 & 0.109 & 0.109125 & \\
\hline \multirow{3}{*}{4} & Length [in.] & 8.625 & 8.627 & 8.624 & 8.625 & 8.62525 & \multirow{3}{*}{0.1057146563} \\
\hline & Width [in.] & 0.986 & 0.982 & 0.98 & 0.981 & 0.98225 & \\
\hline & Thickness [in.] & 0.109 & 0.11 & 0.105 & 0.1065 & 0.107625 & \\
\hline \multirow{3}{*}{5} & Length [in.] & 8.55 & 8.56 & 8.555 & 8.55 & 8.55375 & \multirow{3}{*}{0.1092284531} \\
\hline & Width [in.] & 1.0165 & 1.009 & 1.001 & 1.005 & 1.007875 & \\
\hline & Thickness [in.] & 0.111 & 0.1065 & 0.105 & 0.111 & 0.108375 & \\
\hline \multirow{3}{*}{6} & Length [in.] & 8.625 & 8.626 & 8.6255 & 8.6245 & 8.62525 & \multirow{3}{*}{0.1058959219} \\
\hline & Width [in.] & 0.9835 & 0.98 & 0.975 & 0.97 & 0.977125 & \\
\hline & Thickness [in.] & 0.111 & 0.109 & 0.107 & 0.1065 & 0.108375 & \\
\hline \multirow{3}{*}{7} & Length [in.] & 8.75 & 8.76 & 8.755 & 8.756 & 8.75525 & \multirow{3}{*}{0.109782} \\
\hline & Width [in.] & 1.02 & 1.027 & 1.032 & 1.025 & 1.026 & \\
\hline & Thickness [in.] & 0.105 & 0.11 & 0.107 & 0.106 & 0.107 & \\
\hline
\end{tabular}

Table C.2: Woven 2 direction tension sample dimensions

\begin{tabular}{|c|c|c|c|c|c|c|c|}
\hline Sample \# & Dimension & Mea. 1 & Mea. 2 & Mea. 3 & Mea. 4 & Measure Avg. & Calculated Area [in^2] \\
\hline \multirow{3}{*}{1} & Length [in.] & 7.25 & 7.26 & 7.255 & 7.255 & 7.255 & \multirow{3}{*}{0.105562625} \\
\hline & Width [in.] & 0.94 & 0.945 & 0.95 & 0.952 & 0.94675 & \\
\hline & Thickness [in.] & 0.113 & 0.114 & 0.11 & 0.109 & 0.1115 & \\
\hline \multirow{3}{*}{2} & Length [in.] & 7.6875 & 7.6875 & 7.687 & 7.688 & 7.6875 & \multirow{3}{*}{0.108598} \\
\hline & Width [in.] & 0.9615 & 0.9645 & 0.9725 & 0.98 & 0.969625 & \\
\hline & Thickness [in.] & 0.111 & 0.114 & 0.111 & 0.112 & 0.112 & \\
\hline \multirow{3}{*}{3} & Length [in.] & 7.625 & 7.625 & 7.63 & 7.627 & 7.62675 & \multirow{3}{*}{0.109720625} \\
\hline & Width [in.] & 1.009 & 1.011 & 1.01 & 1.015 & 1.01125 & \\
\hline & Thickness [in.] & 0.109 & 0.11 & 0.108 & 0.107 & 0.1085 & \\
\hline \multirow{3}{*}{4} & Length [in.] & 7.75 & 7.755 & 7.754 & 7.755 & 7.7535 & \multirow{3}{*}{0.1130262188} \\
\hline & Width [in.] & 1.035 & 1.036 & 1.037 & 1.035 & 1.03575 & \\
\hline & Thickness [in.] & 0.112 & 0.109 & 0.108 & 0.1075 & 0.109125 & \\
\hline \multirow{3}{*}{5} & Length [in.] & 7.75 & 7.75 & 7.754 & 7.755 & 7.75225 & \multirow{3}{*}{0.1132725} \\
\hline & Width [in.] & 1.032 & 1.033 & 1.031 & 1.023 & 1.02975 & \\
\hline & Thickness [in.] & 0.111 & 0.11 & 0.109 & 0.11 & 0.11 & \\
\hline \multirow{3}{*}{6} & Length [in.] & 7.625 & 7.624 & 7.625 & 7.626 & 7.625 & \multirow{3}{*}{0.109804875} \\
\hline & Width [in.] & 0.998 & 0.999 & 1.001 & 1.004 & 1.0005 & \\
\hline & Thickness [in.] & 0.109 & 0.11 & 0.11 & 0.11 & 0.10975 & \\
\hline \multirow{3}{*}{7} & Length [in.] & 7.75 & 7.755 & 7.756 & 7.755 & 7.754 & \multirow{3}{*}{0.11036175} \\
\hline & Width [in.] & 0.994 & 0.993 & 0.995 & 0.995 & 0.99425 & \\
\hline & Thickness [in.] & 0.11 & 0.11 & 0.113 & 0.111 & 0.111 & \\
\hline
\end{tabular}




\section{Table C.3: Woven 1 direction compression sample dimensions}

\begin{tabular}{|c|c|c|c|c|c|c|c|}
\hline Sample \# & Dimension & Mea. 1 & Mea. 2 & Mea. 3 & Mea. 4 & Measure Avg. & Calculated Area [in^2] \\
\hline \multirow{3}{*}{1} & Length [in.] & 1.068 & 1.063 & 1.065 & 1.066 & 1.0655 & \multirow{3}{*}{0.114235} \\
\hline & Width [in.] & 1.036 & 1.04 & 1.04 & 1.038 & 1.0385 & \\
\hline & Thickness [in.] & 0.111 & 0.108 & 0.111 & 0.11 & 0.11 & \\
\hline \multirow{3}{*}{2} & Length [in.] & 1.027 & 1.039 & 1.03 & 1.033 & 1.03225 & \multirow{3}{*}{0.119714} \\
\hline & Width [in.] & 1.07 & 1.068 & 1.069 & 1.0685 & 1.068875 & \\
\hline & Thickness [in.] & 0.113 & 0.11 & 0.113 & 0.112 & 0.112 & \\
\hline \multirow{3}{*}{3} & Length [in.] & 0.99 & 0.982 & 0.989 & 0.99 & 0.98775 & \multirow{3}{*}{0.117505625} \\
\hline & Width [in.] & 1.025 & 1.029 & 1.025 & 1.026 & 1.02625 & \\
\hline & Thickness [in.] & 0.116 & 0.113 & 0.114 & 0.115 & 0.1145 & \\
\hline \multirow{3}{*}{4} & Length [in.] & 1.037 & 1.034 & 1.035 & 1.036 & 1.0355 & \multirow{3}{*}{0.1150745625} \\
\hline & Width [in.] & 1.028 & 1.029 & 1.031 & 1.031 & 1.02975 & \\
\hline & Thickness [in.] & 0.113 & 0.115 & 0.104 & 0.115 & 0.11175 & \\
\hline \multirow{3}{*}{5} & Length [in.] & 0.965 & 0.966 & 0.964 & 0.965 & 0.965 & \multirow{3}{*}{0.112329125} \\
\hline & Width [in.] & 1.02 & 1.024 & 1.026 & 1.024 & 1.0235 & \\
\hline & Thickness [in.] & 0.112 & 0.11 & 0.108 & 0.109 & 0.10975 & \\
\hline \multirow{3}{*}{6} & Length [in.] & 1.064 & 1.041 & 1.03 & 1.035 & 1.0425 & \multirow{3}{*}{0.11163525} \\
\hline & Width [in.] & 1.017 & 1.023 & 1.022 & 1.016 & 1.0195 & \\
\hline & Thickness [in.] & 0.111 & 0.108 & 0.109 & 0.11 & 0.1095 & \\
\hline
\end{tabular}

Table C.4: Woven 2 direction compression sample dimensions

\begin{tabular}{|c|c|c|c|c|c|c|c|}
\hline Sample \# & Dimension & Mea. 1 & Mea. 2 & Mea. 3 & Mea. 4 & Measure Avg. & Calculated Area [in^2] \\
\hline \multirow{3}{*}{1} & Length [in.] & 0.947 & 0.923 & 0.924 & 0.93 & 0.931 & \multirow{3}{*}{0.111552} \\
\hline & Width [in.] & 0.993 & 0.998 & 0.999 & 0.994 & 0.996 & \\
\hline & Thickness [in.] & 0.111 & 0.112 & 0.116 & 0.109 & 0.112 & \\
\hline \multirow{3}{*}{2} & Length [in.] & 0.7865 & 0.783 & 0.778 & 0.777 & 0.781125 & \multirow{3}{*}{0.11032875} \\
\hline & Width [in.] & 1.049 & 1.053 & 1.05 & 1.051 & 1.05075 & \\
\hline & Thickness [in.] & 0.108 & 0.108 & 0.1 & 0.104 & 0.105 & \\
\hline \multirow{3}{*}{3} & Length [in.] & 0.765 & 0.753 & 0.738 & 0.741 & 0.74925 & \multirow{3}{*}{0.1063175} \\
\hline & Width [in.] & 0.987 & 0.988 & 0.991 & 0.99 & 0.989 & \\
\hline & Thickness [in.] & 0.109 & 0.108 & 0.106 & 0.107 & 0.1075 & \\
\hline \multirow{3}{*}{4} & Length [in.] & 0.839 & 0.84 & 0.841 & 0.84 & 0.84 & \multirow{3}{*}{0.1101740625} \\
\hline & Width [in.] & 1.02 & 1.026 & 1.0265 & 1.027 & 1.024875 & \\
\hline & Thickness [in.] & 0.109 & 0.11 & 0.106 & 0.105 & 0.1075 & \\
\hline \multirow{3}{*}{5} & Length [in.] & 0.87 & 0.868 & 0.863 & 0.864 & 0.86625 & \multirow{3}{*}{0.11396} \\
\hline & Width [in.] & 1.04 & 1.035 & 1.034 & 1.035 & 1.036 & \\
\hline & Thickness [in.] & 0.109 & 0.108 & 0.109 & 0.114 & 0.11 & \\
\hline \multirow{3}{*}{6} & Length [in.] & 0.86 & 0.85 & 0.855 & 0.856 & 0.85525 & \multirow{3}{*}{0.10968125} \\
\hline & Width [in.] & 1.004 & 1.01 & 1.005 & 1.006 & 1.00625 & \\
\hline & Thickness [in.] & 0.107 & 0.11 & 0.109 & 0.11 & 0.109 & \\
\hline
\end{tabular}

Table C.5: Chopped fiber tension sample dimensions

\begin{tabular}{|c|c|c|c|c|c|c|c|}
\hline Sample \# & Dimension & Mea. 1 & Mea. 2 & Mea. 3 & Mea. 4 & Measure Avg. & Calculated Area [in^2] \\
\hline \multirow{3}{*}{1} & Length [in.] & 10.1 & 10.04 & 10.05 & 10.03 & 10.055 & \multirow{3}{*}{0.1028421875} \\
\hline & Width [in.] & 0.99 & 0.98 & 0.997 & 0.998 & 0.99125 & \\
\hline & Thickness [in.] & 0.102 & 0.108 & 0.106 & 0.099 & 0.10375 & \\
\hline \multirow{3}{*}{2} & Length [in.] & 9.89 & 9.9 & 9.93 & 9.9 & 9.905 & \multirow{3}{*}{0.11207625} \\
\hline & Width [in.] & 1.1 & 1.08 & 1.05 & 1.06 & 1.0725 & \\
\hline & Thickness [in.] & 0.101 & 0.104 & 0.106 & 0.107 & 0.1045 & \\
\hline
\end{tabular}


Table C.6: Chopped fiber compression sample dimensions

\begin{tabular}{|c|c|c|c|c|c|c|c|c|}
\hline Sample \# & Dimension & Mea. 1 & Mea. 2 & Mea. 3 & Mea. 4 & Measure Avg. & Calculated Area [in^2] & Gauge Length \\
\hline \multirow{3}{*}{1} & Length [in.] & 2.975 & 2.974 & 2.975 & 2.973 & 2.97425 & \multirow{3}{*}{0.05405625} & \multirow{3}{*}{0.95} \\
\hline & Width [in.] & 0.468 & 0.466 & 0.4605 & 0.4655 & 0.465 & & \\
\hline & Thickness [in.] & 0.1165 & 0.1155 & 0.116 & 0.117 & 0.11625 & & \\
\hline \multirow{3}{*}{2} & Length [in.] & 2.9705 & 2.9695 & 2.97 & 2.9705 & 2.970125 & \multirow{3}{*}{0.07326096875} & \multirow{3}{*}{0.935} \\
\hline & Width [in.] & 0.507 & 0.5075 & 0.508 & 0.509 & 0.507875 & & \\
\hline & Thickness [in.] & 0.145 & 0.1445 & 0.1445 & 0.143 & 0.14425 & & \\
\hline \multirow{3}{*}{3} & Length [in.] & 2.9725 & 2.98 & 2.975 & 2.973 & 2.975125 & \multirow{3}{*}{0.0561384375} & \multirow{3}{*}{0.987} \\
\hline & Width [in.] & 0.4855 & 0.48 & 0.482 & 0.48 & 0.481875 & & \\
\hline & Thickness [in.] & 0.117 & 0.1175 & 0.1155 & 0.116 & 0.1165 & & \\
\hline
\end{tabular}

